UNIVERSITAT

POLITĖCNICA

DE VALÈNCIA

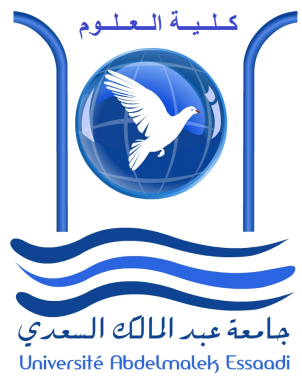

ABDELMALEK ESSAADI UNIVERSITY

POLITECNIC OF VALENCIA UNIVERSITY

- PhD Dissertation - Cotutella -

\title{
Design and Implementation of a UWB Radar Sensor for Non-Destructive Application
}

\section{Author: Ahajjam Younes}

Spanish Supervisors:

José M Catalá Civera

Felipe Peñaranda-Foix
Morrocan Supervisors:

Abdellah Driouach

Otman Aghzout

This Thesis is submitted for the degree of:

- Doctor in Telecommunications Engineering -

Laboratory of Communication and Detection System, Department of Physics, Faculty of Science, Tétouan-Morocco

Laboratory of DiMas, Instituto ITACA. Universitat Politécnica de Valéncia. Camino de Vera s/n. 46022 Valencia, España.

JUNE 11, 2019 

First, I would like to mention that this dissertation was made under an agreement for Co-tutelle of $\mathrm{PhD}$ thesis, this agreement leading to the award of a Dual Doctoral Degree between University Abdelmalek Essaadi, UAE. And The University Polytechnic of Valencia, UPV. (Appendix I) 

To my family 



\section{Acknowledgment}

Firstly, I would like to express my sincere gratitude to my Moroccan advisor Prof. Abdellah Driouach for accepting me as a PhD student in Remote sensing group at faculty of science, for the continuous support and patience during my doctoral dissertation. I would like also to thanks Mr Khamlichi, his guidance and consultancy helped me in all the time of research and writing of this thesis.

My sincere thanks also go to my Spanish Advisors, Profs José M Catalá Civera and Felipe Peñaranda-Foix, for his warming acceptation, for her generous welcome in Dimas laboratory, for helping me with preparing all necessary circumstance and research materials and for their guidance, support and encouragement during my research internships in their laboratories.

My very special thanks and all my gratitude go to Professor Otman Aghzout, I can confess that this thesis could not have been completed without her encouragement, support and assistance. I cannot forget the memorable discussions that we have shared in Valencia. I am deeply honored to be one of his students. I consider that it was my right hand during this dissertation. His nobility has profoundly touched me to such a degree that I shall never forget his character so generous and genuinely modest.

I very appreciate all the professors mentioned above, I couldn't have imagined having better advisors and mentors for my $\mathrm{PhD}$ carriers.

I thank all my fellow labmates in Dimas Laboratory: Isidora, Beatriz, Jose Daniel, Gabriel, Miguel Angel and David, However, a special thanks go to Pedro and Ximo wichs I have acquired plenty of technical skills from them. I am very grateful to have them as mentors, professional trainers and friends.

I certainly appreciated the extremely friendly environment in Smartech laboratory with Badiaa, Mounia, Fahd, Azzedine, Jalal, Abdelmajid, Hicham, Saban, Ibticem; it had been a great honour to pass this great experience in this exceptional environment.

The Great gratitude of this work goes to ERASMUS MUNDUS EMMAG for helping and providing the funding for the work. In particular, I am grateful to $\mathrm{Mr}$ Mohammed L'bachir EL KBIACH from University Abdelmalek Essaadi, and Esther 
from University Polytechnic of Valencia for their best communication, help and support during my period as a holder of this scholarship.

I could not have completed this thesis without the support and the entertainment provided by my friends, Jesus, Mohcine, Said, Karim, Soufian, Salah, Ahmed, sid Ahmed, Otman, Azzedine and Khaled.

Last but not least, I would like to thank all my family: My sweet three sisters: Ikram, Mounia and Mariam. My father Mustapha, I'm very proud of you. And above all my mother Rhimo, he deserves more than this dedication, It is the meaning of my life.

Thank you. 



\section{Abstract}

Due to the relevance of application fields of ultra-wide band UWB radar sensors, and also the requirement of each specific fields, especially in the industrial non-destructive application NDT; there is an increasing demand on compact, low cost and high accuracy design of UWB radar sensors.

To address these demands, this research work deals with a design, implementation and analysis of UWB radar subsystems and system integration. Of one of the leading components of a UWB radar sensor subsystems is the UWB pulse generator. The proposed design of the UWB pulse generator in this dissertation consist of three principal parts; an avalanche transistor circuit, a pulse sharpening circuit and a monocycle forming network circuit MFN. the principal purpose of the MFN is to convert the Gaussian pulse to a monocycle one.

Generally, two kind of measurements are desired in any modern application; long-range detection and high-end resolution. These two goal can be achieved by generating a pulse with a minimum of ringing and a maximum of amplitude. These two goals, have been taking into account at the start and achieved at the end of this dissertation.

In one hand, a UWB pulse with lower ringing and rise time its much required. Therefore, two useful techniques have been proposed, the first one consist of shorting the discharge pathway as much as possible, while the second one consists in modeling the step recovery diode SRD. Then, the developed pulse generator produces an electrical pulse with an amplitude of $12 \mathrm{~V}$, a rise time of $112 \mathrm{ps}$ and pulse width FWHM of 155 ps. In addition, $3.5 \%$ in overshoot as a ringing has been obtained.

On other hand, and in real circumstance, some materials have a lot of loss, e.g., they absorb a lot of electromagnetic energy. Therefore, a high-power pulse is very required to carry out the measurements at the end. To face this challenge, two useful techniques have been proposed in this work. The first one consist of assembling two generators in parallel; while the second technique adopted consists of a two-stage generator. Although the complicated technical specification that will be taking into account to warranty the functionality of this circuit; both techniques 
give rise to a good performance, and the amplitude increase around the double compared with the single one. Therefore, a high-power pulse generator with a minimum of ringing has been obtained.

In order to validate the performance of the proposed design, two kinds of test measurement have been made: the distance range, and the electrical properties. All experiment has been carrying out in an anechoic chamber to avoid any electromagnetic disturbance, the implemented system was built in bi-static configuration and the Material Under Test MUT have been varied from metal to dielectric materials (wood and Polyvinyl chloride PVC).

To transmit and receive the generated ultra-short pulses, two different types of UWB antennas have been used. The first one is a Vivaldi antenna with a bandwidth of about $5.5 \mathrm{GHz}$ ranging from $600 \mathrm{MHz}$ to $6 \mathrm{GHz}$. While the second is a Vivaldi antenna with a $6 \mathrm{GHz}$ in bandwidth ranging from $400 \mathrm{MHz}$ to $6.2 \mathrm{GHz}$.

The uncertainty of the radar sensor has been found to be $14 \mathrm{~mm}$ (measured data scared within $+/-14 \mathrm{~mm}$ for a fixed target). The design and real implementation of the UWB pulse generator presented in this work lead to achieving excellent results. Therefore, the given design of UWB pulse generator will be very attractive in a much future application, especially in non-destructive industrial use. 



\section{Resumen}

Debido a la relevancia de los campos de aplicación de los sensores de radar de banda ultra-ancha UWB, y a los requerimientos de cada campo, especialmente en las aplicaciónes industriales no destructivas NDT; existe una demanda creciente para los radares sensores compactos, de bajo coste y con alta precisión.

Para hacer frente a estas demandas, este trabajo de investigación trata de diseñar y implemetar uno de los componentes principales del radar sensor ; el llamado generador de pulsos de banda ulta-ancha. El generador de pulsos propuesto en esta tesis consiste fundamentalmente en tres partes principales: un circuito transistor en modo avalancha, un circuito de afilacion de pulsos y un circuito de formación de monociclos MFN. El propósito del MFN es de convertir el pulso gaussiano a monociclo.

Actualmente, las aplicaciónes modernas requieren dos tipos de mediciones: la detección a largo alcance y la detección de alta resolución a corto alcance. Esto se lograra mediante la generacion de un pulso con un mínimo de zumbido y un máximo de amplitud. Estos dos objetivos, se han tenido en cuenta al principio y se han conseguido al final de este tesis.

Este trabajo se divide en dos bloques principales; Por un lado, y para mejorar la forma de onda de salida del pulso, es decir con un zumbido y un tiempo de subida muy bajos, se han propuesto dos técnicas útiles, la primera consiste en acortar la vía de descarga del circuito lo minimum posible, mientras que la segunda consiste en modelar el diodo de recuperación de paso SRD. Por lo tanto, el generador de pulsos desarrollado producio un pulso eléctrico con una amplitud de $12 \mathrm{~V}$, un tiempo de subida de 112 ps y un ancho de pulso FWHM de 155 ps. Además, se ha obtenido un 3,5 \% de sobregiro como zumbido.

Por otro lado, y en las circunstancias reales, algunas materiales tienen muchas pérdidas, es decir, absorben mucha energía electromagnética. Por lo tanto, se requiere un pulso con mucha potencia para llevar acabo las mediciones requiridas. Asi que para afrontar este reto, se han propuesto dos técnicas útiles para aumentar la amplitud de los pulsos. La primera consiste en ensamblar dos generadores en paralelo; mientras que la segunda técnica adoptada consiste en diseñar un 
generador con dos etapas; y apesar de la complijidad técnica que se tiene que tener en cuenta para garantizar la funcionalidad de este circuits, ambas técnicas dan lugar a un buen rendimiento, y el aumento de la amplitud se hizo en torno al doble en comparación con el diseño principal.

Para validar el rendimiento del diseño propuesto en esta tesis, se realizaron dos tipos de pruebas: la medida de distancia y la medida de las propiedades eléctricas. Todo el experimento se ha llevado a cabo en una cámara anecoica para evitar cualquier perturbación electromagnética, el sistema implementado fue construido en configuración biestática y el Material Bajo Prueba MUT ha sido variado entre Metales y dieléctrico (madera, cloruro de polivinilo PVC). La transmicion y la recipcion de los pulsos, se hicieron mediante dos tipos diferentes de antenas de UWB. La primera es una antena Vivaldi con un ancho de banda de unos 5,5 GHz que va de $600 \mathrm{MHz}$ a $6 \mathrm{GHz}$. Mientras que la segunda es una antena Vivaldi con un ancho de banda de $6 \mathrm{GHz}$ que va de $400 \mathrm{MHz}$ a 6,2 $\mathrm{GHz}$.

Finalmente, se concluye que la incertidumbre del sensor de radar es de $14 \mathrm{~mm}$ (los datos medidos varien dentro de $+/-14 \mathrm{~mm}$ para un objetivo en estado fijo). El diseño y la implementación real del generador de pulsos UWB presentado en este trabajo han permitido obtener excelentes resultados. Por lo tanto, el diseño dado será muy atractivo en las futuras aplicaciónes, especialmente para el uso industrial no destructivo. 



\section{Résumé}

En raison de la pertinence des domaines d'application des capteurs radar à bande ultra-large $(U W B)$, et aussi de l'exigence de chaque domaine spécifique, en particulier dans l'application industrielle non destructive ( $N D T$ ), il existe une demande croissante pour des capteurs radar compacts, peu coûteux et de haute précision de conception $U W B$.

Pour répondre à ces demandes, ce travail de recherche porte sur une nouvelle conception d'un des principaux composants d'un capteur radar $U W B$, le générateur d'impulsions $U W B$. La conception du générateur d'impulsions $U W B$ proposé dans cette thèse comprend trois parties principales : un circuit de transistor à avalanche, un circuit d'affûtage d'impulsions et un circuit de réseau formant monocycle $(M F N)$. Cependant, le but du $(M F N)$ est de convertir l'impulsion gaussienne en une impulsion monocyclique.

Généralement, deux types de mesures sont souhaités dans toute application moderne : la détection à longue portée et la résolution haut de gamme. Ces deux objectifs peuvent être atteints en générant une impulsion avec un minimum de sonnerie et un maximum d'amplitude. Ces deux objectifs ont été pris en compte au début et atteints à la fin de notre thèse.

D'une part, une impulsion $U W B$ avec un temps de sonnerie et de montée plus bas est très nécessaire. Par conséquent, et pour améliorer la forme d'onde de sortie, deux techniques utiles ont été proposées, la première consistant à courtcircuiter autant que possible la trajectoire de décharge, tandis que la seconde consiste à modéliser la diode de récupération pas à pas $(S R D)$. Le générateur d'impulsions développé produit une impulsion électrique d'une amplitude de 12 V, un temps de montée de 112 ps et une largeur d'impulsion ( $F W H M$ ) de 155 ps. En outre, 3,5\% de dépassement en sonnerie a été obtenu.

D'autre part, et dans les circonstances réelles, certains matériaux ont beaucoup de pertes, par exemple, ils absorbent beaucoup d'énergie électromagnétique. Par conséquent, une impulsion élevée est nécessaire pour effectuer les mesures à la fin. Pour faire face à ce défi, deux techniques utiles ont été proposées dans ce travail pour augmenter l'amplitude des impulsions. La première consiste à assembler 
deux générateurs en parallèle, tandis que la seconde technique adoptée dans ce travail consiste en un générateur à deux étages. Bien que la spécification technique compliquée qui sera prise en compte pour garantir la fonctionnalité de ce circuit, les deux techniques donnent lieu à une bonne performance, et l'augmentation d'amplitude autour du double par rapport à l'unique. Par conséquent, un générateur d'impulsions monocyclique de puissance élevée avec un minimum de sonnerie a été obtenu.

Afin de valider la performance de la conception proposée, deux types de mesures d'essai ont été effectués : la portée et les propriétés électriques. Toute l'expérience a été réalisée dans une chambre anéchoïque pour éviter toute perturbation électromagnétique, le système implémenté a été construit en configuration bi-statique et le matériau sous test (MUT) a été modifié du métal au diélectrique comme le bois et le chlorure de polyvinyle $(P V C)$. Pour émettre et recevoir les impulsions ultra-courtes générées, deux types différents d'antennes $U W B$ ont été utilisés. La première est une antenne Vivaldi avec une largeur de bande d'environ 5,5 GHz allant de $600 \mathrm{MHz}$ à $6 \mathrm{GHz}$. La seconde est une antenne Vivaldi avec une bande passante de $6 \mathrm{GHz}$ allant de $400 \mathrm{MHz}$ à 6,2 GHz.

L'incertitude du capteur radar est de $14 \mathrm{~mm}$ (données mesurées effrayées à + $14 \mathrm{~mm}$ près pour une cible fixe). La conception et la mise en ?uvre réelle du générateur d'impulsions $U W B$ présenté dans ce travail permettent d'obtenir d'excellents résultats. Par conséquent, la conception donnée du générateur d'impulsions UWB sera très attrayante dans une application très future, en particulier dans les applications industrielles non destructives. 


\section{Resum}

A causa de la rellevància dels camps d'aplicació dels sensors de radar de banda ultra ampla $(U W B)$, i també l'exigència de cada camp específic, especialment en l'aplicació no destructiva industrial $(N D T)$; hi ha una demanda creixent de disseny compacte, de baix cost i alta precisió de sensors de radar de $U W B$.

Per fer front a aquestes demandes, aquest treball d'investigació tracta d'un nou disseny d'un dels components principals d'un sensor de radar de $U W B$; el generador de pols de $U W B$. El disseny del generador d'impulsos $U W B$ proposat en aquesta tesi consisteix en tres parts principals; un circuit de transistor d'allaus, un circuit d'afilat de pols i un circuit de xarxa que forma un monocicle ( $M F N)$. Tanmateix, el propòsit del $(M F N)$ és convertir el pols gaussiano en un monocicle.

En general, es desitgen dos tipus de mesures en qualsevol aplicació moderna; detecció de llarg abast i resolució de gamma alta. Aquests dos objectius es poden aconseguir generant un pols amb un mínim de timbres i un màxim d'amplitud. Aquests dos objectius, s'han tingut en compte al principi i s'han aconseguit al final de la nostra tesi.

D'una banda, un pressupost de $U W B$ amb menys sons i temps de pujada és molt necessari. Per tant, i per millorar la forma d'ona de sortida, s'han proposat dues tècniques útils, la primera consisteix a escurçar la via de descàrrega tant com sigui possible, mentre que la segona consisteix a modelar el díode de recuperació de pas $(S R D)$. El generador de polsos desenvolupat produeix un pols elèctric amb una amplitud de $12 \mathrm{~V}$, un temps de pujada de $112 \mathrm{ps}$ i un ample de pols ( $F W H M$ ) de 155 ps. A més, s'ha obtingut $3.5 \%$ de descompte quan s'ha obtingut un to de trucada.

D'altra banda, i en la realitat, alguns materials tenen molta pèrdua, per exemple, absorbeixen molta energia electromagnètica. Per tant, es requereix un pols alt per dur a terme les mesures al final. Per fer front a aquest repte, s'han proposat dues tècniques útils en aquest treball per augmentar l'amplitud dels polsos. El primer consisteix a muntar dos generadors en paral.lel; mentre que la segona tècnica adoptada en aquest treball consisteix en un generador de dues etapes. Encara que la complicada especificació tècnica que tindrà en compte la garantia de la 
funcionalitat d'aquest circuit; ambdues tècniques donen lloc a un bon rendiment, i l'amplitud augmenta al voltant del doble en comparació amb l'únic. Per tant, s'ha obtingut un generador de pols de monocicle d'alta potència amb un mínim de timbres.

Per tal de validar el rendiment del disseny proposat, s'han realitzat dos tipus de mesura de la prova: el rang de distància i les propietats elèctriques. Tots els experiments han estat realitzant-se en una cambra anecoica per evitar qualsevol pertorbació electromagnètica, el sistema implementat va ser construït en configuració biestàtica i el material sota prova $(M U T)$ ha estat variat del metall a dielèctric com la fusta i el clorur de polivinil ( $P V C$ ). Per transmetre i rebre polsos ultracurts generats, s'han utilitzat dos tipus diferents d'antenes de $U W B$. El primer és una antena Vivaldi amb un ample de banda d'uns $5.5 \mathrm{GHz}$ que oscil.len entre els $600 \mathrm{MHz}$ i els $6 \mathrm{GHz}$. Mentre que la segona és una antena Vivaldi amb un ample de banda de $6 \mathrm{GHz}$ que va des de $400 \mathrm{MHz}$ fins a 6,2 GHz.

$S$ 'ha trobat que la incertesa del sensor de radar és de $14 \mathrm{~mm}$ (dades mesurades espantades entre $+14 \mathrm{~mm}$ per a un objectiu fix). El disseny i la implementació real del generador de polsos $U W B$ presentat en aquest treball permeten obtenir resultats excel-lents. Per tant, el disseny donat del generador de pols UWB serà molt atractiu en una aplicació molt més futura, especialment en usos industrials no destructius. 



\section{Contents}

Acknowledgment vi

$\begin{array}{ll}\text { Abstract } & \text { ix }\end{array}$

Resumen $\quad$ xii

Résumé $\quad$ xV

Resum $\quad$ xvii

Table of Contents $\quad$ xx

List of Figures $\quad$ xxiii

List of Tables $\quad$ xxvii

$\begin{array}{lc}\text { List of Publications } & \text { xxix }\end{array}$

1 Introduction $\quad 2$

1.1 Introduction . . . . . . . . . . . . . 3

1.2 Motivation . . . . . . . . . . . . . . 10

1.3 Background and current status. . . . . . . . . . . . 11

1.4 Thesis objectives and methodology . . . . . . . . . . . . . . 13

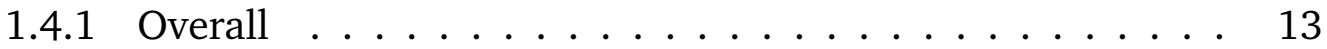

1.4.2 Thesis objectives . . . . . . . . . . . . 13

1.4 .3 Methodology ................... 14

1.5 Thesis outline . . . . . . . . . . . . . . 16

2 Principles and theoretical aspect of UWB Radar Sensor 19

2.1 Fundamentals of Ultra Wide Band systems . . . . . . . . . . 20

2.1.1 UWB basics and specification . . . . . . . . . 23

2.1 .2 UWB pulses signals . . . . . . . . . . . . 27 
2.1.3 Structure of UWB systems . . . . . . . . . . . . 30

2.1 .4 UWB Antenna . . . . . . . . . . . . . . . . . 33

2.2 Fundamentals of Radar Sensors . . . . . . . . . . . . . . . . 41

2.2.1 Historical Review . . . . . . . . . . . . . . . . . 41

2.2.2 Pulsed Radar Sensor . . . . . . . . . . . . . . . . . . 42

2.2.3 Frequency-Modulated Continuous Wave Radar Sensors . . . 43

2.2.4 Setepped-Frequency Continous Wave Radar Sensors . . . . 44

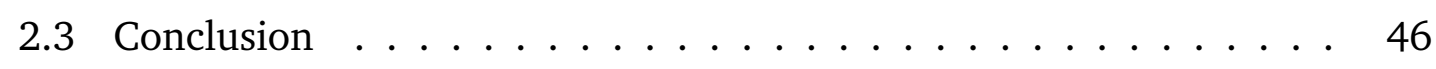

3 Pulse generator design for UWB Radar Sensor $\quad 48$

3.1 Introduction . . . . . . . . . . . . . . . . . . . . 49

3.2 Circuit description of the pulse generator . . . . . . . . 50

3.3 Circuit design of the pulse generator $\ldots \ldots \ldots \ldots \ldots \ldots$

3.3.1 Driver: Avalanche Transistor Circuit effects. . . . . . . . . 52

3.3.2 Pulser: SRD pulse Sharpener circuit. . . . . . . . . . . 59

3.3.3 MFN: Monocycle Forming Network . . . . . . . . . . . . . . . 64

3.4 The complete pulse generator . . . . . . . . . . . 66

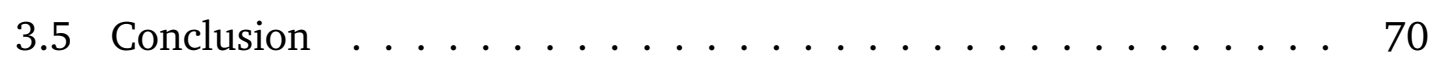

4 High power pulse generator for UWB Radar Sensor $\quad 72$

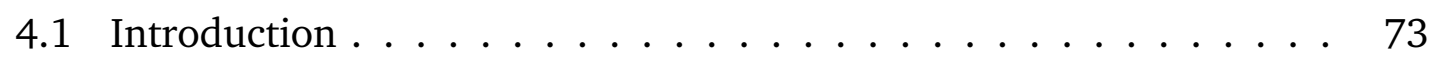

4.2 High power Monocycle pulse transmitter design . . . . . . . . 73

4.2.1 Combining two identical pulse generators . . . . . . . 73

4.2.2 TWO STAGE of the pulse generators _ . . . . . . . 75

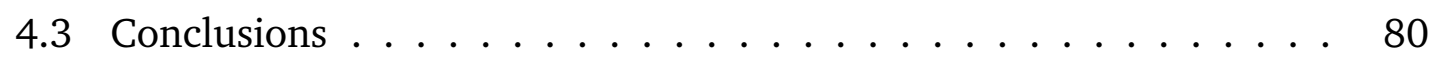

5 System Integration and Measurements $\quad 82$

5.1 Introduction . . . . . . . . . . . . . . . . . 83

5.2 Measurement of range distances. . . . . . . . . . . . . . . . 84

5.3 Measurements of electrical properties. . . . . . . . . . . . 87

5.4 Range accuracy. . . . . . . . . . . . . . . . . . . . . . 91

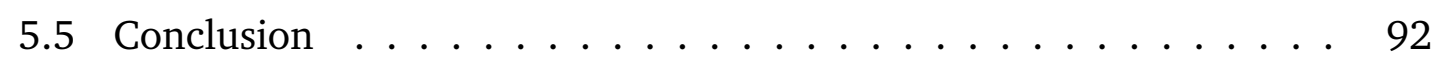

6 Conclusions and Further works $\quad 94$

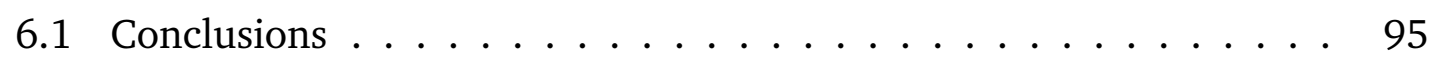

6.2 Further works . . . . . . . . . . . . . . . 96 
Acronyms

6.3 R \& D Project . . . . . . . . . . . . . . . . . . . 119

6.4 Reviewer . . . . . . . . . . . . . . . . . 119

Research internships 


\section{List of Figures}

1.1 Evolution of UWB aplication . . . . . . . . . . . . . . . 5

1.2 Different commercial sensors $\ldots \ldots \ldots \ldots \ldots$

1.3 Different types of radars Application $\ldots \ldots \ldots$. . . . . . . 6

1.4 Radar Classifications . . . . . . . . . . . . . . . . . . . . 7

2.1 Transition from narrowband to wideband and ultra-wideband in the time and frequency domains . . . . . . . . . . . . . . 22

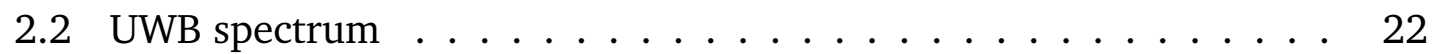

2.3 Indoor UWB systems spectrum mask . . . . . . . . . . . . . 23

2.4 Indoor UWB systems spectrum mask . . . . . . . . . . . . . . 24

2.5 An illustration of IoT based smart city . . . . . . . . . . . 26

2.6 Gaussian pulse and frequency spectrum $\ldots \ldots \ldots \ldots$

2.7 Monocycle pulse and frequency spectrum $\ldots \ldots \ldots \ldots$

2.8 Gaussian Doublet pulse and frequency spectrum . . . . . . . . . . 29

2.9 The power of narrowband signals vs ultrawideband signal $\ldots \ldots 30$

2.10 Behavior of narrowband vs UWB in time and frequency domain . . 31

2.11 diagram of UWB transmitter . . . . . . . . . . . . . . . 31

2.12 diagram of UWB Receiver . . . . . . . . . . . . . . . . 32

2.13 An example showing the antennas function in a wireless communication link . . . . . . . . . . . . . . . . . . 33

2.14 Examples of typical antennas. (a) Dipole antenna, (b) Rectangular patch antenna, (c) Waveguide aperture antenna, (d) Horn antenna 34 2.15 A basic diagram of the operation mode of antenna . . . . . . . 35

2.16 Traveling-wave antenna. Horn (left) and tapered slot (right) antenna 38

2.17 Frequency-independent antenna. Spiral (left) and bi-conical (right)

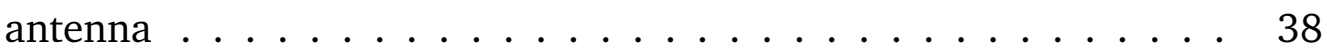

2.18 Multiple resonance antenna. Yagi antenna . . . . . . . . . . . 38

2.19 Small element antenna. Folded Spherical (left) and CPW-fed bowtie slot (right) antenna . . . . . . . . . . . . . . . . . . . . 39

2.20 Photo of the RFSPACE UWB1 and the diagram of the bandwidth. . 39 
2.21 Photo of the RFSPACE UWB2 and the diagram of the bandwidth.

2.22 waveforms of pulsed radar sensors:(a) impulse (b)mono-pulse, where $\mathrm{T}$ is the pulse width and $V_{p}$ is the peak amplitude (c) modulated pulse. 43

2.23 FMCW radar sensor . . . . . . . . . . . . . . . . . . . . 44

2.24 SFCW radar sensor . . . . . . . . . . . . . . . . . . 45

3.1 Block diagram of the proposed pulse generator. . . . . . . . . . 51

3.2 (a): The circuit schematic of the Avalanche transistor circuit, (b): Layout of the Avalanche transistor circuit. . . . . . . . . . . . 52

3.3 $I_{c}-V_{C} E$ Avalanche breakdown characteristics of a bipolar transistor [124] . . . . . . . . . . . . . . . . .

3.4 $I_{c}-V_{C} E$ characteristics of a bipolar transistor for Avalanche mode of operation [124].

3.5 Amplitude output pulse of Avalanche transistor circuit versus supply voltage $V_{c} c$ with $C_{c} c=110 \mathrm{pF} \ldots \ldots \ldots \ldots$

3.6 FWHM of output pulse of Avalanch transistor circuit as a function of supply voltage $V_{c} c$ with $C_{c} c=110 \mathrm{pF} \ldots \ldots \ldots$

3.7 Rise-time of output pulse of Avalanche transistor circuit as a function of supply voltage $V_{c} c$ with $C_{c} c=110 \mathrm{pF} \ldots \ldots$

3.8 Amplitude of output pulse of Avalanche transistor circuit versus $C_{c} c \quad 56$

3.9 Rise-time and FWHM of output pulse of Avalanche transistor circuit versus $C_{c} c \ldots \ldots \ldots \ldots \ldots \ldots \ldots$

3.10 Rise-time and FWHM of output pulse of Avalanche transistor circuit versus $C_{c} c \ldots \ldots \ldots \ldots \ldots \ldots \ldots$

3.11 Amlitude of output pulse of Avalanche transistor circuit as a funcion

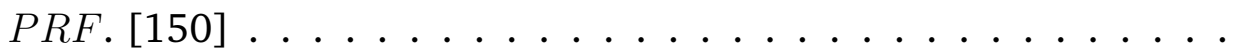

3.12 Photo and result before (a) and after (b) including the technic of the discharge path short. . . . . . . . . . . . . 59

3.13 The circuit schematic and Layout of SRD pulse sharping circuit. . . 60

3.14 SRD pulse sharping circuit. . . . . . . . . . . . . 60

3.15 Amplitudes variation with the bias currents Ic for the SRD of AWR . 61

3.16 Amplitudes variation with the length of Delay line the SRD of AWR 61

3.17 (a): SRD in SOT-23 package, (b): Shottky diode in SOD-323 package. 62

3.18 operating mode of SRD pulse sharping circuit. . . . . . . . . . 62

3.19 (a): SRD of AWR Microwave Office. (b): New model of a step recovery diode $(\mathrm{SRD}) . \ldots \ldots 63$ 
3.20 Output waveform before (a) and after (b) the application of new model of SRD respectively. . . . . . . . . . . . . . . . 65

3.21 Output waveform Gaussian measured using SRD from MA44769-

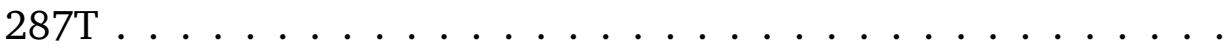

3.22 the variation of the monocycle waveform with the length of the stub in the distributed form of the MFN . . . . . . . . . 66

3.23 (a) Lumped and (b) distributed monocycle forming network. . . . 67

3.24 Fabricated monocycle forming network. . . . . . . . . . . . . 67

3.25 A personal picture at Dimas laboratory of ITACA Institut, and the Photo of the separated Ultra-short pulse generator. . . . . . . . 68

3.26 Photo of the compacted Ultra-short pulse generator. . . . . . . . . 68

3.27 Simulated and measured results of the monocycle pulse generator.. 69

3.28 monocycle pulse with impact of LPF and HPF.. . . . . . . . . . . . 69

4.1 Photo of the Mini-circuit power splitter ZN2PD2. . . . . . . . . 74

4.2 Block diagram of the proposed Radar pulses transmitter. . . . . . . 74

4.3 Photo of the proposed Radar Transmitter. . . . . . . . . . . . 75

4.4 Output waveform of the proposed radar transmitter. . . . . . . . 75

4.5 Circuit design and a photo of the two-stage generator based on avalanche transistor. . . . . . . . . . . 76

4.6 Output waveform of the proposed radar transmitter. . . . . . . 77

4.7 The photo of the function generator and the oscilloscope used in the all of the measurement. . . . . . . . . . . . . 78

4.8 Results of the proposed high power monocycle pulse two stage gen-

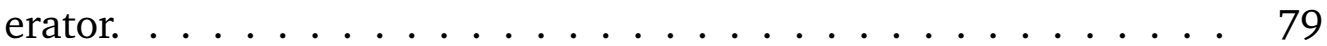

4.9 The distance measurements for the PVC placed at 3.25 meters. . . 79

5.1 Diagram and setup of the whole system measurement. . . . . . . 83

5.2 Photograph of the UWB antennas with the radiation pattern. . . . . 84

5.3 Photograph of measurement setup and a photograph of UWB impulse generator. . . . . . . . . . . . . . 85

5.4 The time-domain response of the radar sensor measurement towards a metal plate located at $300 \mathrm{~cm}$. . . . . . . . . . 85

5.5 The time-domain response of the radar sensor measurement towards a metal plate located at $180 \mathrm{~cm}$. . . . . . . . . . . 86 
5.6 The time-domain response of the radar sensor measurement towards a metal plate located at $80 \mathrm{~cm} \ldots \ldots \ldots \ldots . \ldots 86$

5.7 Bi-static System Configuration and measurement setup. . . . . . 88

5.8 Circuit diagram of the proposed Gaussian pulse generator. . . . . . 89

5.9 Results of measurement of distance at $50 \mathrm{~cm}$. . . . . . . . . . 90

5.10 Results of measurement of PVC from a different distance. . . . . . . 91

5.11 The accuracy Variation vs atahe range distance. . . . . . . . . . 92 


\section{List of Tables}

1.1 Summary of FCC Restrictions on UWB Operation. . . . . . . . . . . 4

4.1 Output pulse parameters for diferent charging capacitor values. . . 77

4.2 Output pulse parameter for different RL values. . . . . . . . . . 78 



\section{List of Publications}

\section{A- JOURNAL PAPERS}

1. Ahajjam Younes, José M Catala civera, Felipe Peñaranda Foix, Abdellah Driouech, "Bibliography, Background and Overview of UWB radar sensor" ISSN: 2248-9622, Vol. 4, Issue 11(Version 5), November 2014, pp.37-40, International Journal of Engineering Research and Applications (IJERA). Accepted

2. Ahajjam Younes, Otman Aghzout, José M Catala-civera, Felipe Peñaranda Foix and Abdellah Driouech, "Accurate and Compact High Power Monocycle Pulse Transmitter for Microwave Ultra-Wideband Radar Sensors with an enhanced SRD model, Applications for Distance Measurement for lossy Materiel " Advanced Electromagnetics, (AEM).Accepted with modification.

3. Ahajjam Younes, otman Aghzout, José M Catala-civera, Felipe Peñaranda Foix and Abdellah Driouech, "New Generator Design with Enhanced Output Waveform for Non-Destructive Radar Sensor Measurements" MATEC Web of Conferences, (MATEC). Accepted

4. Ahajjam Younes, otman Aghzout, José M Catala-civera, Felipe Peñaranda Foix and Abdellah Driouech, " Range Distance Measurements Using an UWB Tapered Slot $0.43 \mathrm{GHz}$ to $6 \mathrm{GHz}$ Antenna for IoT Application" Procedia Manufacturing, (ELSEVIER). Accepted.

5. Ahajjam Younes, otman Aghzout, José M Catala-civera, Felipe Peñaranda Foix and Abdellah Driouech, " Am advanced Electrical Properties Measurements Approach with a designed Bi-static Ultra wideband Impulse Radar sensor" Progress In Electromagnetics Research (Pier M). Accepted

\section{B- CONFERENCE PAPERS}

1. Y. Ahajjam and all, "Ultra-wideband Microstrip Quasi-horn Antenna for Radar Sensor", The first edition of the Doctoral day in Physics, JDP, Faculty of science, Tétouan 10 April 2014. 
2. Y. Ahajjam and all, "Low-Cost Short Pulse Generators for Radar Sensor", The 3rd meeting of young researchers, 3RJC, Faculty of science, 29 - 30 et 31 Mai 2014. Faculty of science, Tétouan.

3. Y. Ahajjam and all, "New and Low-cost Generator Of Impulsion Monocycle For Non-Destructive Test", International Workshop on Technology Innovation and Entreurship IWTIE'14, June 04, 2014, Ensias, University of Mohamed Vsouisi , RABAT.

4. Y. Ahajjam and all, "The Hardware of UWB Radar Sensor for Industrial Application", I Meeting of Doctoral Students of the Polytechnic University of Valencia, 12 de Junio de 2014 CPI. UPV.

5. Y. Ahajjam and all, "The Hardware of impulse Radar Sensor For NDT", Workshop on Innovation on Information and Communication Technologies, ITACAWIICT 2014, le 04 Julio 2014, The polytechnic city of innovation of the Polytechnic University of Valencia, ITACA-WIICT 2014.

6. Y. Ahajjam and all, "Simple, Compact and Low-Cost Pulse Transmitter for UWB Microwave", The international congress MedCIT15 (Mediterranean Conference On Informacion and Communication Technologies , 2015), days of 7-9 may, hotel Believe, the city of Saidia, Maroc.

7. Y. Ahajjam and all, "UWB Pulse Radar Sensor for Non-Destructive Detection Applications", III Meeting of Doctoral Students of the Polytechnic University of Valencia, June 30, 2016, CPI. UPV.

8. Y. Ahajjam and all, "A New Compact UWB Subnanosecond-Pulse Generator for Microwave Radar Sensor with Ringing Miniaturization", the international congress ICMCS'16 (5th International Conference on Multimedia Computing and Systems), 29 September-1 October 2016, Marrakech MOROCCO.

9. Y. Ahajjam and all, "High Power Monocycle Pulse Transmitter Ultra-Wideband Radar Sensor for Lossy Materiel", the international congress ICMCS'16 (5th International Conference on Multimedia Computing and Systems), 29 September1 October 2016, Marrakech MOROCCO.

10. Y. Ahajjam and all, "Two different methods to increase the power of ultrawideband impulse generator design for radar sensor", on June 6, 2017, 
The polytechnic city of innovation of the Polytechnic University of Valencia, ITACA-WIICT 2017.

11. Y. Ahajjam and all, "New Generator Design with Enhanced Output Waveform for Non-Destructive Radar Sensor Measurements", International Congress of Non-Destructive Evaluation of Composite Structures, 25 of November 2017 in Tetouan-Morocco.

12. Y. Ahajjam and all, "Gain Improvements of C-Band in WDM Optical LongHaul Networks using GFF ", The Third International Conference on Electromagnetic Radiation and Impact on the Environment JREMIE'3, 28th April 2018.

13. Y. Ahajjam and all, " Circuit modeling of a Coupled lines-based Bandpass Filter for wireless communication technologies ", The Third International Conference on Electromagnetic Radiation and Impact on the Environment JREMIE'3, 28 April 2018.

14. Y. Ahajjam and all, "Range detection Measurements using TSA UWB PCB Tapered Slot 0.43-6 GHz Antenna", the third International Conference on Electromagnetic Radiation and Impact on the Environment JREMIE'3, 28 April 2018.

15. Y. Ahajjam and all, "A Bi-static configuration UWB radar sensor using a TSA UWB PCB Tapered slot antenna for the electrical properties measurement", the third International Conference on Electromagnetic Radiation and Impact on the Environment JREMIE'3, 28 April 2018.

16. Y. Ahajjam and all, "performance Enhancement analysis of WDM Optical Long Haul Network using Gain Flattening Filter", International conference "Technologie, Innovation et Système d'Information" (CITISI'18) , 17 et 18 Mars 2018.

17. Y. Ahajjam and all, "Gain Enhancement of Vivaldi Antenna for Radar and Medical Applications ", International conference "Technologie, Innovation et Système d'Information" (CITISI'18), 17 et 18 Mars 2018.

18. Y. Ahajjam and all, "Analysis study and Theoretical Verification of a Compact Planar Bandpass Filter for ISM and Wi-fi Applications " International confer- 
ence "Technologie, Innovation et Système d'Information" (CITISI'18), 17 et 18 Mars 2018.

19. Y. Ahajjam and all, " The real part of Permivity Measurement using a UWB Tapered Slot Antenna in Bi-static configuration", International conference "Technologie, Innovation et Système d'Information" (CITISI'18), 17 et 18 Mars 2018.

20. Y. Ahajjam and all, "Range detection Measurements using UWB Tapered Slot antenna 0.6-6 GHz for NDT application", International conference "Technologie, Innovation et Système d'Information" (CITISI'18), 17 et 18 Mars 2018.

21. Y. Ahajjam and all, " Range Distance Measurements Using an UWB Tapered Slot $0.43 \mathrm{GHz}$ to $6 \mathrm{GHz}$ Antenna for IoT Application", The 12th International Conference INTER-ENG 2018 Interdisciplinarity in Engineering, U.M.F.S.T. Tirgu-Mures , Romania 4 - 5 October 2018.

22. Y. Ahajjam and all, "Two-Stage Design of High Power UWB Monocycle Generator for Radar Sensor Applied in The Four Industry Revolution", International conference "IEEE - International Symposium on Advanced Electrical and Communication Technologies" (ISAECT 2018), Kenitra, Morocco, 21-23 November 2018 



\section{Introduction}

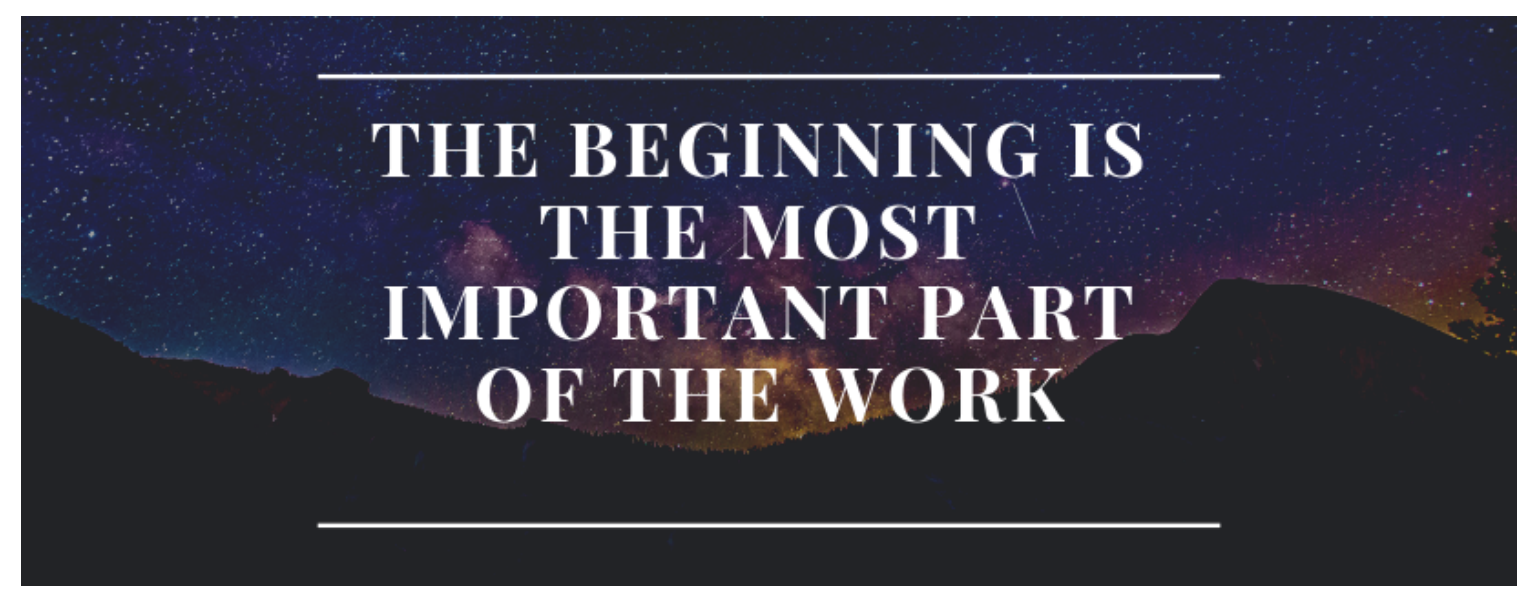

Athenian philosopher 348-347 BC.

Plato

$\mathrm{T}^{\mathrm{N}}$ this chapter, a general introduction of the thesis is presented. En details, the 1 Ultra-Wide Band UWB communication systems are defined, applications that have use the UWB and some future prospects of are described. Moreover, the difference between radar and sensors are also described. a particular emphasis on the the stat of the art, motivation and methodology is also presented. 


\subsection{Introduction}

7 He Ultra-Wide Band UWB communication systems are defined as any commu1 nication system whose instantaneous bandwidth is much greater than the minimum bandwidth required to transmit information. This excess bandwidth is the defining characteristic of UWB. In addition, the UWB provide high data rate at low power consumption. Within the last years, many research and innovation have been made in order to propose some practical UWB communications systems. However, some limits and restriction have been facing those progress, especially, the restriction of the range of frequencies used. For this reason, many personal and collective identities began petitions to the FCC to operate unlicensed UWB systems, and to authorize to work in frequency bands that were not used before. In 2000, the FCC had received more than 1,000 documents from more than 150 different organizations in response to their Notice of Inquiry, to assist the FCC in developing an appropriate set of specifications. Specifically, the FCC was concerned about the potential interference from UWB transmissions on Global Positioning System (GPS) signals and commercial/military avionics signals. [1]. In 2002, the FCC decided to change the rules to allow UWB system operation in a broad range of frequencies [1]. Therefore, the FCC defines UWB as a signal with either a fractional bandwidth of $20 \%$ of the center frequency or $500 \mathrm{MHz}$ [11]. In addition, the FCC issued a First Report and Order, which classified UWB operation into three separate categories: The Communication and Measurement Systems, the Vehicular Radar Systems and the Imaging Systems, including Ground Penetrating Radar, Through-Wall Imaging and Surveillance Systems, and Medical Imaging. Each category was allocated a specific spectral mask. Table 1.1 summarizes the various UWB operational categories and their allocated bandwidths, along with restrictions on organizations that are allowed to operate in that particular mode.

The UWB has many great differentiation to a narrow-band system; firstly, it have a large instantaneous bandwidth, secondly, it have a Short duration of pulses and a Low power spectral density; and finally, the Data rate may be traded for power spectral density and multipath performance. With the features mentioned above, the UWB it's enable to provide robust performance in dense multi-path environments, also it's allows coexistence with existing users and has a Low Probability of Intercept (LPI). 
Table 1.1: Summary of FCC Restrictions on UWB Operation.

\begin{tabular}{|c|c|c|}
\hline Application & $\begin{array}{l}\text { Frequency Band } \\
\text { for Operation }\end{array}$ & User Restrictions \\
\hline $\begin{array}{l}\text { Communications and Measurement Sys- } \\
\text { tems (sensors) }\end{array}$ & $\begin{array}{l}\text { 3.1-10.6 GHz } \\
\text { (different emis- } \\
\text { sion limits for } \\
\text { indoor and out- } \\
\text { door systems) }\end{array}$ & None \\
\hline $\begin{array}{l}\text { Vehicular Radar for collision avoidance, } \\
\text { airbag activation, and suspension system } \\
\text { control }\end{array}$ & $24-29 \mathrm{GHz}$ & None \\
\hline $\begin{array}{l}\text { Ground Penetrating Radar to see or detect } \\
\text { buried objects }\end{array}$ & $\begin{array}{l}\text { 3.1-10.6 GHz and } \\
\text { below } 960 \mathrm{MHz}\end{array}$ & $\begin{array}{l}\text { Law enforcement, } \\
\text { fire and rescue, } \\
\text { research insti- } \\
\text { tutions, mining, } \\
\text { construction }\end{array}$ \\
\hline $\begin{array}{l}\text { Wall Imaging Systems to detect objects } \\
\text { contained in walls }\end{array}$ & $\begin{array}{l}\text { 3.1-10.6 GHz and } \\
\text { below } 960 \mathrm{MHz}\end{array}$ & $\begin{array}{l}\text { Law enforcement, } \\
\text { fire and rescue, } \\
\text { mining, construc- } \\
\text { tion }\end{array}$ \\
\hline $\begin{array}{l}\text { Through-wall Imaging Systems to detect } \\
\text { location or movement of objects located } \\
\text { on the other side of a wall }\end{array}$ & $\begin{array}{l}1.99-10.6 \quad \mathrm{GHz} \\
\text { and below } 960 \\
\mathrm{MHz}\end{array}$ & $\begin{array}{l}\text { Law enforcement, } \\
\text { fire and rescue }\end{array}$ \\
\hline $\begin{array}{l}\text { Medical Systems for imaging inside peo- } \\
\text { ple and animals }\end{array}$ & 3.1-10.6 GHz & $\begin{array}{l}\text { Medical person- } \\
\text { nel }\end{array}$ \\
\hline $\begin{array}{l}\text { Surveillance Systems for intrusion detec- } \\
\text { tion }\end{array}$ & $1.99-10.6 \mathrm{GHz}$ & $\begin{array}{l}\text { Law enforcement, } \\
\text { fire and rescue, } \\
\text { public utilities, } \\
\text { and industry }\end{array}$ \\
\hline
\end{tabular}

Otherwise, there are many applications that have used the UWB, the background and chronology of these uses and applications will be described in the next chapter. 
However, UWB technology has a lot of future prospects, especially with the arrival of the IOT. Figure 1.1.
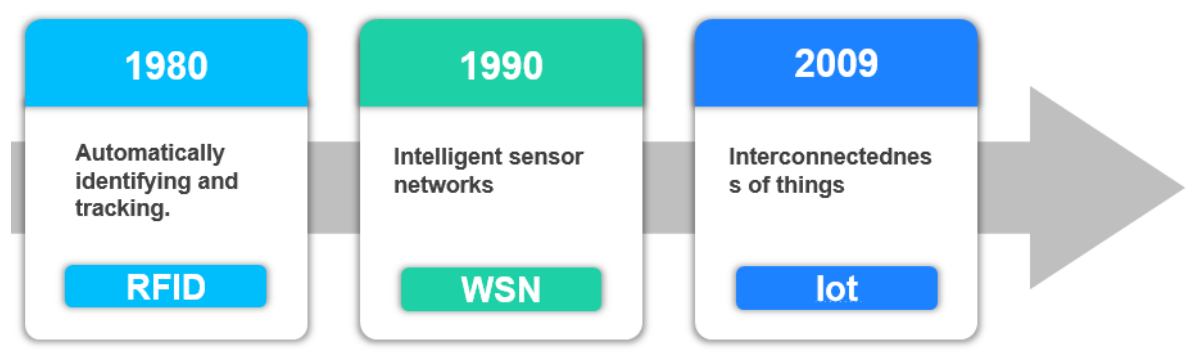

Figure 1.1: Evolution of UWB aplication

The Internet of Things (IoT) can be understood as a global network that provides the functionality of integrating the physical world. This is done through the collection, processing and analysis of data generated by IoT sensors. In addition, the IoT is considered as a new paradigm that is rapidly gaining ground in the modern wireless telecommunications landscape, the concept is the widespread presence around us of a variety of things or objects - such as radio frequency identification (RFID) tags, Sensors, actuators, cell phones, etc. The main strength of the IoT idea is the expected high impact on various aspects of everyday life and the behavior of potential users. Looking at the definition of IoT, as well as some of the benefits and real-world use cases, it's critical to examine how sensors play a role in this equation. If the software is the brains of the IoT, sensors are the nervous system collecting continuous streams of data to be processed [1]- [2]. There is more number of IoT applications in fields like transportation, retail and logistics, infrastructure, wearable, industrial, environment, security, etc. However, every application require some type of sensors to collect data in real time, Figure 1.2. In this work, the NDT industrial applications have been chosen as a Iot application, therefore, the sensor will be developed in order to work in the industrial circumstance.

Sensors are the devices that have capability to sense the real time data and convert that data into the machine understandable codes. Sensor can also be defined as a physical object that receives a change in the environment and responds to that change with an electrical signal output. The sensors also is able to detect external actions or stimuli and respond accordingly. With the sensors we can measure temperature, atmospheric pressure, heart rate or Geo-location. . 


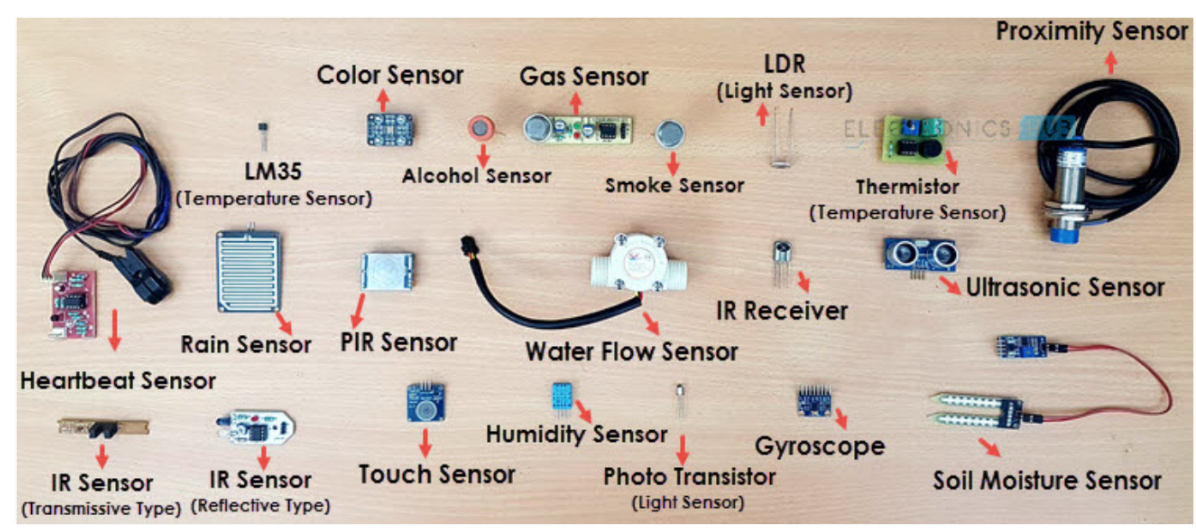

Figure 1.2: Different commercial sensors

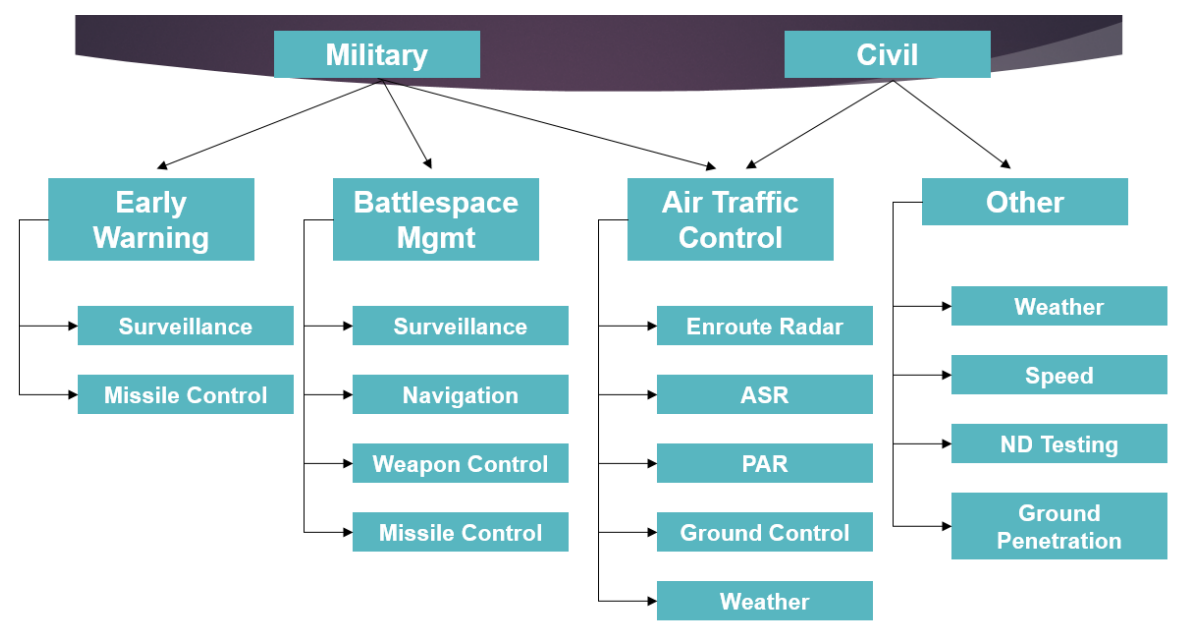

Figure 1.3: Different types of radars Application

In contrast to the sensors, which are passive devices: that is, they detect the variations and convert it to an electrical signal (Analog or digital); the radars are classified as active devices, since to detect the variation of their environment they have to send short pulses, and compare it with the reflected echoes to extract information from its surroundings. The principle of such a system is very simple. A switch provides a short electrical pulse, which is directly radiated against the subject; solid or liquid surface. The reflected pulse is recorded by an envelope (threshold) detector.

Nowadays, there are different application that the Radars can be used, Figure 1.3, shows more details about the different applications. In other hand, there are many radar systems operating; Microwave, Optical and Ultrasonic Radar systems. Each one has its strengths and weaknesses application [4].

- LADAR (Laser Detection And Ranging) systems use light to determine the distance to an object. Since the speed of light is well known, LADAR uses a 
short pulsed laser to illuminate a target and then how long it takes the light to return. This technique is known as the time of flight [5] [6].

- SODAR (sound detection and ranging) is considered as a chipper technology. One's weaknesses of this technology are the high attenuation because the ultrasonic is a material wave. [7]. the attenuation is proportional with the frequency; Thus, ultrasonic sensors for larger ranges must work at low frequencies [8]. Therefore, the ultrasonic transmitter has to provide high power to handle the large ranges, a few meters as discussed in this thesis [7]. Another weakness of this technology is the temperature dependency, e.g., the velocity of ultrasonic waves depends on temperature. For this reason and as calibration technic, a temperature sensor is commonly installed in front of the ultrasonic radar [9].

- Microwave sensor radar is presented as an alternative, because it presents many advantages especially in the industrial field, since it is lower affected and influenced by the industrial environment parameters, such as vapour, heat, dust, and deposition of mud. Nevertheless, wider bandwidth starting at low frequencies of the ISM (industrial, scientific and medical) bands [10].

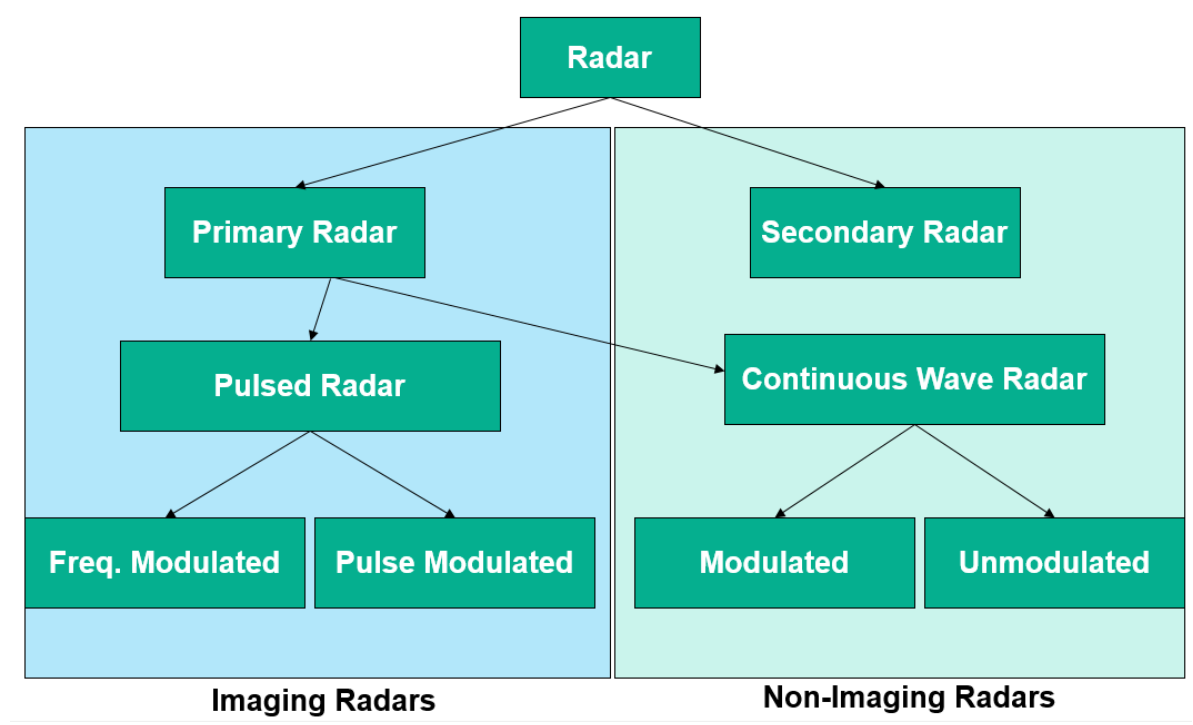

Figure 1.4: Radar Classifications

The type of the waveform used for transmission and reception it is another parameter, which we can differentiate into two-different kind of radar sensors: the continuing wave (CW) radar sensor and the pulsed radar sensor, Figure 1.4. However, the pulsed are preferred in many applications, due to her ultra-width 
band provided, and to the accurate measurement achieved. A UWB short pulse generator is one of the most parts of any UWB system [11]- [12]- [13]. In the past decades, UWB technology was mainly used for military communications, medical applications, radar, and sensing applications. With the approval of Federal Communications Commission (FCC) in February 2002, UWB technology pushes the limits of high data-rate and has been proposed for high-rate, short-range communications, such as home networks, in-building communications, and cordless phones [14]. The first UWB communication was in 1901 when Marconi sent a transmission from the Isle of Wight to Cornwall on the British Mainland using Spark Gap Emitter [15]. Many years later; especially in the late 1970s and early 80s, Fullerton has demonstrated the workability and feasibility of modern low power impulse radio techniques, using the time-modulated ultra wide band approach [16]. In contrast to the typical narrowband (Sinusoidal waveform signal), a UWB signal consists of a train of nanosecond pulses. The frequency is inversely proportioned with time; therefore, the wider bandwidth in the frequency domain (from DC to several gigahertz $\mathrm{GHz}$ ) corresponds to the narrowness of the pulses in the time domain (around picosecond). However, the switching from one domain to another can be made using the Fourier transformation. In addition, the UWB has the features of multi-frequency components with minimal interference with other signals. Therefore it is widely applied in many application fields [17]- [18].

Recently, according to UWB technology development, increased demands on wireless personal area networks as well as on high-resolution positioning facility is required. Therefore, attracted attention by many researchers have been concentrated more and more on sub-nanosecond pulses [19]- [21]; because Ultra-short pulses with well-defined output waveform play a crucial role in the UWB transmitter design. A sub-nanosecond pulse generator is a fundamental and critical part of any UWB radar sensor. The wide bandwidth of UWB pulses ensures fine range resolution and high penetration capability. Normally, the lower frequencies up to 3.5 GHz are preferred for the application radar in lossy material, because losses of common construction materials go up to unacceptable levels in the higher frequency bands. The corresponding pulse width of the generated baseband pulses is around 200 ps. There are various techniques to generate UWB pulses in the order of a picosecond. The basis of a classical UWB short pulse generator is a driver, a pulse sharpened and a pulse-forming network. The driver converts the step-like waveform in Gaussian pulses, and the pulse sharpened converts slow 
rise time waveform edge to a faster one. However, the pulse forming network forms the output pulse to the adequate and favourite pattern: Gaussian or monocycle [22]. Special semiconductor devices are usually utilized as pulse sharpener: avalanche transistor, bipolar diode [23], tunnel diode [24], Step Recovery Diode (SRD) [25] and FETs [26]. Avalanche diodes are advantageous as high power sharpener but have the disadvantage in the limitation of the maximum pulse repetition frequency, because of the power dissipation in the transistor, Tunnel diodes offer the fastest transition time (sub-picosecond) at very low power (about $\mathrm{mW}$ ). The SRDs are a compromise alternative for these devices and offer ultra-short transition time, (around 100 ps) at moderate power levels, (changing from hundreds of $\mathrm{mW}$ to tens watt) and with high repetition frequency. This makes them very appropriate to be used in current UWB generator. An SRD works as a charge controlled switch, which can alter from low impedance to high impedance state much quicker. This qualification of the SRD is used to sharpen the slow waveform edges. The time of the fast impedance change is called transition time, which vary around than 100 ps for SRDs currently available on the market. The more details of theory and application of SRDs as pulse sharpening is well described in [27]. Moreover, a Uniplanar sub-nanosecond monocycle pulse generator has been reported in [28] and a UWB monocycle pulse generator with dual resistive loaded shunt stubs is presented in [29] and an Ultra-wideband monocycle pulse generator with good performance is presented in [30]. In all of these works, the monocycle pulse amplitude is limited, the SRD model is not described and have a lot of the ringing in the output waveform [31,34].

In respect to transmitting and receiving information, the ringing in the output form involves more distortion and damage the signal; therefore, more difficult appears to extract the exact information regarding the data processing. Normally, the ringing is constructed after the driver and the sharpening part circuits, then it will be accumulated in the output of the pulse. Therefore, it is the neediness to intervene in both parts to perform the pulses. To fulfill this challenge two techniques will be proposed in this thesis; inserting a new model of SRD, and shortening the circuit discharge as much as possible.

It is noteworthy that the ultra-wideband radar sensor is less discussed in the literature and far away from practical use $[35,36]$. However, there are many problems to be solved yet to establish a UWB system for practical use. Main issues are: 
- Generating a high peak transmitted power for large range measurement.

- Generating a sharpened pulse for the high measurement accuracy.

- Compacting the system as much as possible.

- Reducing antenna size and simultaneously maintaining narrow beam width.

In order to face a part of these problems, this thesis is aimed to analyze, design and fabricate a novel pulse generator for an advanced radar sensor system. In details, this work, present a new, compact, low power and low-cost pulse generator based on a BJT transistor working in avalanche mode. Moreover, a sharpening circuit based on SRD and an MFN was added to generates the adequate and desired waveform. The circuits are designed and fabricated using microstrip line. In addition, two techniques solutions have been studied in details in order to enhance and amplify the pulse amplitude, in order to use it in some specific non-destructive applications. The first one consist of an accurate and complete modeling of the SRD in AWR Microwave office and Multisim; therefore the simulation accuracy has been improved and the rise-time of the output pulse has been decreased from $630 \mathrm{~ns}$ to $450 \mathrm{~ns}$. While the second ones consist of shortening the discharge path as short as possible; therefore the ringing of the output pulses has been established around 3.6\% in overshoot. However, and unlike the generator described by Zhong Li [37] and Protiva [38], our pulse transmitter has the advantage of producing pulses with low ringing levels and reasonably high output amplitude.

The complete system has been tested for two different measurements; range detection and electrical property of materials. All measurement has been carried out in an anechoic chamber, which any disturbance is avoided. The prototype has been proven that the characteristic data are very promising for further industrial implementation.

\subsection{Motivation}

With the arrival of the IOT, many technical demands have arisen to follow this great qualitative jump. One of these demands is the design of a UWB radar sensor with a large bandwidth, able of making measurements in a long range with great accuracy. The main reason for the use of the UWB pulse radar sensor, because it's an efficient, accurate and low-cost technique in various applications; also, it is due to the extremely wide bandwidth of the signal. This broadband 
signal includes both low and high-frequency components. Meanwhile, the desired performance characteristics of UWB pulse sensor radar are long-range detection and high resolution. To achieve these characteristics, the UWB signal is suitable because the low-frequency signal it is able to get long-range detection while the high frequency provides high resolution. In addition, and in comparison to the radar Continue Wave radar (CW), the pulse radar sensor can be implemented with a small compacted circuit. Also, It is possible to achieve higher transmission power with a simple circuit structure. Moreover, The cost of signal processing required on detection is lower because does not require any data conversion processing from the frequency domain to the time domain, as in the case of the frequency modulation radar. Taking into account these attractive aspects system structure and cost, the pulse radar sensor has been chosen and adopted in this thesis.

\subsection{Background and current status.}

One of the pioneering work that has been done in the development of an underground profiling pulse radar was done by Daniel $[39,40]$. Avezedo and McEwan then developed a compact, energy-efficient pulse radar sensor, the so-called "Micro-power Pulse Radar" [41]. Duzdar and Kompa have also introduced a pulse radar sensor with a bandwidth of $6 \mathrm{GHz}$, which can be implemented at low cost and is used in high-resolution applications [42]. Yarovoy et al. have developed a $3 \mathrm{GHz}$ ground-penetrating impulse radar and demonstrated its ability to detect small, shallow buried objects $[43,44]$. Lee has also developed a pulse radar system for underground penetration radar applications and showed the potential of its application to pavement evaluation [45]. J, Sach in 2007 [46] has applied a new method called M-sequences that employs pseudo-random codes to stimulate test objects. And with his team, has taken advantage of the advantages of the UWB radar sensor to apply it in medicine instead of catheter or X-ray techniques [47]. The most important part of the UWB pulse sensor radar is the pulse generator $[48,49]$, which will emit pulses of short duration with a repetition frequency (PRF) of a few KHz.

Actually, many approaches have been published for the design of pulse generators for radar sensor applications such as the classic GUUN elements [50,51], and BJT transistors in avalanche mode. Pulse generation with the transistors in avalanche mode is based on the well-known avalanche phenomenon [52,55], 
which occurs in the bipolar transistor junction (BJT) when the transistor experiences "breakdown" after a high polarization voltage is applied to them. To achieve a pulse emitter with a very short rise time (sub-nanoseconds), specific semiconductor components such as pulse sharpeners are used, e.g. tunnel diodes [56] and step recovery diodes (SRD) $[57,60]$. Tunnel diodes offer a faster transition time (in the sub-picosecond range) at shallow power levels (in the $\mathrm{mW}$ range) [61]. SRDs are a committed alternative to these devices. These diodes offer an ultrashort transition time (typically in the range of tens of picoseconds to a few hundred picoseconds) at moderate power levels (ranging from a few hundred $\mathrm{mW}$ to tens of watts) [58]. Therefore these diodes are very suitable for use as sharpeners [61].

The other important part of UWB pulse sensor radars is the receiver circuit which must have a low conversion loss and a very wide bandwidth to cover the entire frequency band of the transmitted signal. Most receivers are based on the equivalent time-sampling method [62] and were built using analogue technology. This type of technology uses a front door analogue sampling gate to convert the radio frequency $(\mathrm{RF})$ to another intermediate frequency signal. The typical sampling gate consists of Schottky diodes [63] or sampling phase detectors (SPD) $[64,66]$. Unlike analog receivers, digital receivers are more stable and flexible [67] because the signal is digitized directly into a digital receiver.

The radar transmitter and receiver pulse sensor are designed and implemented as a microwave integrated circuit (MIC). With the development of semiconductor technology, UWB designs are increasingly focused on CMOS RFIC technology due to its low cost, low power consumption and easy integration with other components such as digital circuits and flat antennas.

Nevertheless, even though several microwave circuits were developed, or are commercially available, there are always new transmitter and receiver circuits that are designed according to the following new motivations and requirements: The compactness as can as possible of circuits, in order to use it in some new micro-application. Circuits must be manufactured easily and at low cost. And the transmitter circuit must be designed to generate pulses with a high power and a fast rise-time. 


\subsection{Thesis objectives and methodology}

\subsubsection{Overall}

The overall aim of this Ph.D. Thesis was to add knowledge in the field of radar sensor by analyzing, designing and fabricating a new powerful prototype of UWB radar sensor. Moreover, the complete system has been tested in range distance measurements and in electrical properties inspection. The prototype can be classified as a promising system for further industrial implementation.

\subsubsection{Thesis objectives}

The UWB pulse sensor radars can be divided into two principals parts: the signal processing part and hardware part. The hardware part of a UWB pulse sensor radars consists of a pulse generator, a receiver and two antennas in the bistatic case $[68,70]$. This type of radar-sensors has, until today, typical application domains, such as distance measurement of objects buried underground (GPR), water level measurement in tanks (in the industry), etc.

On the other hand, the techniques of control and monitoring in industrial fields are based mainly on contact techniques (cavity or transmission lines). These techniques have the advantage of giving good results, but presents a disadvantage to be not compatible with some applications .e.g., hard MUT (Material under test) or in high-temperature high-temperature process.

Our doctoral thesis proposes a great solution to this problem since we want to design and implement a new prototype of a UWB pulse sensor radar for NDT applications, able of monitoring and controlling the variations of a dielectric material (dielectric properties and thickness ) within an industrial process.

Following, we list in detail the main objectives of this Thesis:

1. Development of a new design of a monocycle pulse generator for the purpose of using it in a pulsed radar system. The required monocycle pulse must have a rise-time around hundred of picoseconds, an amplitude more than 5 Volts, and a minimum of ringing after the principal pulse generated. Chapter 3 of this work is named "Pulse generator design for UWB radar sensor", and presents the detail and procedures of the development and manufacturing of the proposed monocycle pulse generator. 
2. Ameliorate and enhanced the performance of the pulses described in the bibliography, making them more sharpened in order of few picoseconds. for this reason, two useful techniques will be proposed. The section of "Circuit design of the pulse generator" in the chapter tree presents the proposed technique applied in this work and how its impact in ameliorating the principal pulses.

3. Amplify the power of the pulses using many techniques, in order to use it in a specific application that requires this type of pulses. This objective was fixed for the purpose to applied some measurements to lossy materials, in which the absorption of the electromagnetic energy it's higher. For this reason, an entire chapter, chapter four has been allocating to fulfill this challenge.

4. Test the prototype system for range detection measurement. This test is considered one of the goals fixed in term of the measurement of our system developed. Chapter 5, section Measurements range distance, will present the way and procedure of this measurement.

5. Test the prototype system for electrical properties measurement is considered as another goal of the proposed system in term of measurement application. Chapter 5, section Measurements of electrical properties, will present the theoretical method adopted and procedure of this measurement.

From a scientific perspective, the value of this Thesis in terms of novelty and relevance of the field is attested by the acceptance of the appended international papers and the referred international conference proceedings through an established scientific reviewing process.

\subsubsection{Methodology}

The development of an advanced pulse radar system is divided into two different disciplines: the discipline of microwave circuit design and the discipline of signal processing. In our thesis, we focus more on the design of microwave circuits for a UWB pulse generator, and their integration into a compact and complete microwave module of a radar sensor. Leaving the signal processing to a developed program with LabView/Matlab. Our goal is to develop a prototype of a UWB pulse generator for the radar sensor system, and apply it to a non-destructive industrial process: measurement of the relative permittivity and thickness of several layers 
of samples.Normally, two fundamental parameters of the UWB radar sensor are crucial: the resolution range and the penetration depth. Both parameters will be taken into account during this work since it are very determinants for our proposed non-destructive application.

During the Thesis period, the first step consist of a designed circuit of the pulse generator using the AWR Microwave office. However, we had to use Multisim software for electromagnetic simulation in order to validate the AWR Microwave office results and achieve more accurate approximation including RF connector, material losses, and fabrication effects. The equivalent circuit modeling has been provided for all designs. Therefore, the prototype with measurement results is necessary to complete the design procedure and evaluate the goodness of the described design techniques. For this reason, we used the LPKF circuit board plotter to fabricate the proposed circuit; The LPKF it is available at DIMAS Group in ITACA Institute at University Polytechnic of Valencia.

After manufacturing the proposed prototype, we proceeded to perform the measurements to prove the validity of the simulated results. We used HP-Generator of pulse-8112A, an Agilent Infinium 8000 series oscilloscopes and 2 UWB Vivaldi antennas. The computer is connected to the pulse generator and the receiver (Oscilloscope) via a GPIB cable. All measurement has been carried out in a rectangular anechoic chamber to avoid any perturbation electromagnetic. The measure of the range distance and the electrical properties have been made with different materials (Wood, Metal, PVC, Etc.) The fabrication tolerances and the calibration concept were studied and performed to obtain the real prototype with good matching between simulated and measured results. Once the experimental data are analyzed, and a better agreement is achieved, we moved on to write and submit scientific and academic papers for publication in international journals and conferences.

The majority of work in this thesis has been elaborated at DIMAS laboratory of the ITACA Institute, which is a group of excellence dedicated to scientific and applied research, to both transfer and technological development initiatives in the field of microwave engineering. It also offers consulting services, high-frequency measurements and feasibility studies in technical development projects in the field of applied electromagnetism, sensors for non-destructive detection by microwave and microwave heating.

To carry out this work, we need to use this list of sinews: 
- Human resources: Dimas is composed mainly of university personnel specializing in electromagnetism and microwaves, with the assistance of contracted researchers, highly qualified technicians, and university students. The research team, with more than 15 years of activity, is now well established with close ties to the national and European industry.

- Material resources: Dimas has the complete software (Labview, Microwave Office, Matlab, and HFSS...) and hardware laboratories (Pulse Generator, oscilloscopes, Detectors, Antennas, Network Analyzers...) to design and build various prototypes and microwave systems. At the same time, ITACA has the appropriate resources to develop projects by the requirements of the industry.

\subsection{Thesis outline}

The primary objective of this Thesis is to introduce efficient advancement in the design of a UWB pulse radar sensor for non destructive application, especially in the industrial fields. This task has been divided into two main parts. The first part addresses issues related to the design and fabrication of compact UWB pulse radar sensor, a great amount of effort is focused to decrease the ringing at the output of pulse. However the second part addresses the design techniques of a high power of UWB pulse radar sensor for some requirement of specific application. In more detail, the outline of this Thesis is as follows.

The introductory part, first Chapter, presents the general introduction of the thesis, which describe the framework of the thesis, the interest of the UWB and the radar sensor in the future, specially with arrivals of the IOT. The introductory part closes with the motivation, objective and goal of the current work.

In the second chapter, the principal theory aspects, and the fundamental of UWB radar sensor are presented. An overview of non-contact sensor ranging sensors is presented also. In addition, the radar equation for level sensing is derived, and the effect of radar equation parameters on the radar detection range is discussed. 
The Third Chapter presents a design of the UWB pulse generator. First, a description of the pulse generator is presented, which is consists basically of an avalanche transistor circuit and a pulse sharpener circuit. Then, effects of the external parameter variation of the avalanche transistor circuit and sharpener circuit on the generator pulse are discussed. Finally, the fabrication of the proposed ultrashort pulse generator is presented.

In the fourth Chapter, a High power impulse radar sensor has been presented, two principal fulfill techniques have been studied in details. Good results have been achieved.

In chapter 5, the measurements setup and measured results for the developed UWB radar sensor are presented. Experiments regarding distance and electrical properties measurements are discussed. The measurements are has been performed with different targets such as metal, wood, and PVC. In addition, the timedependent measurement accuracy of the radar sensor is presented.

Finally, the last part of this dissertation elaborates on conclusions and provides a brief overview over other research works in progress and the possible continuation of the work introduced in this Thesis. 


\section{Principles and theoretical aspect of UWB Radar Sensor}

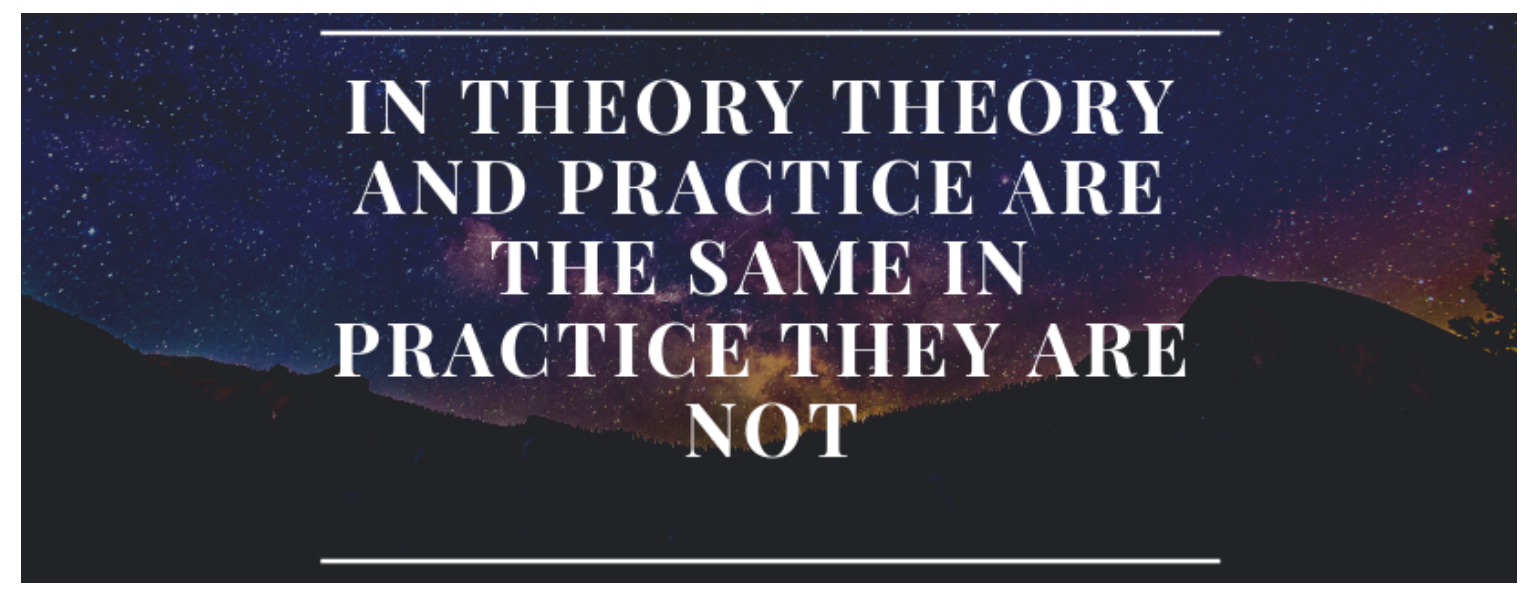

Theoretical physicist 1879-1955.

Albert Einstein

His chapter presents a review of the basic concepts of UWB systems, with
a special emphasis on UWB radar sensor. In details, a general definition and the interesting use of UWB are presented, the history and the legislation of UWB from two different international committees, the ECC and FCC are described. The restriction of the coexistence with other communication standard is displayed also. After that; the advantages, applications and the future of UWB are presented. The chapter Limping on UWB PULSES signals generation challenges, and different kinds of UWB pulses (Gaussian. monocycle and doublet). The structure of UWB systems, (Transmitter, receiver and antennas ) and their advantage comparing with conventional narrowband systems are treated also. The end of this chapter presents the fundamentals of Radar sensors. The and history of RADAR sensor is described with a special emphasis of the pulsed radar sensor and their difference with the continuous wave radar sensors. 


\subsection{Fundamentals of Ultra Wide Band systems}

Ultra Wideband (UWB) is an emerging technology for future short-range wireless communications with high data rates as well as radar and geolocation [71]. Indeed, the use of large bandwidths offers multiple benefits including high data rates, robustness to propagation fading, accurate ranging and geolocation, superior obstacle penetration, resistance to jamming, interference rejection, and coexistence with narrow bandwidth systems. It should be noted that the first UWB signals were generated in experiments by Hertz who radiated sparks via wideband loaded dipoles. However, this type of communication was abandoned at that time due to non-availability of resources to recover the wideband energy effectively. Later during the 1960s and 1970s, impulse radio technologies were being used to develop radar, sensing, military communications and niche applications. A landmark patent in UWB communications was submitted by Ross in 1973. However, it was in 1989 that the term "Ultra Wideband" appeared in a publication of department of defence in the United States (U.S.) and the first patent with the exact phrase "UWB antenna" was filed on behalf of Hughes in 1993. Thus, interest in UWB has revived in the 1990s thanks to the improvements in digital signal processing and notably the investigation on Impulse Radio (IR) by Win and Scholtz [72].

Finally, it was in 2002 when the interest for UWB systems was greatly magnified by the decision of the United States frequency regulating body, the Federal Communications Commission (FCC), who released a report approving the use of UWB devices operating in several unlicensed frequency bands [0-960 MHz], [3.1-10.6 GHz], and [22-29 GHz]. Since then, regulations were defined through notably emission spectral masks around the world.

In Europe, the Electronic Communications Committee (ECC) has proposed its most recent proposal in April 2009. In contrast to the FCC's single emission mask level over the entire UWB band, this report proposed two sub-bands with the low band ranging from $3.1 \mathrm{GHz}$ to $4.8 \mathrm{GHz}$ (authorized until 2011 with mitigation techniques included to ensure coexistence) and the high band from $6 \mathrm{GHz}$ to 8.5 GHz. The upper bound for Effective Isotropic Radiation Power (EIRP) is common and has been set out to be $-41.3 \mathrm{dBm} / \mathrm{MHz}$. Even if the authorized frequency bands are different according to the world regions, the definition of UWB is universal. UWB describes wireless physical layer technology which uses a bandwidth 
of at least $500 \mathrm{MHz}$ or a bandwidth which is at least $20 \%$ of the central frequency in use. Two approaches have been developed for UWB systems: pulsed operation and multiple narrow bands. Among these techniques, the original approach is based on the IR concept. Impulse Radio refers to the use of a series of very short duration pulses, which are modulated in position or/and amplitude. As signals are carrier-less, i.e., only base-band signals exist; therefore no intermediate frequency processing is needed. Alternative schemes are Multi-Band Orthogonal Frequency Division Multiplexing (MB-OFDM) and Multi-Carrier Code Division Multiple Access (MC-CDMA).

To guarantee the coexistence of UWB with other communication standards, the authorized transmitted power is always very low which limits the development of UWB communication systems with very high data rates and/or the coverage of larger distances. The association of Multiple Input Multiple Output (MIMO) systems (which exploit rich scattering environments by the use of multiple antennas) with UWB technology is more and more studied. It seems to be a very potential approach for enhancing capacity, increasing range, raising link reliability and improving interference cancellation [73], [74].

Recent works have also shown the prospects of using the UWB technology into the next generation RFID (Radio Frequency Identification) systems. Indeed, promises have been highlighted in order to achieve larger operating range, accurate localization, robustness to interference and more security in multiple access systems [75]- [77]. Further, when the wireless systems that are potential candidates for cognitive radio are considered, UWB seems to be one of the tempting choices because it has an inherent potential to fulfil some of the key requirements of cognitive radio [78]. These requirements include no spurious interference to licensed systems, adjustable pulse shape, bandwidth and transmit power, support of various throughputs, provision of adaptive multiple access, and security of information. However, it is not claimed that a cognitive wireless system using only the UWB technology can handle all the requirements of an ideal cognitive radio. Advances in reconfigurability of RF front-ends, particularly reconfigurable (multiple) antennas, afford a new "hardware" dimension for optimizing the performance of wireless communication systems [79].

Although UWB and spread-spectrum techniques share the same advantage of expanded bandwidth, the method of achieving the large bandwidth is the main distinction between the two technologies. In conventional spread-spectrum tech- 

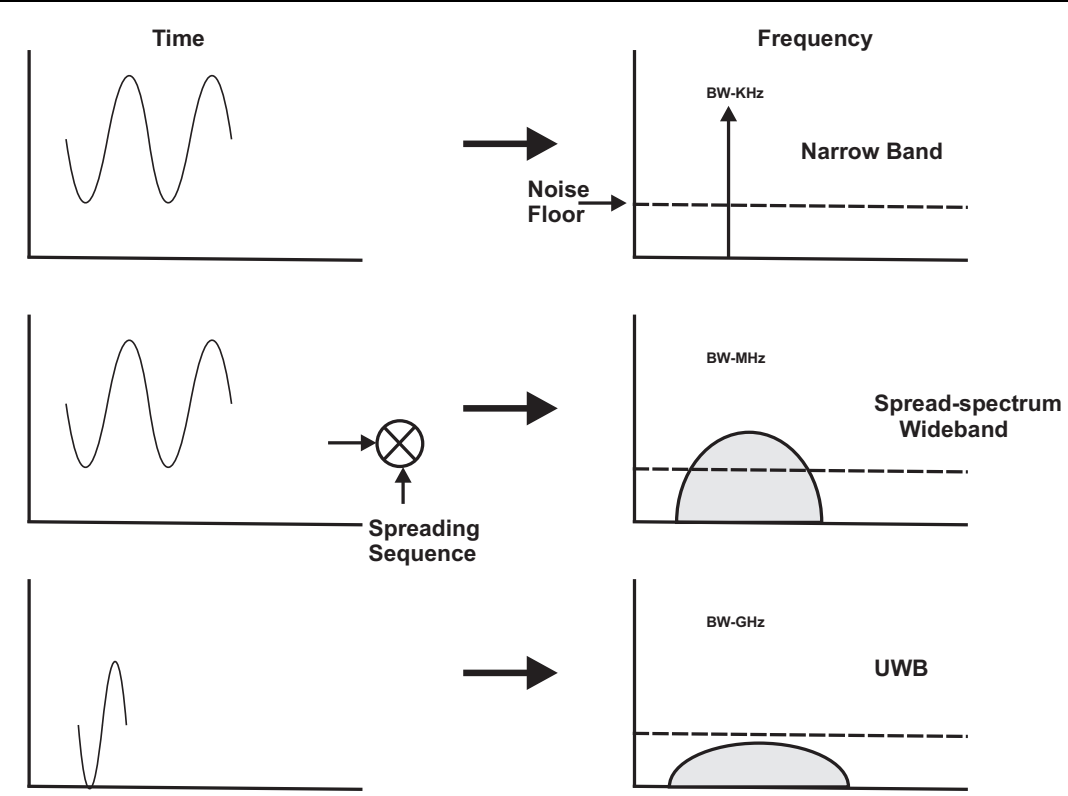

Figure 2.1: Transition from narrowband to wideband and ultra-wideband in the time and frequency domains

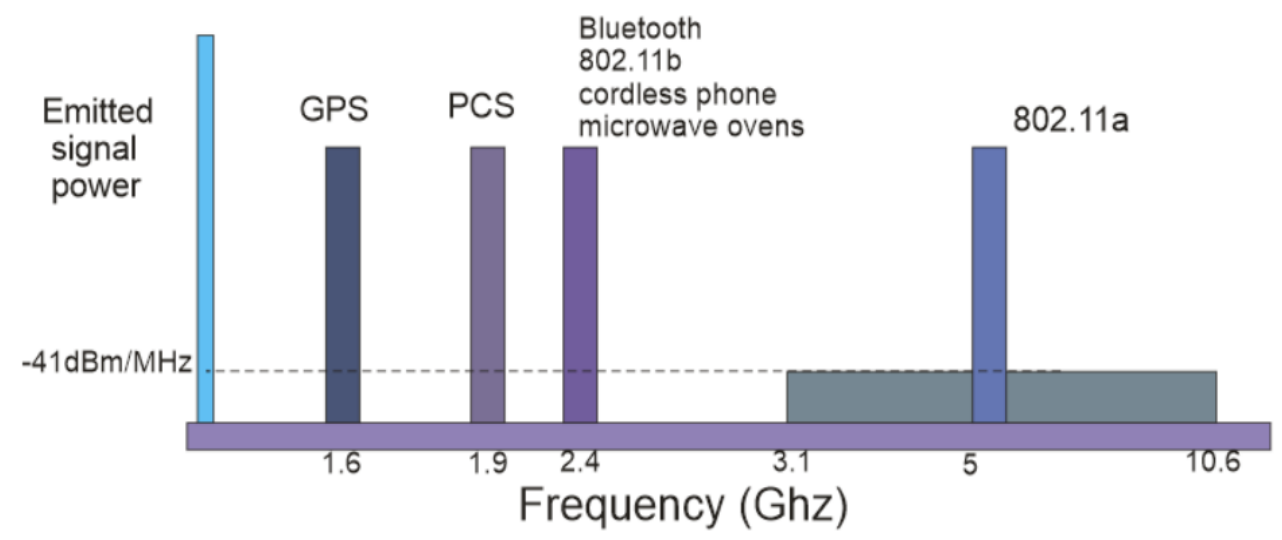

Figure 2.2: UWB spectrum

niques, the signals are continuous-wave sinusoidal that are modulated with a fixed carrier frequency. In UWB communications, on the other hand, there is no carrier frequency; the short duration of UWB pulses directly generates an extremely wide bandwidth (as can be seen in eq. 1-2). Another distinguishing factor in UWB is the very large bandwidth. Spread-spectrum techniques can offer megahertz of bandwidth, while UWB pulses provide several gigahertz of bandwidth. Figure 2.1 shows the time and frequency domain representation of narrow-band, wideband, and UWB signals. The FCC ruling permits the UWB spectrum overlay as indicated in Figure 2.2. 


\subsubsection{UWB basics and specification}

\subsubsection{UWB definition}

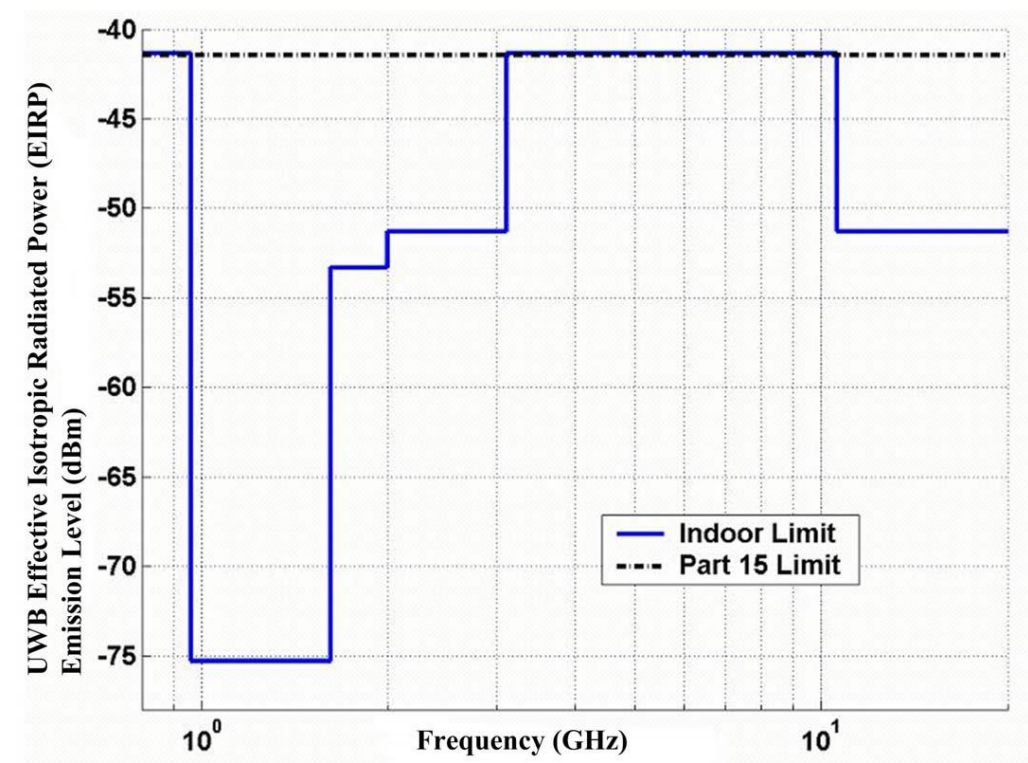

Figure 2.3: Indoor UWB systems spectrum mask

The FCC has defined UWB signals like that, over $3.1 \mathrm{GHz}$ to $10.6 \mathrm{GHz}$ band, 10- $\mathrm{dB}$ bandwidth of the signal occupies an absolute bandwidth greater than 500 $\mathrm{MHz}$ or a fractional bandwidth greater than 0.20 . However, one of the important conditions is that the power levels of the UWB signal in this spectrum must be low enough to avoid interference with the already existing technologies. The FCC specifies the power emission levels suitable for co-existing with other technologies in the UWB allocated band. The spectrum mask for in-door applications is shown in Fig. 2.3, where the part 15 limit is the maximum allowed power spectral density of unintentional radiators, which is $-41.3 \mathrm{dBm} / \mathrm{MHz}$.

Here the fractional bandwidth is the bandwidth expressed as a fraction of the center frequency. Assume $f_{H}$ is the highest frequency limit and $f_{L}$ is the lowest frequency limit of the $10-\mathrm{dB}$ bandwidth, the fractional bandwidth of the UWB signal is defined as:

$$
\text { FractionalBandwidth }=\frac{2\left(f_{H}-f_{L}\right)}{f_{H}+f_{L}} \geq 20 \%
$$




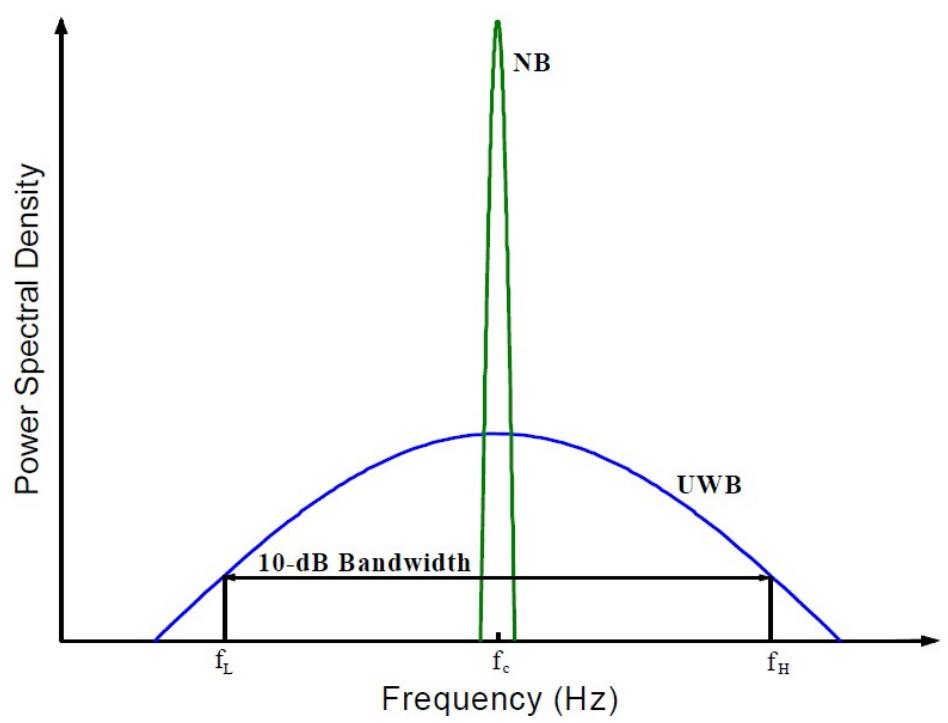

Figure 2.4: Indoor UWB systems spectrum mask

\subsubsection{UWB advantages}

The UWB technology, it is the technology when a short duration of pulses was used. Normally these short pulses are in order of picoseconds. Instead, the continuous wave, the pulses generate a high bandwidth signal. Therefore, the pulse spreads the energy over a wide frequency band, as is shown in Fig. 2.2.

Compare with conventional narrow-band systems, the UWB systems have many advantages.

Low complexity: The UWB system produces a very narrow time-domain pulse, unlike the traditional narrow-band systems. These pulses can propagate without any mixing with the carrier signal. Therefore, it is not necessarily an additional up-conversion and amplification.

Low cost: The low complexity leads to low cost because the systems it does not needs a local oscillator, the associated complex delay and phase tracking loops. Therefore, the UWB systems can be implemented in low cost, low power, integrated circuit process, such as CMOS technology.

Low probability of interception: The UWB signal has much broader bandwidth than that of typical narrow-band NB, Fig. 2.2, hence, much lower energy density. For this reason, the ultra-wide frequency range appears as the noise to the most wireless devices, which makes them in a difficult to be detected, and results in a low probability of interception/detection.

Excellent immunity to interference from other existing radio signals: Due to the shortness of duration of the UWB pulses (a nanosecond in most cases), the 
reflected pulse has a low of opportunity to collide with the line of sight (LOS) pulse and cause signal degradation, therefore, a very high multi-path resolution is achieved.

Good time-domain resolution: The very narrow time-domain pulses and good substrate penetration characteristics make the UWB systems able to offer timing precision much better than global positioning system (GPS) and other radio systems.

In other hands, the UWB spectrum covers a vast range of frequencies from near DC to several gigahertz; this diversity makes UWB signals relatively resistant to interference because no interference can alter every frequency in UWB spectrum at once. Therefore, the UWB systems offer excellent immunity to interference from other existing signals.

\subsubsection{UWB applications}

UWB communication having ultra-wideband characteristic has many advantages for the short-distance wireless communication, one of them is high data rates and large channel capacity. There are two reasons causing the high data rates; high signal power and low noise power. It is evident from Hartley-Shannon's capacity formula:

$$
C=B \cdot \log _{2}(1+S N R)
$$

Where $\mathrm{C}$ is the maximum channel capacity in bits/second, $\mathrm{B}$ is the signal bandwidth in Hertz, and SNR is the Signal-to-Noise ratio. Consequentially, the highest channel capacity can be obtained by increasing the signal bandwidth and low signal to noise power. The major advantage of UWB communication is to use the large bandwidth. Moreover, the advantages described above make the UWB technology a good candidate in many applications. Some of the potential application areas of the UWB technology are listed below.

Communications: The major commercial UWB application is for communication since it has very high data transfer rate (up to hundreds of megabits per second) for short distance. UWB transceivers can send and receive high-speed data with very low power at relatively low cost. UWB communication systems are often advantageous in a short-range wireless market.

Radars: The UWB technique is widely used for both indoor and outdoor 3-D positioning because provide highly accurate time resolution (Ground Penetration 
Radar GPR for detecting internal structure under the ground). Another important application is imaging as microwave remote sensing, in which UWB signals is able to detect the objects inside the building.

Location finding: Due to the good performance of UWB devices in multi-path channels, this technology can provide a accurate location for environments where the GPS cannot work. Another important application is radio frequency identification (RFID). The RFID can be implemented as identification cards; these devices can be made to have a long lifetime on a single battery at a relatively low cost, Because of the low power required and relatively low data rate.

\subsubsection{Future of the UWB}

After new FCC regulation authorizing the use of a wide bandwidth to transmit signals in an unlicensed frequency band from $3.1 \mathrm{GHz}$ to $10.6 \mathrm{GHz}$, UWB technology attracted many engineers' attention due to its advantages, high transmitting data rate and low power consumption. But the early developments in UWB lacked performance, cost too much and were not compatible with worldwide standards which have been subject to much debate and conflict. In addition to them, the economic drawback makes UWB industry go downhill and representative companies leading to the UWB technology shut the door and run out of funding.

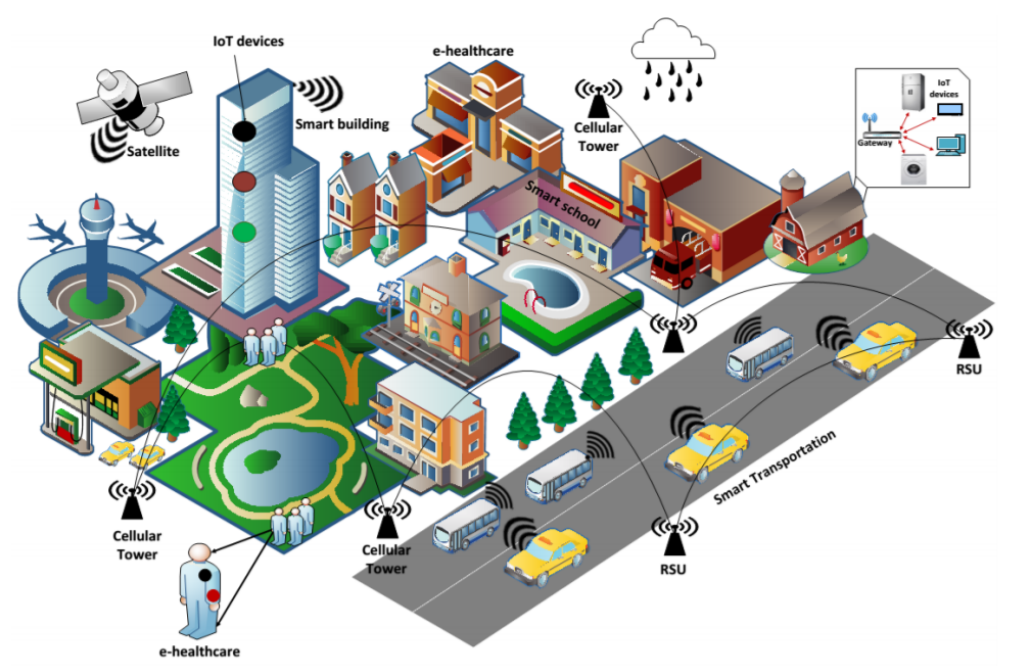

Figure 2.5: An illustration of IoT based smart city

However, these are all common growing pains for any new technology like Bluetooth and WiFi which experienced these difficulties. Compared with them, UWB is five times faster than WiFi, 10 times more power efficient and superior 
user density. There is no better technology to transfer media content wireless, at high-speed and low-power. Thus, UWB communication is a potential candidate for wireless personal area network (WPAN). In the future, UWB technology will be applied to numerous fields such as stealth, LAN, position location, security and vehicular radar system.

The prospects of UWB are always growing, however, the future systems using UWB technology involve many new challenges, especially, related to the design and modeling of compact UWB systems with high accuracy to use it in current Revolution of IOT in many fields, like smart cities, smart industries, smart metering, etc.

\subsubsection{UWB pulses signals}

The pulse generation and pulse shaping are the most challenges in any UWB systems design. The selection of pulse-signal types for UWB pulse systems is one of the fundamental considerations in designing UWB pulse systems, antennas, and circuits because the type of the pulse determines the UWB signal?s spectrum characteristic.

Actually, many kinds of UWB pulse can be used in UWB systems. However, there are just three kinds which are typically used in UWB impulse systems. i.e., Gaussian pulse, Monocycle pulse, and Gaussian doublet-pulse.

Particularly, the monocycle pulse is preferred in most UWB pulse systems because provide a special spectral characteristics (having no dc) which facilitate easier the wireless transmission than the Gaussian pulse, and also present wider bandwidth than the multi-cycle pulse, in addition, its easier to realize than the Gaussian doublet pulse.

\subsubsection{Gaussian pulse}

A Gaussian pulse has a shape of Gaussian distribution as shown in Fig. 2.3 and is expressed as:

$$
y(t)=A e^{-a^{2} t^{2}}
$$

Where $\mathrm{A}$ is the amplitude of the Gaussian pulse, a is the time constant. The power density spectrum of the Gaussian impulse is: 

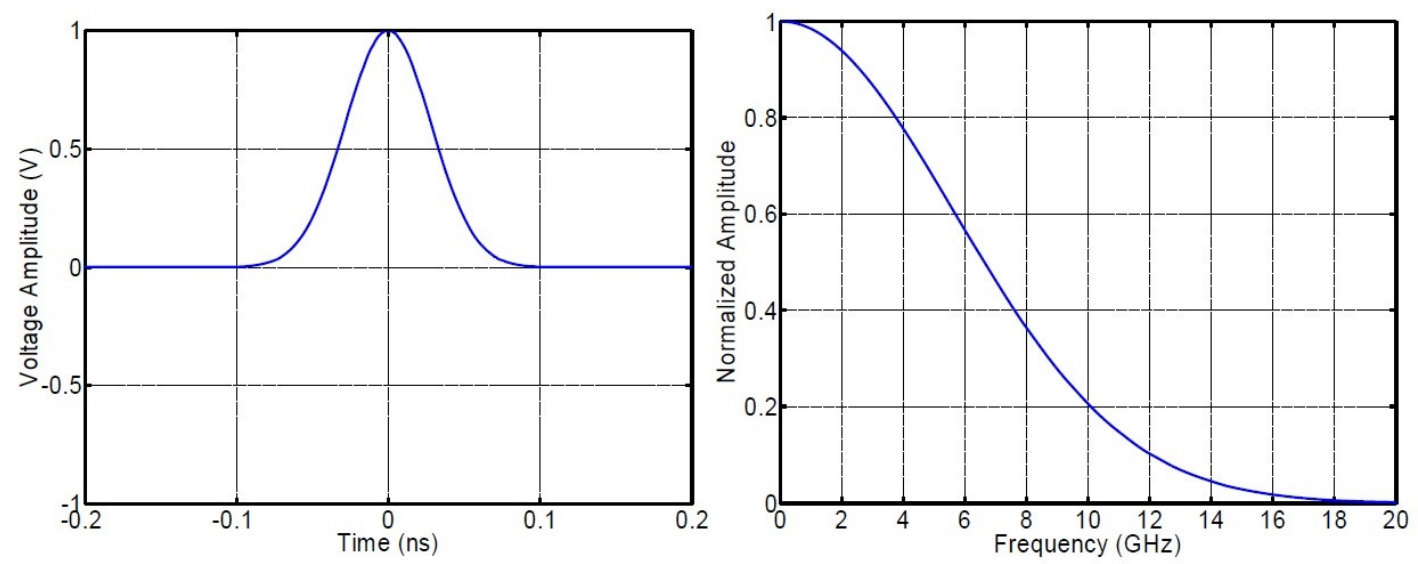

Figure 2.6: Gaussian pulse and frequency spectrum

$$
y(\omega)=\frac{A}{a \sqrt{2}} e^{\frac{-\omega^{2}}{4 a^{2}}}
$$

The corresponding frequency with peak value of power density spectrum is

$$
f_{c}=0
$$

Therefore, the $3 \mathrm{~dB}$ bandwidth can be derived as

$$
\Delta f=0.8326 \frac{a \sqrt{2}}{2 \pi}
$$

\subsubsection{Gaussian monocycle pulse}
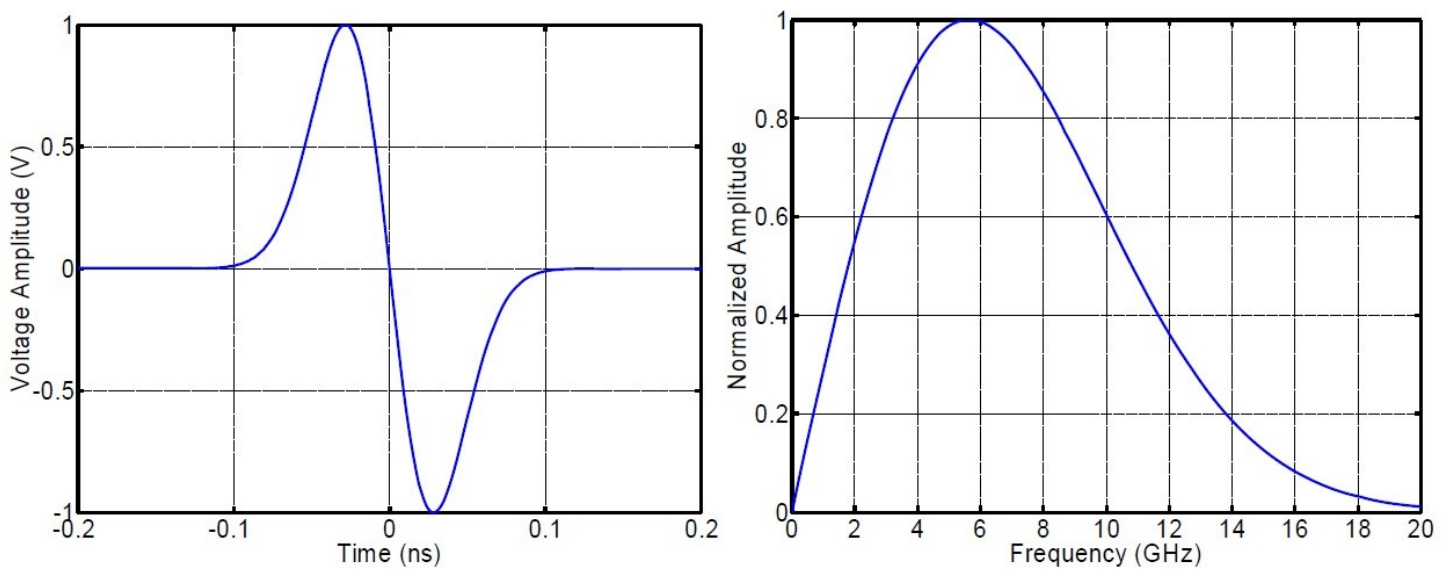

Figure 2.7: Monocycle pulse and frequency spectrum

Monocycle pulse is the first derivative of the Gaussian pulse signal, which is shown in Fig. 2.4. Its general formula is shown as follows: 


$$
y(t)=-2 a^{2} A t e^{-a^{2} t^{2}}
$$

where A is the amplitude of the monocycle pulse, a is the time constant. The power density spectrum of the Monocycle pulse is

$$
y(\omega)=\frac{i A \omega}{a \sqrt{2}} e^{\frac{-\omega^{2}}{4 a^{2}}}
$$

The corresponding frequency with peak value of power density spectrum is

$$
f_{c}=\frac{a \sqrt{2}}{2 \pi}
$$

and the $3 \mathrm{~dB}$ bandwidth can be derived as

$$
\Delta f=1.155 \frac{a \sqrt{2}}{2 \pi}
$$

\subsubsection{Gaussian doublet pulse}
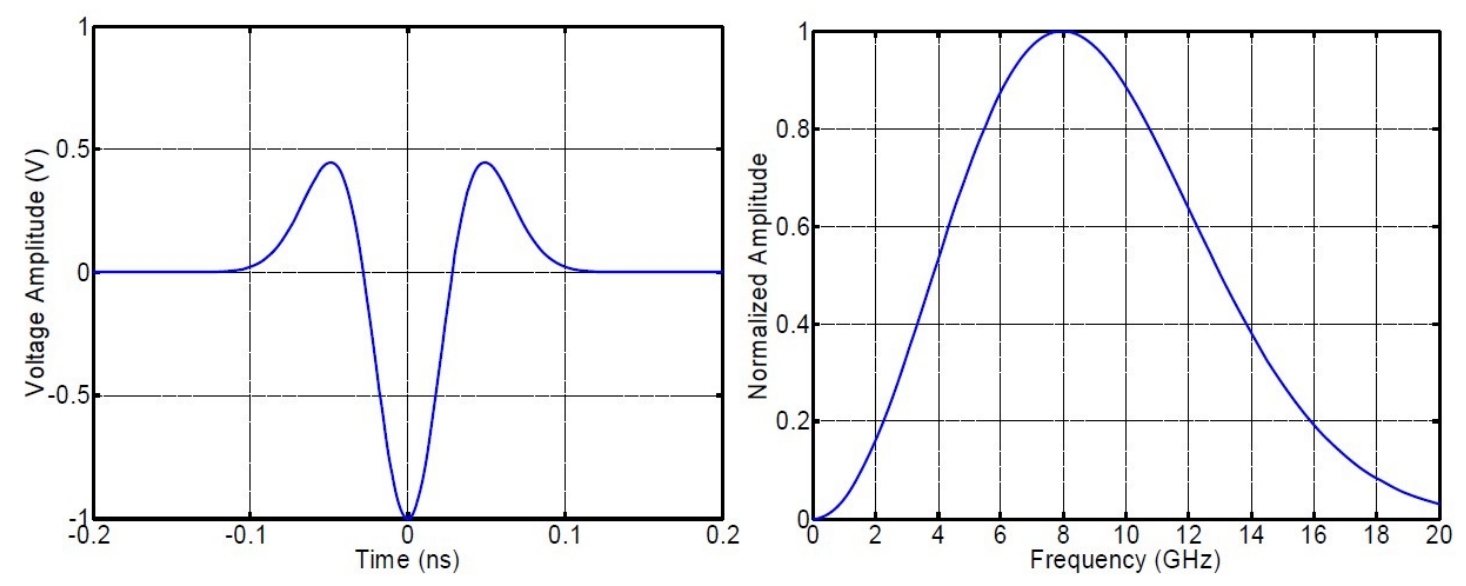

Figure 2.8: Gaussian Doublet pulse and frequency spectrum

Gaussian doublet pulse is the second derivative of the Gaussian pulse signal, which is shown in Fig. 2.5. Its general formula is shown as follows

$$
y(t)=-2 a^{2} A e^{-a^{2} t^{2}}\left(1-2 a^{2} t^{2}\right)
$$

Where A is the amplitude of the Gaussian doublet pulse, a is the time constant. The power density spectrum of the Gaussian doublet pulse is

$$
y(\omega)=\frac{-A \omega^{2}}{a \sqrt{2}} e^{\frac{-\omega^{2}}{4 a^{2}}}
$$

The corresponding frequency with peak value of power density spectrum is 


$$
f_{c}=\frac{a}{\pi}
$$

And the $3 \mathrm{~dB}$ bandwidth can be derived as

$$
\Delta f=1.155 \frac{a \sqrt{2}}{2 \pi}
$$

The power density spectrum of the Gaussian pulse is distributed in low-frequency and close to DC, that leads these types of pulses to front great problems on the transmission antenna of the UWB system. However, the power density spectrum of the Monocycle and the Gaussian doublet pulse it is similar, and no presents major low-frequency components, which makes the signal transmission through the antenna much easier.

\subsubsection{Structure of UWB systems}

The UWB systems have several advantages over conventional narrow-band systems, Fig 2.9. The basic architectures of the UWB system are divided into two principal parts; UWB Transmitter and UWB receiver. This part presents the basic architectures of the proposed pulse UWB system, which include the front-end modules of the UWB transmitter and receiver.

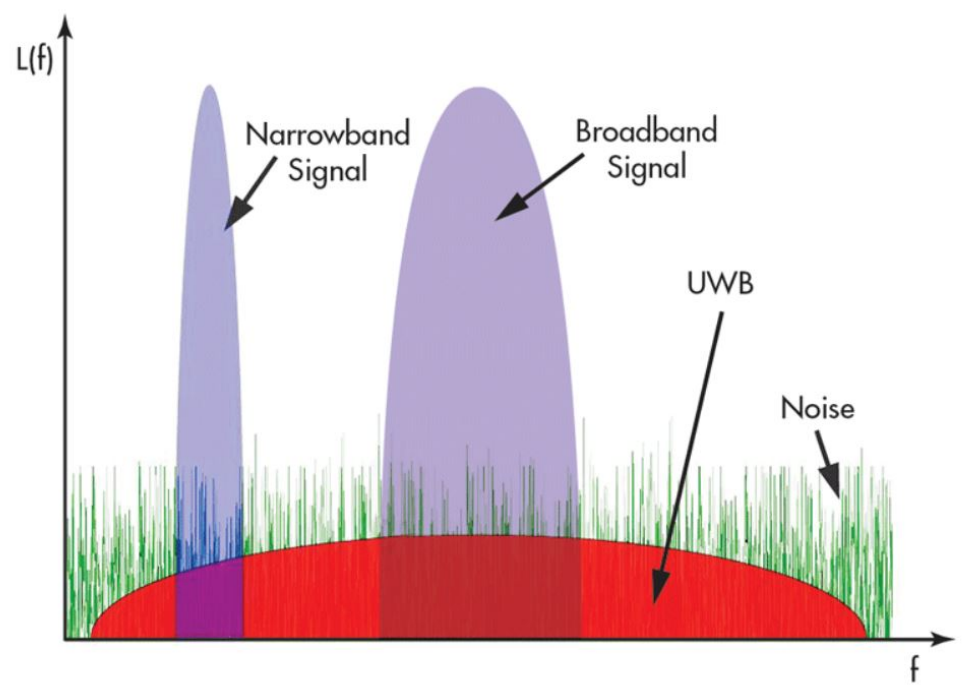

Figure 2.9: The power of narrowband signals vs ultrawideband signal

\subsubsection{UWB Transmitter}

Unlike the traditional transmitters (continuous-wave transmitters), which contains complex modules such as the power frequency synthesizer, amplifier (PA), 


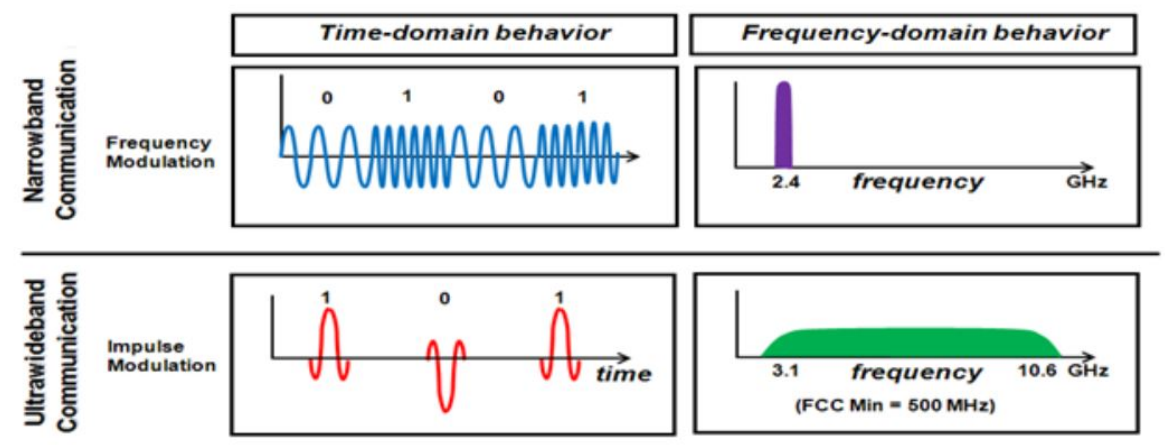

Figure 2.10: Behavior of narrowband vs UWB in time and frequency domain

the voltage-controlled oscillator (VCO), the phase-locked- loop (PLL) and mixers [80]- [81]; the UWB transmitter presents great advantages: Low cost and moderately easy to design and implement because of its simpler structures.

The block diagram is shown in Fig. 2.11. It consists of two principal parts; a pulse generator and a digital-controlled modulator. The first one generates the desired waveform (Gaussian or Monocycle pulses), while the second one controls the timing of the transmitted pulse. Depend on the timing modulation requirement, the modulator circuit modulates the pulse signal with incoming digital data information using BPSK or PPM topology. An additional part consist of the local oscillator was added just to establish the pulse repetition frequency (PRF) of the system.

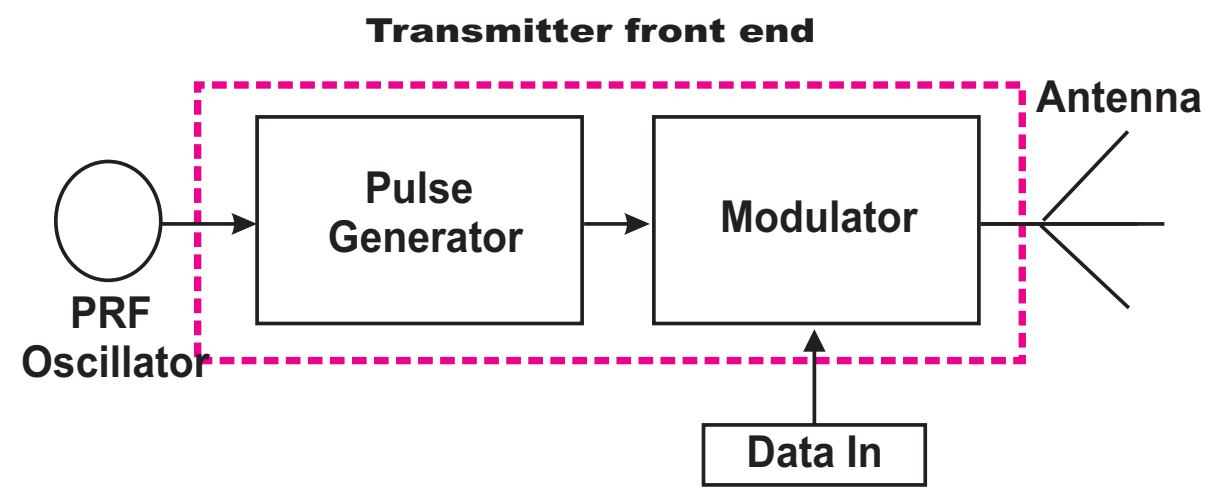

Figure 2.11: diagram of UWB transmitter

There are two topologies to generate the short pulse signals; the time-domain and the frequency-domain topology.

In the time-domain topology, whatever the pulse generators use spark gaps [85], or the hybrid circuits based on Schottky diode, step recovery diode (SRD), and planar transmission lines [82]- [83]. There are big problems in term of large- 
size circuits and increased cost. In addition, it is not optimized for power consumption and the feasibility of integrating them into a wireless device. Therefore, it is not an option for consumer electronics due to their size.

Regarding the frequency-domain topology, it is considered a very accurate in theory [86]- [87]. The Principe work of this topology is to implement the waveform generation in the frequency domain using the Fourier series method. Even though the accuracy pulse signal generated, it presents an awakens which consist in requires a highly complex transmitter design due to a large number of harmonic components. Therefore, it is not suitable for most wireless UWB applications.

Unfortunately, all the design topology mentioned above presents the problem of large circuit size and high cost. This problem makes them not the good choice for the compact UWB applications existing today.

In this dissertation, the novel pulse generator is developed to produce both Gaussian pulse and monocycle pulse.

\subsubsection{UWB Receiver}

The block diagram of the UWB receiver is shown in Fig. 2.12, its role is to converts the received RF signal into a base-band output signal.

Normally the receivers are made up of three principal parts: an LNA, a correlation circuit, and a template pulse generator. However, the local oscillator drives the pulse generator and determines the PRF of the system.

One of the requirements for to enhancing the processing gain and SNR, is having the similar shape among the template waveform and received signal. After that, the received pulse signal is correlated and the input pulse train is converted to a base-band signal in one stage.

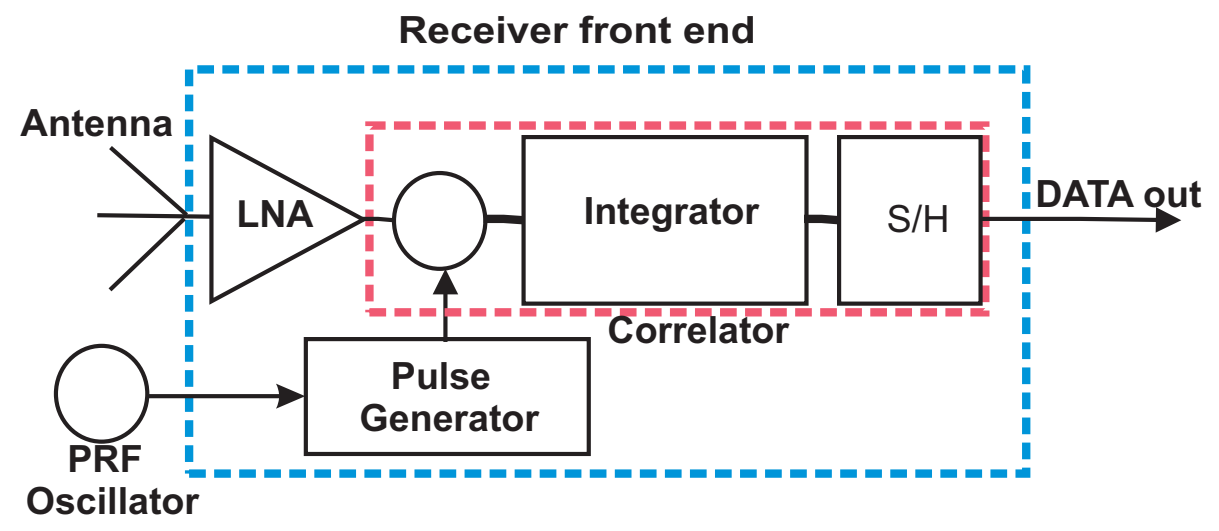

Figure 2.12: diagram of UWB Receiver 
The correlator is a key component of the receiver UWB; it consists of the multiplier, integrator, and sampling/holding $(\mathrm{S} / \mathrm{H})$ circuit. The first one multiplies the received signal with the template waveform. A great challenge present in the correlator speed; the multiplier and integrator must be fast enough to process each pulse. [88].

\subsubsection{UWB Antenna}

\subsubsection{Overview of antennas}

An antenna is a device used for transmitting or receiving radio frequency (RF) signals used in wireless communication systems. In addition, the antenna acts as a transducer which converts the signal on a transmission line into electromagnetic wave in free space in the transiting phase and vice-versa in receiving phase.

In the UWB radar sensor systems, the antenna plays a crucial role. its used to transmit and receive very short-time duration pulses. In these systems, the function of the antenna during transmission phase is to concentrate the radiation energy into a desired direction, and during the reception is to collects the energy reflected by the target and delivers it to receiver.

Fig, 13 illustrates the functions of antennas in a wireless communication link. For the transmitting function, the transmitting antenna delivers the EM wave from the feeding source and radiates the EM wave into the free-space. For the receiving function, the receiving antenna receives the EM wave from the space and sends it into the receiver.

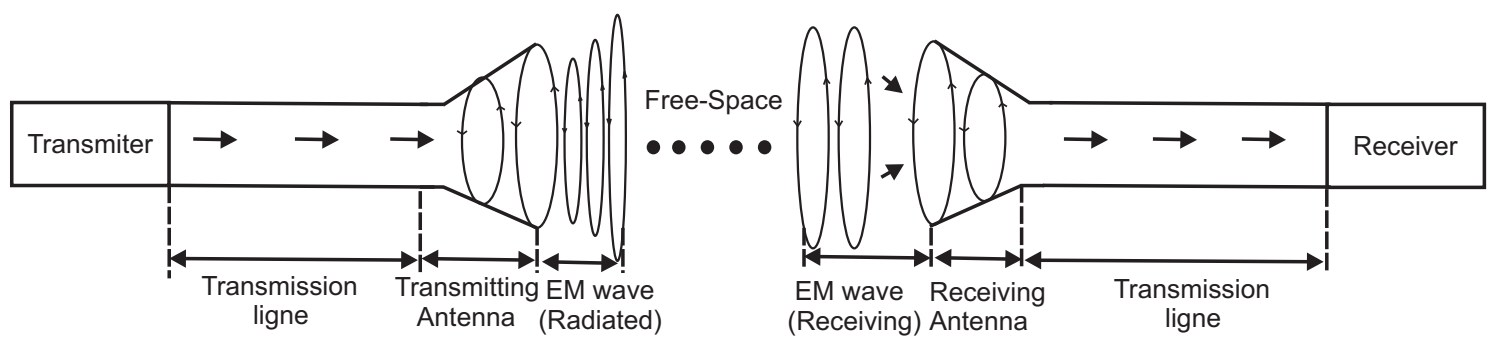

Figure 2.13: An example showing the antennas function in a wireless communication link

Fig 2.14 illustrates examples of typical antennas. A dipole antenna, shown in Fig 2.14 (a), is a wire antenna and is widely used in basic applications such as television, FM radio, etc.. The rectangular patch antenna, in Fig 2.14 (b), is a microstrip antenna and consists of a rectangular flat sheet on top of a ground plane, 


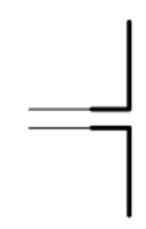

(a)

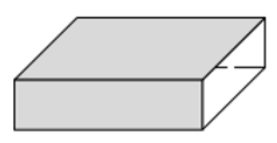

(c)

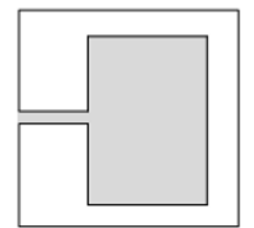

(b)

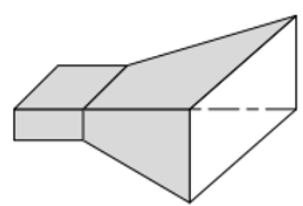

(d)

Figure 2.14: Examples of typical antennas. (a) Dipole antenna, (b) Rectangular patch antenna, (c) Waveguide aperture antenna, (d) Horn antenna

connected with a feed line. This antenna is simple, low cost and can be fabricated using the printed circuit board (PCB) technology. An open-ended waveguide antenna shown in Fig 2.14 (c), is Type of aperture antenna and is configured so the direction of EM radiation direction is based on the orientation of the waveguide propagation. This antenna is simple, efficient and can also be installed on the surface of the spacecraft or aircraft [89]. A horn antenna, shown in Fig 2.14 (d), is also a wave-guide aperture antenna that has a large aperture at the end for improving the antenna gain and radiation patterns.

The radiation performance of an antenna can be expressed in terms of directivity. The directivity of an antenna is defined as [89].

$$
D=\frac{U}{U_{0}}=\frac{4 \pi U}{\operatorname{Prad}}
$$

In decibels;

$$
D(d B)=10 \log _{10}[D]
$$

where:

$D$ is the directivity.

$U$ is the radiation intensity (W/unit solid angle).

$U_{0}$ is the radiation intensity of isotropic source (W/unit solid angle).

Prad is the total radiated power (W). 


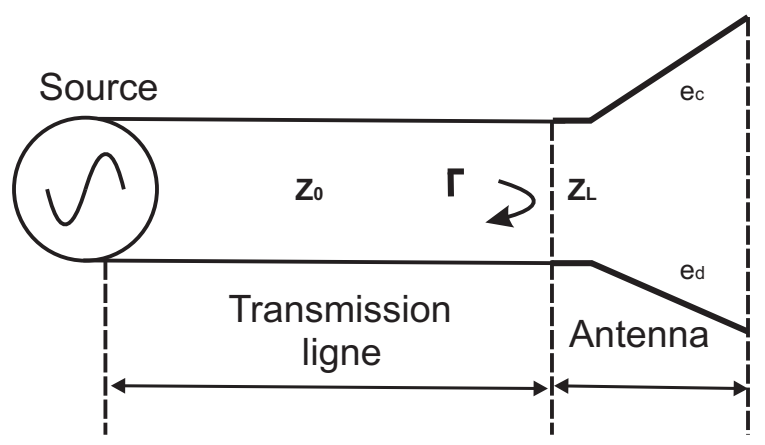

Figure 2.15: A basic diagram of the operation mode of antenna

A diagram of antenna usage shown in Fig 2.15 is used to describe the antenna efficiency which is related to the antenna gain and directivity. Antenna gain is an antenna parameter used to describe the transmitted power in the maximum radiation direction. It is associated with the directivity and antenna efficiency, defined as [89].

$$
G=e_{0} D
$$

where:

$G$ is the gain of the antenna

$e_{0}$ is the total efficiency of the antenna

The total efficiency of an antenna is defined as in [89]:

$$
e_{0}=e_{r} * e_{c} * e_{d}
$$

where:

$e_{r}=1-|\Gamma|^{2}$ is the reflection or mismatch efficiency.

$\Gamma=\left(Z_{L}-Z_{0}\right) /\left(Z_{L}+Z_{0}\right)$ where $Z_{L}$ is the load impedance at input terminals of an antenna, $Z_{0}$ is the characteristic impedance of the transmission line.

$e_{c}$ is the conduction efficiency.

$e_{d}$ is the dielectric efficiency.

$\operatorname{VSWR}=(1+|\Gamma|) /(1-|\Gamma|)$ is the voltage standing wave ratio. 


\subsubsection{Design of Ultra Wideband Antennas}

An antenna is usually required to optimize or concentrate the radiation energy in some directions and to suppress it in the others at certain frequencies. A good design of the antenna can relax system requirements and improve overall system performance. In practice, to describe the performance of an antenna, there are several commonly used antenna parameters, such as impedance bandwidth, radiation pattern, directivity, gain, input impedance, and so on. Particularly, a UWB antenna is defined as an antenna having a fractional bandwidth greater than 0.2 and a minimum bandwidth of $500 \mathrm{MHz}$.

$$
F B W=\frac{2\left(f_{H}-f_{L}\right)}{\left(f_{H}+f_{L}\right)} \succeq 0.2 \quad \text { and } \quad f_{H}-f_{L} \succeq 500 M H z
$$

where $f_{H}$ and $f_{L}$ present the highest and lowest frequencies which defining the antenna's operational band. For example, an IR-UWB system, which would comply with the emission mask and operate within the $3.1-10.6 \mathrm{GHz}$ frequency range allocated in U.S, needs an antenna achieving almost a decade of impedance bandwidth spanning 7.5 GHz. Generally, UWB antennas try to achieve the same goals, and are subjected to the same physical constraints (e.g., low cost, small size, integration capability, etc.) and the same electrical constraints (e.g., impedance matching, radiation pattern, directivity, efficiency, polarization, etc.) as in the case of narrow-band antennas. Further, due to the large bandwidth, the electrical parameters become frequency dependent complicating the design and analysis. In addition to the conventional characterization parameters, some specific parameters must be examined in order to take into account the distortion effects, notably, critical for IR applications. These specific parameters include group delay, phase response and impulse response. The radiation pattern is desired to be constant within the overall operating frequency in order to guarantee the pulse properties to be the same in any direction. The group delay is given by the derivative of the unwrapped phase of an antenna. If the phase is linear throughout the frequency range, the group delay will be constant for the frequency range. This is an important characteristic because it helps to indicate how well a UWB pulse will be transmitted and to what degree it may be distorted or dispersed. The specifications of the antenna design will be a trade-off of these parameters taking into account not only the expected application but also the technique of transmission (multiple narrow bands or pulsed operation) to be used. 
Some parameters have to be declared more important than others. Two types of requirements can be distinguished. The physical constraints arise when one strives to develop antennas of small size, low profile and low cost (materials, maintenance and fabrication), and with embedding capability. The electrical constraints arise while designing antennas with wideband impedance bandwidth covering all sub-bands (for MB-OFDM) or the bandwidth where most of the energy of the source pulse is concentrated (for IR), steady directional or omnidirectional radiation patterns, constant gain at directions of interest, constantly desired polarization, high radiation efficiency and linear phase response (for IR).

In 2003, a history of UWB antennas is presented by H.G. Schantz who emphasizes the relevant past works on UWB antennas and their important wide variety [90]: Ultra-Wideband has its roots in the original spark-gap transmitters that pioneered radio technology. This history is well known and has been well documented in both professional histories and in popular treatments. The development of UWB antennas has not been subjected to similar scrutiny. As a consequence, designs have been forgotten and then re-discovered by later investigators. Thus, in recent years, a lot of UWB antenna designs have been reported and presented in the academic literature [91]- [93] and in some patents [94]. The main challenge to design a UWB antenna comes from the coverage of large bandwidth because the matching and energy transmission require to be verified for the entire bandwidth. However, the traditional trade-offs such as size vs. efficiency and size vs. bandwidth (Chu-Harrington limit) still influence the characteristics and performance of antennas. UWB antennas may be categorized into different types according to their radiating characteristics:

Traveling-wave antennas: Traveling-wave antennas offer for the guided wave a smooth, almost not recognizable transition with the fields accelerated to free space propagation speed $C_{0}$. Traveling wave antennas include horn antennas, tapered slot antennas and dielectric rod antennas (as seen in Figure 2.16).

Frequency-independent antennas: Frequency independent antennas, such as bi-conical, spiral, conical spiral and log periodic antennas are classic broadband and UWB antennas (as seen in Figure 2.17). They can offer real constant impedance and consistent pattern properties over a frequency bandwidth greater than 10:1. There are two principles for achieving frequency independent characteristics. The first one was introduced by Rumsey in the 1950s. Rumsey's principle suggests that the pattern properties of an antenna will be frequency independent if the antenna 
shape is specified only in terms of angles. The second principle accounting for frequency independent characteristics is self-complementary, which was introduced by Mushiake in the 1940s derived from the Babinet's principle in optics. Mushiake discovered that the product of input impedance of a planar electric current antenna (plate) and its corresponding "magnetic current" antenna was the real constant $\eta^{2} / 4$, where $\eta$ is the intrinsic impedance. Hence, if an antenna is its own complement, the frequency independent impedance behavior is obtained.

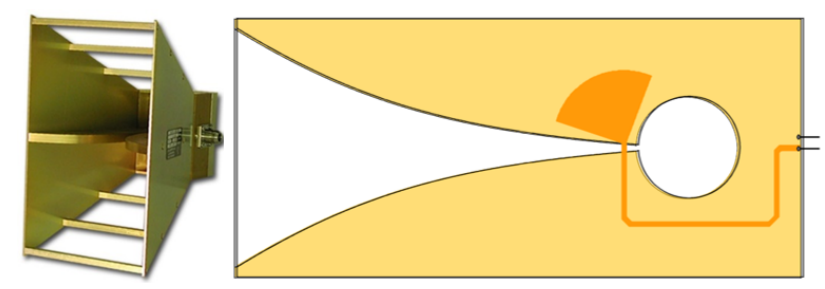

Figure 2.16: Traveling-wave antenna. Horn (left) and tapered slot (right) antenna

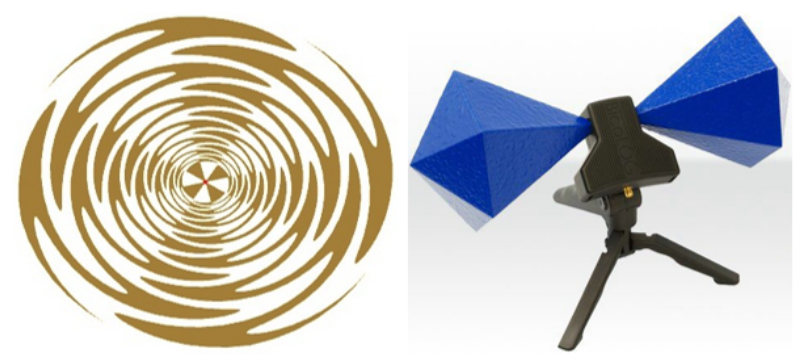

Figure 2.17: Frequency-independent antenna. Spiral (left) and bi-conical (right) antenna

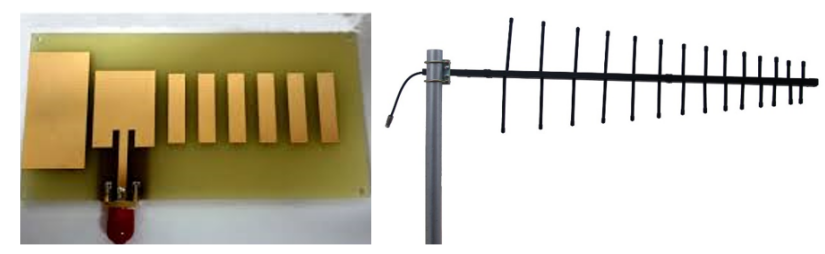

Figure 2.18: Multiple resonance antenna. Yagi antenna

Multiple resonance antennas: Multi-resonant antennas are composed of an arrangement of multiple narrowband radiating elements. This type of antenna includes log periodic antennas or Yagi antennas (see Figure 2.18). Planar versions of these antennas also exist. Although these antennas are UWB, yet they are not convenient for IR-UWB systems because their phase centers are not fixed in frequency and therefore exhibit dispersion. 

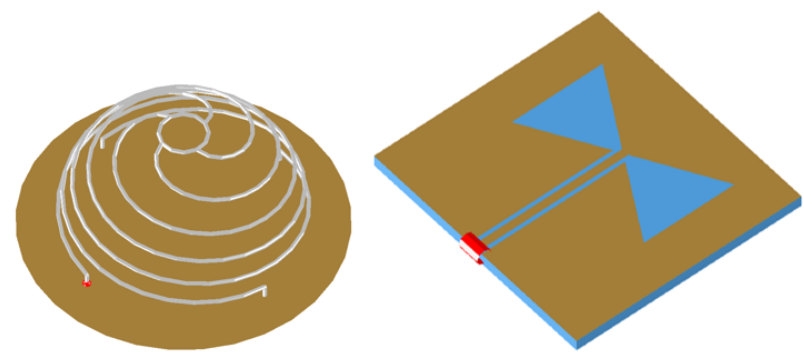

Figure 2.19: Small element antenna. Folded Spherical (left) and CPW-fed bow-tie slot (right) antenna

Small element antennas: Small-element antennas include Lodge's biconical and bow-tie antennas, Mater's diamond dipole, Stohr's spherical and ellipsoidal antennas, and Thomas's circular dipole (as seen in Figure 2.19 ). These antennas are the direct evolution of monopole and the basic dipole (doublet of Hertz). Antenna engineers discovered that starting from a dipole or monopole antenna, thickening the arms results in an increased bandwidth. Thus, for a thick dipole or monopole antenna, the current distribution is no longer sinusoidal and where this phenomenon hardly affects the radiation pattern of the antenna, there this strongly influences the input impedance too. This band widening effect is even more severe if the thick dipole takes the shape of a biconical antenna.
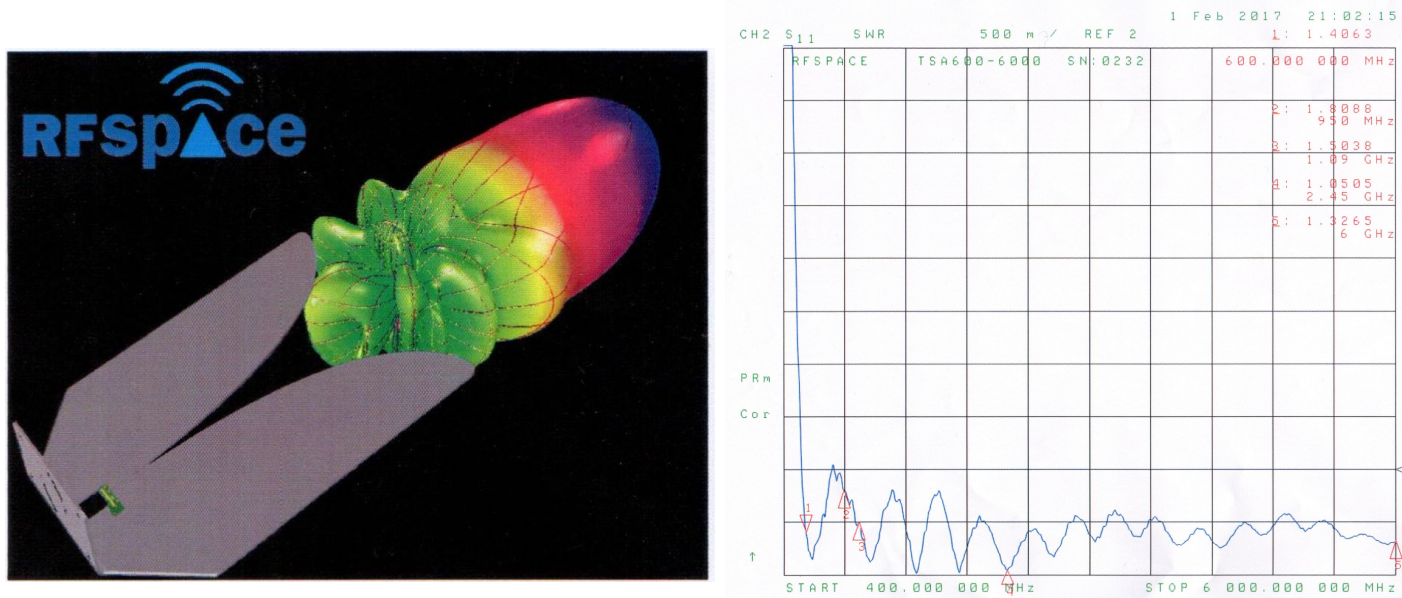

Figure 2.20: Photo of the RFSPACE UWB1 and the diagram of the bandwidth.

\subsubsection{Design challenges of Ultra Wideband Antenna}

One of the key challenges in the design of UWB radar sensors is the availability of an antenna, which transmits and receives very short pulses. Therefore, its indispensable in any design to respect the FCC regularization, minimize the pulse 

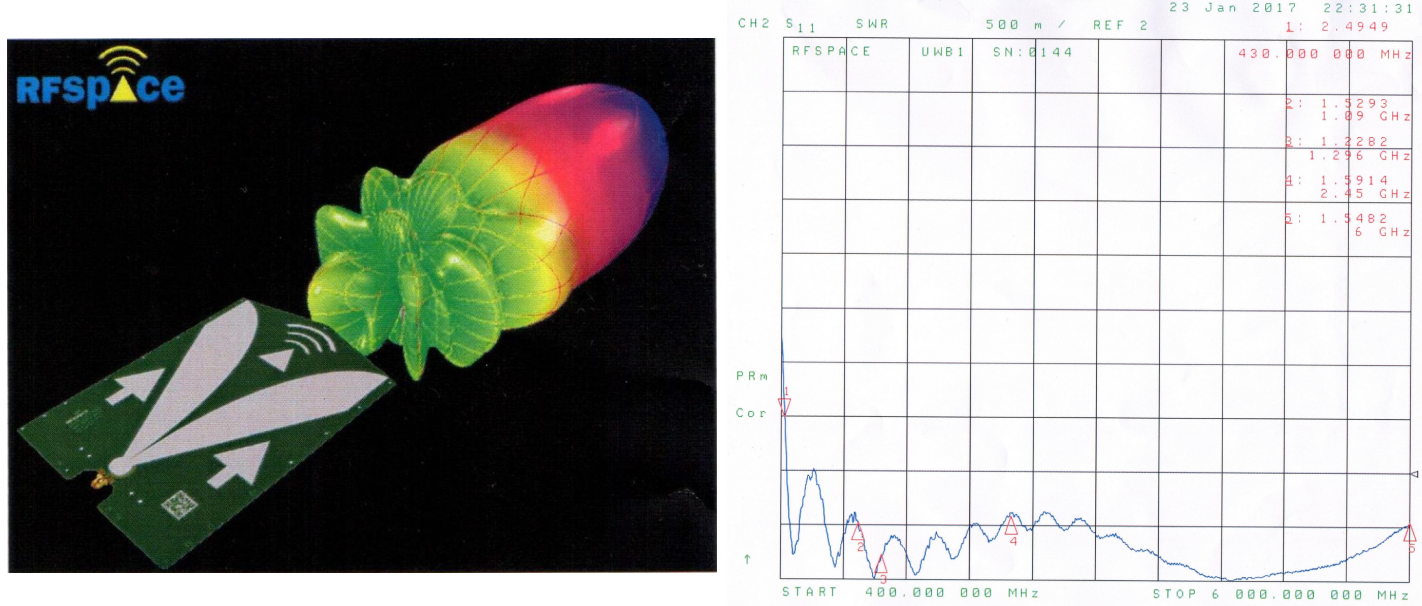

Figure 2.21: Photo of the RFSPACE UWB2 and the diagram of the bandwidth.

reflection, to be a directional high gain and has a small size in order to use it in a practical UWB radar sensor systems.

\subsubsection{UWB antennas used in this Thesis}

Due to the requirements mentioned above, as well as the challenges presented when making a UWB antenna. This thesis has focused only on the design of a UWB pulse generator, so that to complete the prototype for a UWB sensor radar, we have purchased a UWB antenna. These are the characteristics of commercial antennas purchased:

The RFSPACE UWB1: is an aluminum, wide-band antenna optimized for high gain, low VSWR and broadband response. the antenna has $9 \mathrm{dBi}$ in Gain, $6 \mathrm{Ghz}$ in Wide band. Fig 2.20.

The RFSPACE UWB2: Is a PCB wide-band antenna optimized for high gain , low VSWR and brad band response. Present a clean pulse response. The antenna has $10 \mathrm{dBi}$ in gain, a bandwidth form $600 \mathrm{mhz}$ to $6 \mathrm{Ghz}$. Fig 2.21

Both antennas, have been used in the measurements, the behavior of each one is detailed in chapter 5 , but I can advance that it should, and it is; the behavior of the UWB1 is better than the UWB2, since its width of band starts from $430 \mathrm{Mhz}$, unlike that of UWB2, which starts at $600 \mathrm{Mhz}$, knowing the sensitivity of the low frequencies in the transmission of the pulses. 


\subsection{Fundamentals of Radar Sensors}

\subsubsection{Historical Review}

In the past decades, ultra-wideband (UWB) was mainly used for military communications, radar, and sensing applications. With the approval of Federal Communications Commission (FCC) in February 2002, UWB technology pushes the limits of high data-rate, and has been proposed for high-rate, short-range communications, such as home networks, in-building communications, and cordless phones [95].

UWB technology can also be used to achieve other wireless applications, such as through-wall and medical imaging systems, radars, ground penetrating radars (GPRs), and military applications with relatively high emission power levels [96].

Recently, the Radar sensors have been used as an accurate and cost-effective technique for nondestructive characterization of surface and subsurface in various applications, such as measuring distance, thicknesses or moisture contents, detecting and localizing buried mines or archaeological sites, and profiling the surface or subsurface of pavement [96]- [100].

An incident electromagnetic wave is scattered in all directions when it encounters an object that has different electrical or magnetic properties to the environment. A detailed and careful analysis of the scattered electromagnetic waves leads to a better understanding of the characteristics of the medium.

The transmitted pulses radiated by the transmitting antenna, are reflected by the target and return in the direction of the radar. The reflected pulse is collected by the receiving antenna and detected by the receiver. The two-way travel time ( $t$ ) of the electromagnetic wave is associated with the range (R) of the target, as defined by:

$$
\Gamma=\frac{2 R}{C}
$$

Where $\mathrm{C}$ is the speed of light in free space, the important parameters of radar sensors are "penetration depth" and "resolution". The maximum value of penetration depth $\left(R_{\max }\right)$, which is achieved when the receiving power $P_{r}$ is equal to the receiver sensitivity $S_{i}$, depends on the propagating medium's property, the antenna gain, the transmitting power $P_{t}$, the receiver bandwidth $\mathrm{B}$ and so on, as expressed by [101].

$$
R_{\max } \alpha\left[\frac{P_{t} G_{t} G_{r} e^{\left(-4 \alpha R_{\max }\right)}}{S_{i}}\right]^{\frac{1}{4}}
$$


Where $S i=k T B F(S N R)$, and $G_{t}$ and $G_{r}$ are the transmitting and receiving antenna gains, respectively, and $\alpha$ is the attenuation constant of the medium. It is useful to consider the average transmitting power $P_{\text {tav }}$, which is the product of the transmitting power $P_{t}$ and the inverse of the bandwidth B, hence Eq. (2-2) is modified as:

$$
R_{\max } \alpha\left[\frac{P_{t a v} G_{t} G_{r} e^{\left(-4 \alpha R_{\max }\right)}}{K T F(S N R)}\right]^{\frac{1}{4}}
$$

It can easily be deduced that more average transmitting power (Eq. 2-3) or more peak transmitting power combined with less bandwidth (Eq. 2-2) results in deeper maximum penetration.

The absolute bandwidth (B) of the transmitted EM waves determines the range (or vertical)resolution $\Delta R$, which is the ability to distinguish closely spaced targets within a specific range $\mathrm{R}$. It is given by:

$$
\Delta R=\frac{C}{2 B}
$$

The range resolution is inversely proportional to the bandwidth that can be associated with the shape of the waveform. Thus, one of the important design constraints of a radar sensor is the choice of an appropriate waveform. According to the waveform used for transmission, the radar sensor can be categorized as a pulsed radar sensor or Continuous-Wave (CW) radar sensor.

\subsubsection{Pulsed Radar Sensor}

The pulsed radar sensor, also known as the time-domain radar sensor, typically employs a train of impulses, mono-pulses or modulated pulses, as the transmitting waveform (Figure 1.1).

The impulse radar transmits a short pulse train with a pulse repetition interval (PRI). Such an impulse can be generated by using avalanche transistors, step recovery diodes (SRD) [102]- [104], or tunnel diodes [105] to produce a high peak power or a pulse of short duration [105]- [106].

The pulsed radar sensors typically use the two-way travel time of the transmitted pulse to measure the range of a target.

The pulsed radar sensor has been widely used in many applications owing to its simple structure and effective cost. However, it has been found that this sensor is inappropriate and has severe constraints while operating as a High-Resolution Radar (HRR) sensor. To be an HRR sensor, the bandwidth (B) of the pulse needs to be increased as seen by equation (2-4). As the bandwidth of the pulse is increased 
by shortening the pulse width $\tau$, which in turn is restricted by available technologies, this type of sensor finds its usage effectively constricted by technological limitations and hence finds itself limited in high resolution based radar applications. It is worthwhile to note that the increased bandwidth degrades the receiver sensitivity, which results in decreasing the penetration depth [120]. Pulsed radars with a few hundred Pico-seconds of pulse width can be designed, but only at very low power levels, up to a fraction of a watt of the average power [103]- [107]- [108]. This means that the pulsed radars cannot achieve both high range resolution and deep penetration simultaneously unless the pulse compression technique is used.

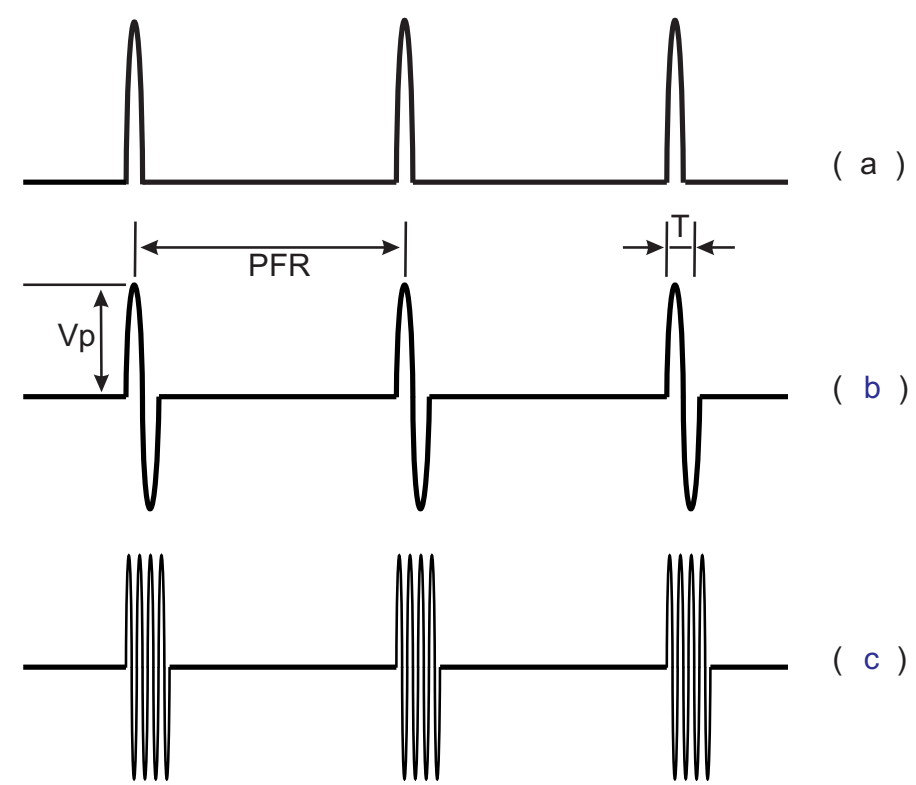

Figure 2.22: waveforms of pulsed radar sensors:(a) impulse (b)mono-pulse, where $\mathrm{T}$ is the pulse width and $V_{p}$ is the peak amplitude (c) modulated pulse.

In other hand, CW radar sensors can be implemented either as frequencymodulated continuous wave (FMCW) radar sensors or stepped-frequency continuous wave (SFCW) radar sensors. These sensors can achieve an average power much higher than that of a pulsed radar sensor [121]. Both of these sensors are briefly discussed below.

\subsubsection{Frequency-Modulated Continuous Wave Radar Sensors}

FMCW radar sensors, also known as frequency domain radar sensors, have also been widely used as subsurface radar sensors, for instance, in measuring the thickness of a coal layer and detecting buried objects under the ground [109][111]. 


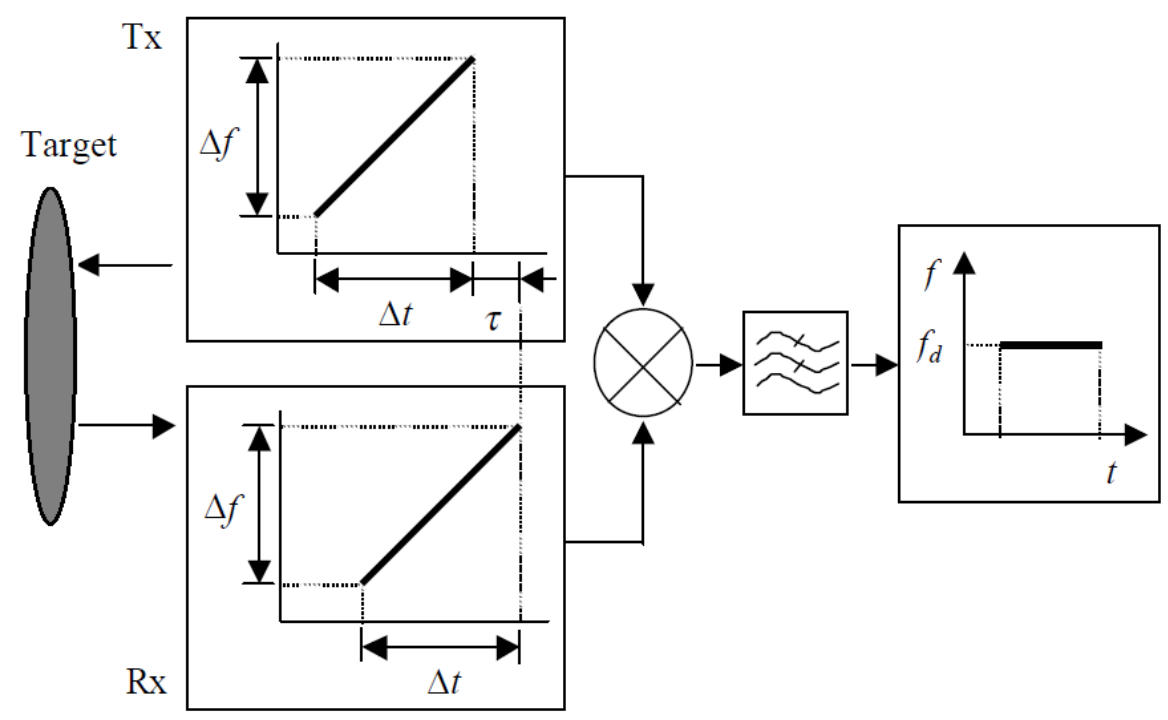

Figure 2.23: FMCW radar sensor

Figure 2.23 shows the FMCW radar sensor using a beat frequency (fd) to seek the range $(R)$ information of a target, as defined by:

$$
R=\frac{C \tau}{2}=\frac{C f d}{2 m}
$$

Where $(\mathrm{m})$ is the rate of sweeping frequency and the beat frequency accounts for the relative time delay $(\tau)$ of the transmitted signal to the returned signal.

An important characteristic of FWCW radar sensors is that the rate of sweeping frequency $(\mathrm{m})$ should be carefully observed to obtain a satisfactorily accurate range of the target. However, it is quite difficult to achieve this specification over a wide band, due to the non-linearity of the voltage-controlled oscillator (VCO).

Moreover, its wide bandwidth degrades the receiver's sensitivity, which results in reducing penetration depth. Hence, these drawbacks limit the FMCW radar sensor in some applications that need a greater degree of accuracy [121].

\subsubsection{Setepped-Frequency Continous Wave Radar Sensors}

The SFCW radars, also known as frequency-domain radar sensors, transmit and receive consecutive trains of $\mathrm{N}$ frequencies changed by the frequency step $(\Delta f)$.

Basically, the SFCW radar transforms the amplitudes $\left(A_{i}\right)$ and phases $\left(\varphi_{i}\right)$ of the base-band I and Q signals in the frequency domain to a synthetic pulse in the 


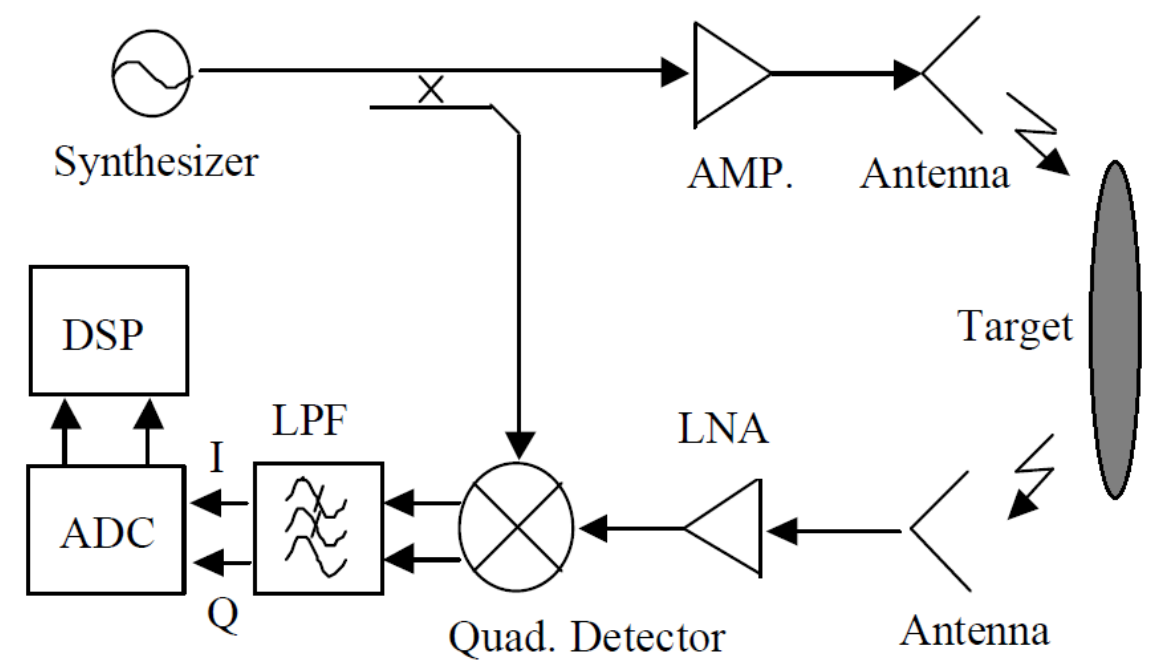

Figure 2.24: SFCW radar sensor

time domain to find the range $(\mathrm{R})$ of a target [112], as defined by:

$$
I_{i}=A_{i} \cos \theta=A_{i} \cos \left(-\frac{\omega_{i} 2 R}{c}\right)
$$

And

$$
Q_{i}=A_{i} \sin \theta=A_{i} \sin \left(-\frac{\omega_{i} 2 R}{c}\right)
$$

The advantages of SFCW radar sensors are as follows [115]- [116]: Firstly, it has a narrow instantaneous bandwidth that significantly improves the receiver's sensitivity while maintaining the average power. Secondly, it can transmit a high average power, resulting in a deeper penetration, due to the use of $C W$ signals. Thirdly, the non - linear effects caused by the inherent imperfections of the transmitter and receiver can be corrected through appropriate signal processing. Furthermore, the received signals propagated through dispersive media can be accurately compensated through signal processing if the properties of the media are known, as the system transmits only one frequency at a particular instant of time. Lastly, the Analog - to - Digital $(A / D)$ converter uses a very low sampling frequency, due to a low frequency of the base-band $I / Q$ signals. This enables greater precision and ease in designing the circuits. On the flip side, a few disadvantages of the SFCW radar sensors include their high complexity and cost. However, owing to the impending ramifications due to the above advantages, there is a significant impetus for exhaustive research in this field [121].

The concept of the stepped-frequency technique was first presented to detect buried objects by Robinson at Stanford Research Institute in 1972 [116], but active research began only in the early nineties. An $S F C W$ sensor operated at 
$0.6-1.112-G H z$ was developed for detecting moisture content in the pavement subgrade by Pippert et al. in 1993 [117]. Another SFCW radar sensor was developed at $490-780-\mathrm{MHz}$ for detection of buried objects by Langman in 1996 [118] while a 10-620-MHz system was reported by Stickely in 1997 [119]. Langman et al. also developed a microwave $S F C W$ radar sensor operating in the 1-2-GHz was presented for detecting landmines in 1998 [97]. A Network Analyzer was used as a $S F C W$ radar sensor at $0.5-6 \mathrm{GHz}$ to detect concrete cracks by Huston in 1998 [120]. Joongsuk Park, was developed a new stepped-frequency radar sensor for surface and subsurface profiling based on a coherent super-heterodyne using MICs a MMICs in 2003 [121]. And finally, IoanNicolaescu has developed newly stepped-frequency continuous wave $(S F W C$ ) ground-penetrating radar in a frequency range from 400 to $4845 \mathrm{MHz}$ in 2012 [121].

\subsection{Conclusion}

This chapter presents the principles theoretical aspect of UWB Radar Sensor, an overview of the fundamentals UWB systems and their huge application has been presented also. In which we tried to summarize in a general and brief, the various types of radar, from pulsed radar sensor to CW radar sensors, its advantages and disadvantages in each field.

This chapter has demonstrated also that the UWB radar sensor is a great technology and is used in a wide application today. However, the new application fields require a smaller size, lower cost and power consumption. Moreover, the future UWB radar sensor is required to provide more and more a finer range solution and a higher accuracy measurement in order to be used in a various future application. All this technical aspect will be presented in the next section, moreover, a proposed UWB pulse generator for the UWB radar sensor will be studied and analyzed in details. 


\title{
Pulse generator design for UWB \\ Radar Sensor
}

\author{
IN MATTERS OF \\ STYLE SWIM WITH \\ THE CURRENT, IN \\ MATTERS OF \\ PRINCIPLE STAND \\ LIKE A ROCK.
}

Statesman, diplomat lawyer and architect 1743-1826.

Thomas Jefferson

$\mathrm{T}^{\mathrm{N}}$ this chapter, a sub-nanosecond pulse generator for Ultra-wideband radar sen-

1 sor is presented. The generator circuit is composed by three essential parts, an avalanche transistor, an SRD pulse sharping and an MFN. The main idea in this chapter is to generates a monocycle pulse. in order to improve the output response a new model of step recovery diode has been proposed as a sharpener circuit. A monocycle pulses with over $10 \mathrm{~V}$ in amplitude and $3.5 \%$ in overshoot is obtained. 


\subsection{Introduction}

A key challenge in the design of a UWB radar sensor is the avaibility of a pulse generator with a required and suficient peak power pulse with a rise-time as short as possible.

Recently, and according to Ultra-wideband technology development, increased demands on high-resolution positioning in the lossy material is required. Furthermore, attracted attention by many researchers have been concentrated more and more on sub-nanosecond pulses [122]- [123] ; because Ultra-short pulses with well-defined output waveform play a crucial role in the UWB transmitter design. However, sub-nanosecond pulse transmitter is the fundamental part of any ultrawideband (UWB) radar sensor [124], because the wide bandwidth of UWB pulses ensures fine range resolution and high penetration capability. Generally, and instead of higher frequencies, which the losses are enormous, Lower frequencies up to $3.5 \mathrm{GHz}$ are preferred for NDT application in the lossy material. The corresponding pulse width of the generated base-band pulses is approximately 200 ps.

Normally, there are various techniques to generate UWB pulses around this range. The basis of a classical UWB short pulse generator is a driver, a pulse sharpener and a pulse forming network. The driver converts the step-like waveform in Gaussian pulses, and the pulse sharpener converts slow rise time waveform edge to a faster one. However, the pulse forming network forms the output pulse to the adequate and favourite pattern: Gaussian or monocycle. Special semiconductor devices are usually utilized as pulse sharpener: avalanche transistor, bipolar diode [125]- [126], tunnel diode [127], Step Recovery Diode $S R D$ [128], and FETs [129]. Although the disadvantage presented in term of low value of $P R F$, the avalanche diode is very advantageous as high power sharpener due to low power dissipation in the transistor. Tunnel diodes offer the fastest transition time (sub-picosecond) at very low power (about $\mathrm{mW}$ ). The $S R D s$ are a compromise alternative for these devices and offer ultra-short transition time (around $100 \mathrm{ps)}$ at moderate power levels (changing from hundreds of $\mathrm{mW}$ to tens watt) and with high repetition frequency [130]- [131]. This makes them very appropriate to be used in the current UWB generator.

Usually, a $S R D$ works as a charge controlled switch, which can alter from low impedance to high impedance state much quicker. This qualification of the $S R D$ 
is used to sharpen the slow waveform edges. The more details of theory and application of $S R D s$ as pulse sharpening is well described in [132]. The basis of the generated circuit Gaussian pulse generator consists of a simple transistor driver and a $S R D$ sharpener with a pulse-forming circuit.

In the majority of the work presented previously, the monocycle pulse amplitude is limited, and not satisfied the criteria of a good generator required by an advanced UWB radar sensor. Therefore, there is an increasing demand for a monocycle pulse having a high amplitude and a little of ringing; because an extralevel in ringing at the output waveform involves more distortion, damage and also presents more difficulties to extract information regarding the data processing. To face this challenge: two useful technique has been proposed in this manuscript; the first one consists of making the discharge path of the BJT transistor as short as possible. This useful technique leads to decrease the ringing of the output pulse; around $3.6 \%$ in overshoot. While the second one consists in presenting a new model for $S R D$, since, it has not an accurate model of $S R D$ in the simulator's software (AWR Microwave office and Multisim), therefore the simulation accuracy has been improved and the rise-time has been decreased from 630 ns to 450 ns.

This two advantages, satisfy perfectly the requirement in getting a system having an accuracy non-destructive measurement methods. Unfortunately, many pulses in the literature have a lot of the ringing in the output waveform [133][135]. However, and unlike the generator described by Zhong Li and Protiva [136]- [137], our pulse transmitter has the advantage of producing pulses with low ringing levels and reasonably high output amplitude.

Moreover, adding a Monocycle Forming Network $M F N$ gives a monocycle pulses with $9.7 \mathrm{~V}$ in amplitude and $600 \mathrm{ps}$ in total width. The prototype circuit model has been manufactured using microstrip line technology. All results prove the high performance of the system.

In this chapter, a low-cost and compact UWB radar sensor, using a BJT avalanche transistor is presented.

\subsection{Circuit description of the pulse generator}

A block diagram of the proposed ultra-short pulse generator using an avalanche transistor and SRD is shown in figure 3.1. It consists of the following circuits: 
- Avalanche transistor circuits.

- SRD pulse shaping Circuit.

- Monocycle Forming Network.

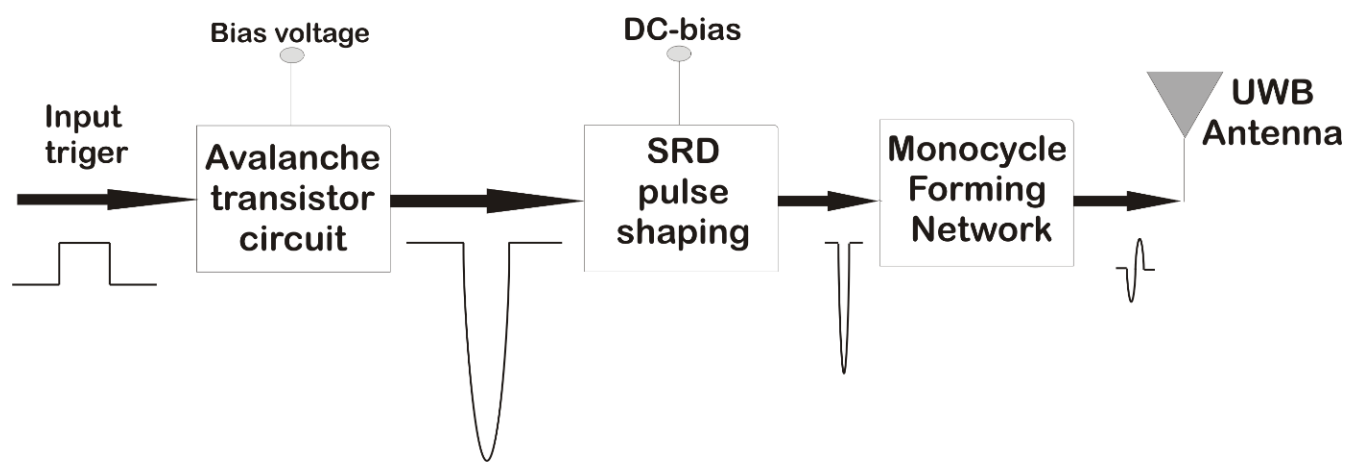

Figure 3.1: Block diagram of the proposed pulse generator.

The quadratic trigger received by the Avalanche transistor circuit, is then converted into a Gaussian pulse. In order to minimize the current consumption of the circuit, the input pulse width is set to a few nanoseconds e,g. around $5 \mathrm{~ns}$. Moreover, the rise time has been fixed at $2 \mathrm{~ns}$.

The edge-triggered driver generates a well-defined pulse with sufficient power and speed to drive an $S R D$. This pulse is independent of the input waveform amplitude and duty-cycle.

The following stage of the pulse generator is the $S R D$ pulse sharping which consists of two main parts: The Step recovery diode and. The purpose of a $S R D$ pulse sharpener is to sharpen the leading falling edge of the driving waveform. The sharpened step-like pulse is then processed in a pulse-forming circuit to produce a Gaussian-like pulse.

When no input driving pulse is present, the $S R D$ is forward biased by an adjustable constant current source $\mathrm{Ib}$, and a large amount of charge is injected into the diode making the impedance low.

After the triggering, the device continues as low impedance until all charge is totally removed, at the point where the diode switches rapidly from the low to high impedance [138].

The ability of the SRD to store charge and change its impedance level rapidly is used to sharpen the slow waveform edges in the nanosecond region.

The pulse generator has been designed and simulated by the AWR-Microwaveoffice and Multisim-transient simulator respectively. 


\subsection{Circuit design of the pulse generator}

\subsubsection{Driver: Avalanche Transistor Circuit effects.}

The corresponding detailed circuit diagram of the system is shown in figure.3.2.

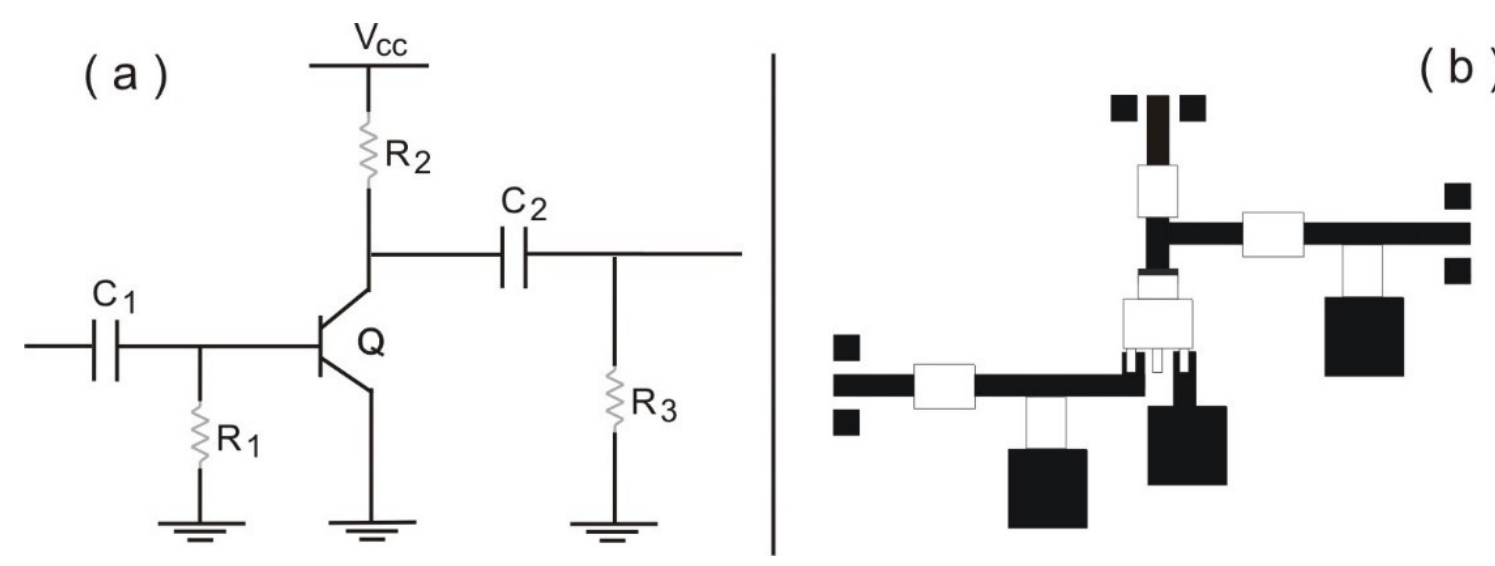

Figure 3.2: (a): The circuit schematic of the Avalanche transistor circuit, (b): Layout of the Avalanche transistor circuit.

The first part of the generator consists in an Avalanche transistor circuit, composed by $Q, C_{1}, R_{1}, C_{2}$ and $R_{2}$ as shown in figure 3.3. The transistor $Q$ operates as a common-emitter switch and generates a negative voltage pulses with sufficient power to drive the SRD. The driving waveform passes via a coupling capacitor $C_{2}$ to the $S R D$ pulser. As can be shown in figure. 3.2. The discharge current of the avalanche transistor circuit flows from the capacitor $C_{2}$ trough the avalanche transistor and resistor $R_{3}$.

figure 3.3 shows shematically the output current-voltage characteristics $\left(I_{C^{-}}\right.$ $V_{C} E$ ) of a Bipolar transistor for Avalanche mode operation. Witout trigger, the transistor is in off-state, i.e. non-conducting. At low voltage $V_{C} C$, the collector $I_{c}$ is very low and increases only slighly with increasing supply voltage. However when the voltage approaches $B V_{C} E R$ (Collector-emitter breakdown voltage) with the fixed base-emiter resistor value $R_{B} E$, the electrical field in the collectoremitter path becomes very high so that carieer multiplication effects occur; therefor, the currents increase disproportionately. Exceeding $B V_{C} E R$, the transistor break down and may reach point B (dependent on the dynamic load line), which is no a stable operation point, thus, reaching point B' [21], [124].

When the high current in B' exceeds the rated dissipation power of the tran- 
sistor (mostly temperature effect), second breakdowns will happen, which means that the transistor is destroyed.

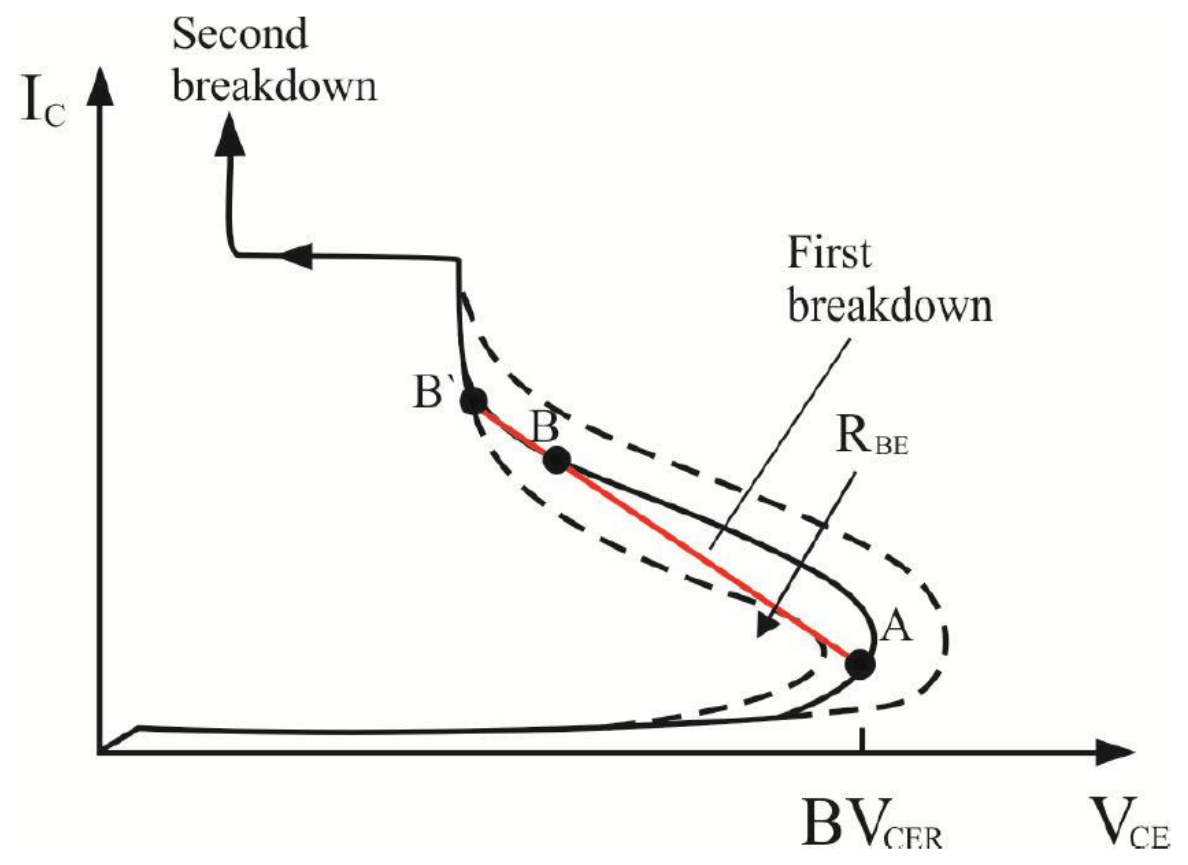

Figure 3.3: $I_{c}-V_{C} E$ Avalanche breakdown characteristics of a bipolar transistor [124].

As can be see in figure 3.3. the $I_{c}-V_{C} E$ characteristics depends on the value of base resistor. the lower of $R_{b} e$, the higher the breakdown voltage $B V_{C} E R$. The figure 3.4. illustrates the avalanche mode operations. After triggering and after the capacitor has been discharged, the transistor is switched into its off-state. The capacitor is recharged again by the supply voltage $V_{C} C$ through $R_{2}$ and $R_{3}$ with a time constant Tho

$$
\tau=C_{C C}\left(R_{C C}+R_{L}\right) \approx C_{C C} R_{C C} \quad\left(R_{L}<<R_{C C}\right)
$$

until the quiescent point $\mathrm{A}$ is reached. In this point, the $I_{c}$ current is very low, typically around the uA region. The electrical filed in the collector-base is extremely high. When the base is triggered, current flows starts and electrons are accelerated and gain high kinetic energy to generate multiple electron-hole pairs, which indicates the avalanche breakdown. Therefor, the current increase rapidly.

However, the capacitor discharges and the voltages $V_{c}$ decrease, then the breakdown can no longer be maintained. Therefore, after avalanche collapse, the current switches to a low off-state value. Then the charging of the capacitor 
begins again, and having reached the quiescent point $\mathrm{A}$, the circuit is waiting for the next trigger signal.

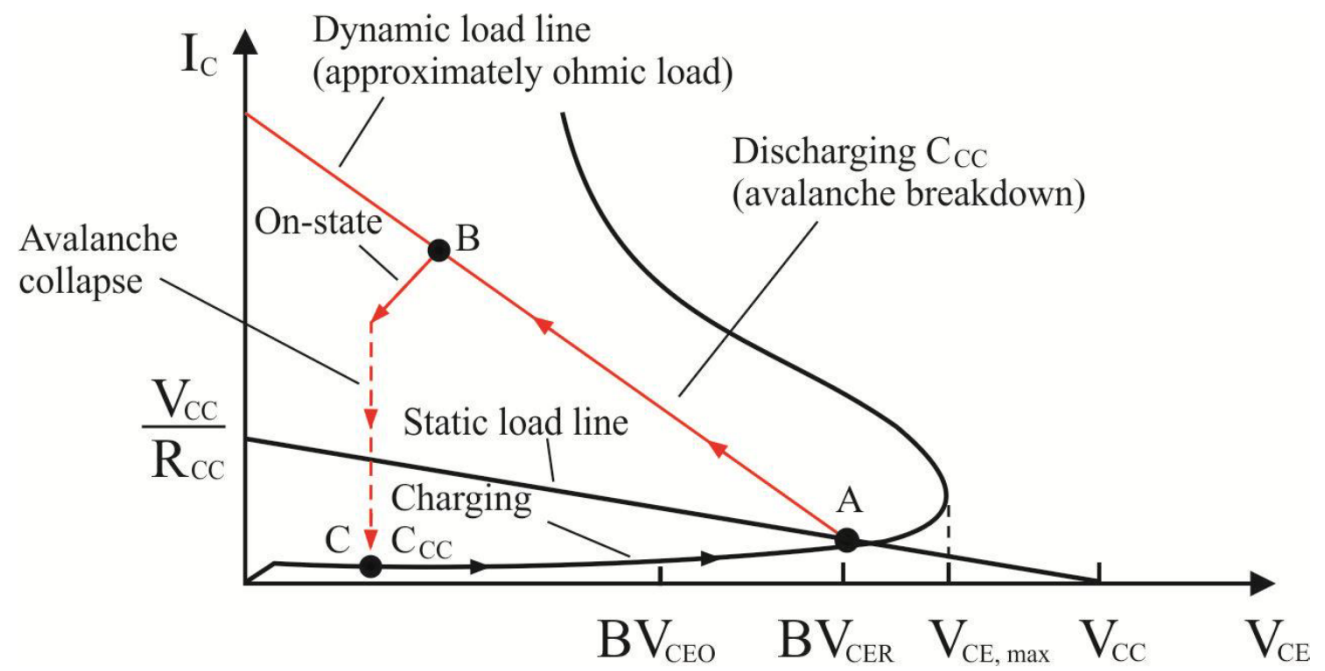

Figure 3.4: $I_{c}-V_{C} E$ characteristics of a bipolar transistor for Avalanche mode of operation [124].

Because of the very fast effect of avalanche multiplication, the switching time of the avalanche transistor lies on the order of 1 ns or less. The shape and amplitude of the ouput pulse $V_{o} u t$ depends on the value of $V_{c} c, C_{2}$, and $R_{3}$.

The value of $V_{c} c, C_{2}$, and $R_{3}$ of the avalanche transistor circuit show in figure 3.2 were varied to investigate the effect on the output pulse parameters such as rise-time $\left(t_{r}\right)$, pulse width $(F W H M)$ and amplitude. Each measurement has been repeated at lease 5 times, and the average value of these value has been recorded.

\subsubsection{The variation of the pulse characteristics versus the change supply $V_{c} c$.}

To evaluate the variation of the pulse characteristics due to the change supply $V_{c} c$, the circuits parameters shows in figure 3.2. have been chosen as $C_{2}=110 \mathrm{ps}$, $R_{C} C=50 \mathrm{kohm}, R_{B}=50 \mathrm{Ohm}, R_{B} E=50 \mathrm{Ohm}, R_{3}=50 \mathrm{Ohm}$ and $C_{b}=2 \mathrm{nF}$. Based on the measurements, it is evaluated that the avalanche breakdown action begin at $V_{c} c=45 \mathrm{~V}$. Therefor, $V_{c} c$ was changed between $40 \mathrm{~V}$ and $60 \mathrm{~V}$. The amplitude of the output pulse is shown in figure 3.5 as a function of $V_{c} c$.

The variation of pulse width (FWHM) and rise-time $\left(t_{r}\right)$ with respect to $V_{c} c$ are represented in figure 3.6 and 3.7, respectively. It can be seen that the pulse width and rise-time decrease with the increase of $V_{c} c$. 


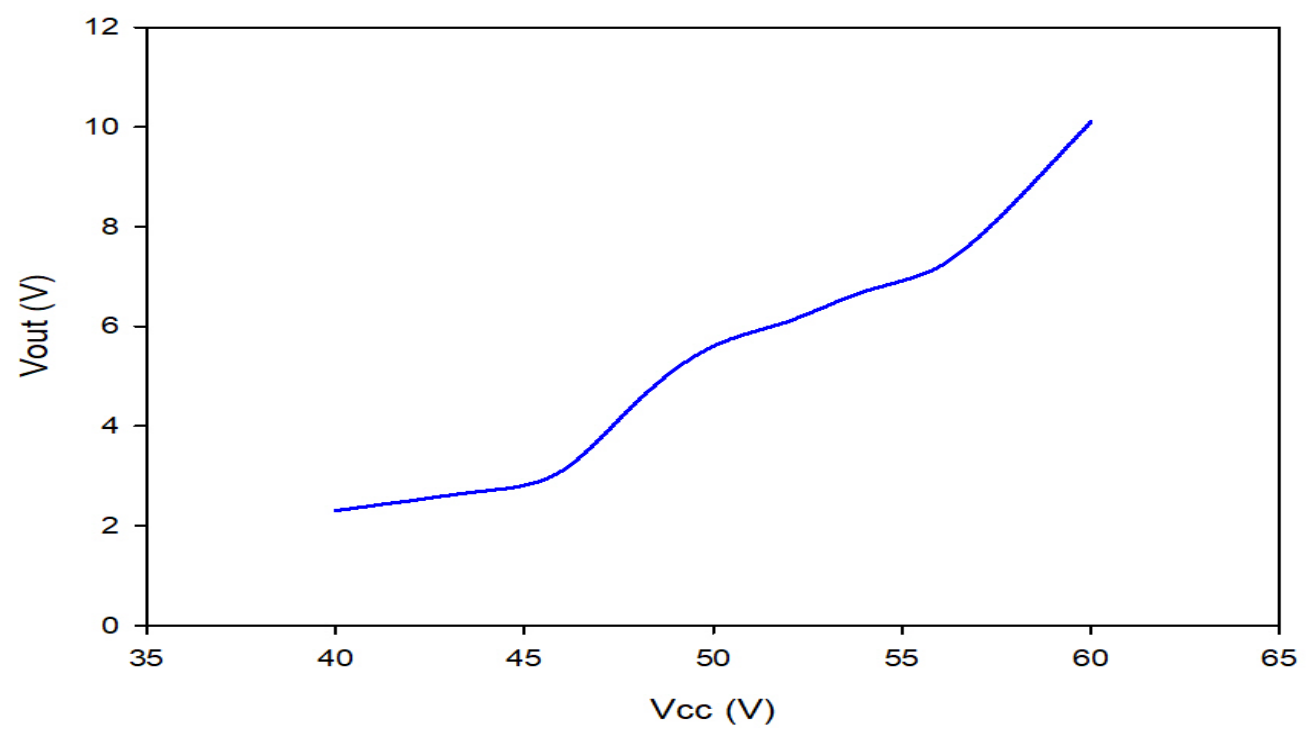

Figure 3.5: Amplitude output pulse of Avalanche transistor circuit versus supply voltage $V_{c} c$ with $C_{c} c=110 \mathrm{pF}$

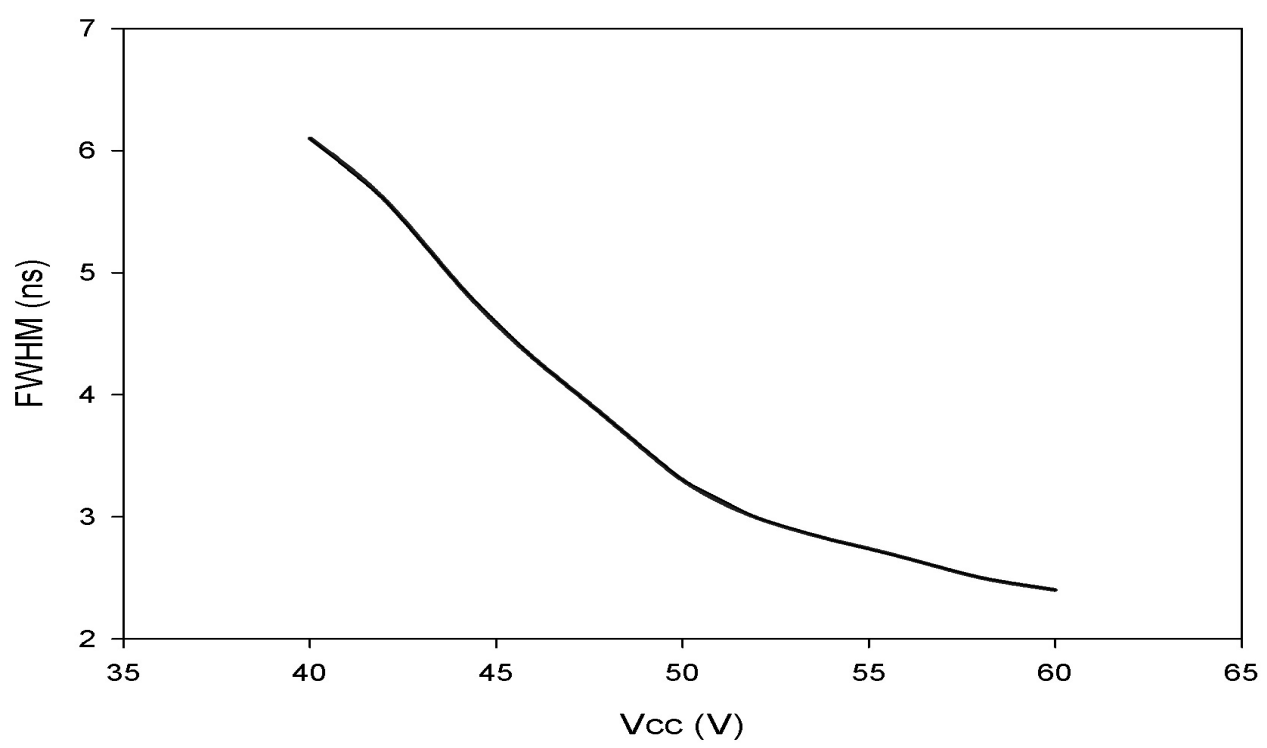

Figure 3.6: FWHM of output pulse of Avalanch transistor circuit as a function of supply voltage $V_{c} c$ with $C_{c} c=110 \mathrm{pF}$

Considering the pulse amplitude, pulse width (FWHM) and rise-time, it can be summarized that the best selection of $V_{c} c$, which provide fast, high amplitude pulse would be $60 \mathrm{~V}$.

\subsubsection{The variation of the pulse characteristics versus the charge $c_{c} c$.}

To evaluate the variation of the pulse characteristics due to the charge $C_{c} c$, the 


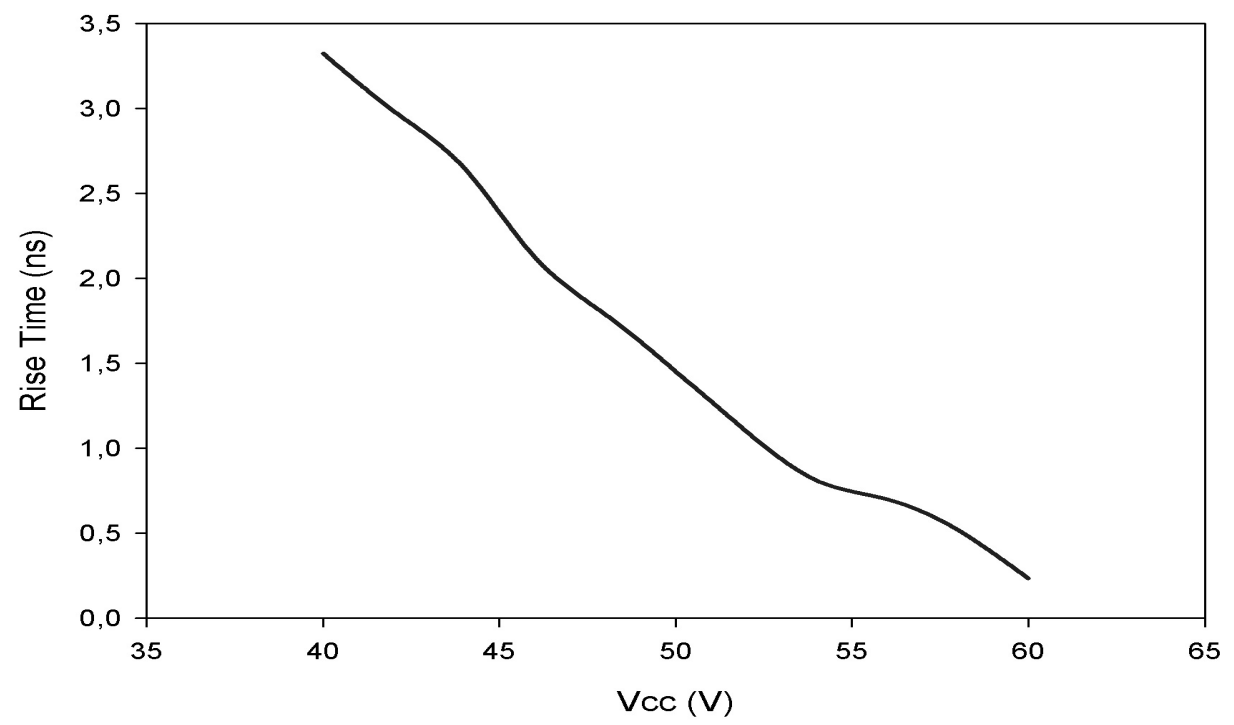

Figure 3.7: Rise-time of output pulse of Avalanche transistor circuit as a function of supply voltage $V_{c} c$ with $C_{c} c=110 \mathrm{pF}$

circuit parameters have been chosen as $V_{C} C=60 \mathrm{~V}, R_{2}=50 \mathrm{ohm}$. The value of $C_{c} c$ has been changed in $20 \mathrm{pF}$ step. The effect of changing $C_{c} c$ value on the pulse parameters rise-time, FWHM and amplitude of the output pulse are presented in figures $3.8 ; 3.9$ and 3.10 .

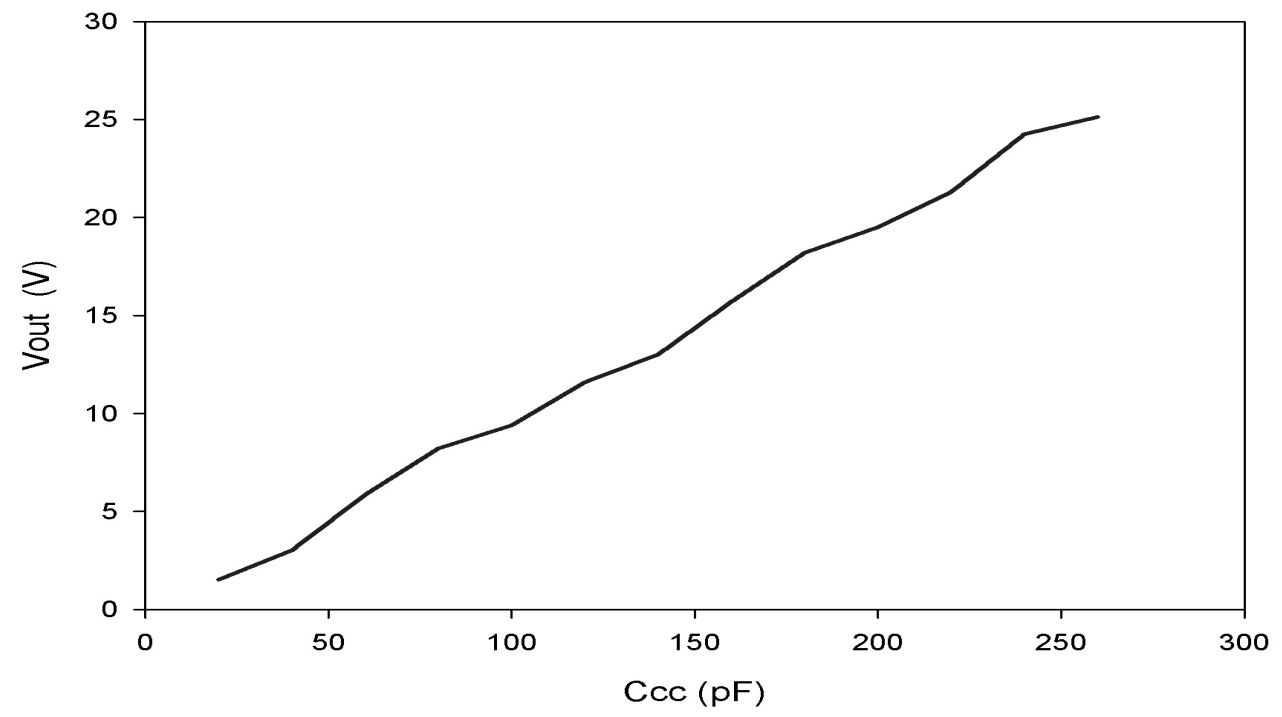

Figure 3.8: Amplitude of output pulse of Avalanche transistor circuit versus $C_{c} c$

Its evident from these Figure that the rise-time, pulse width and amplitude of the pulse increase with the increase of $C_{c} c$. 


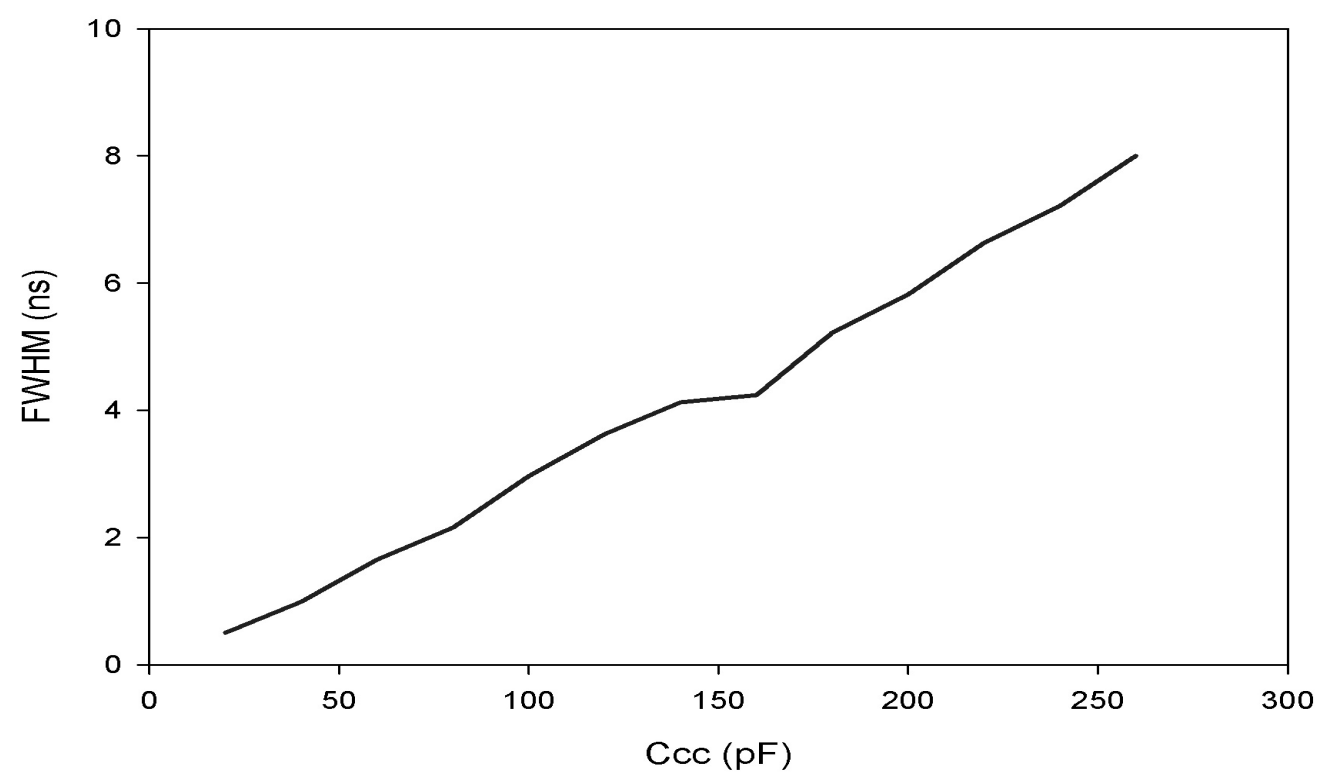

Figure 3.9: Rise-time and FWHM of output pulse of Avalanche transistor circuit versus $C_{c} c$

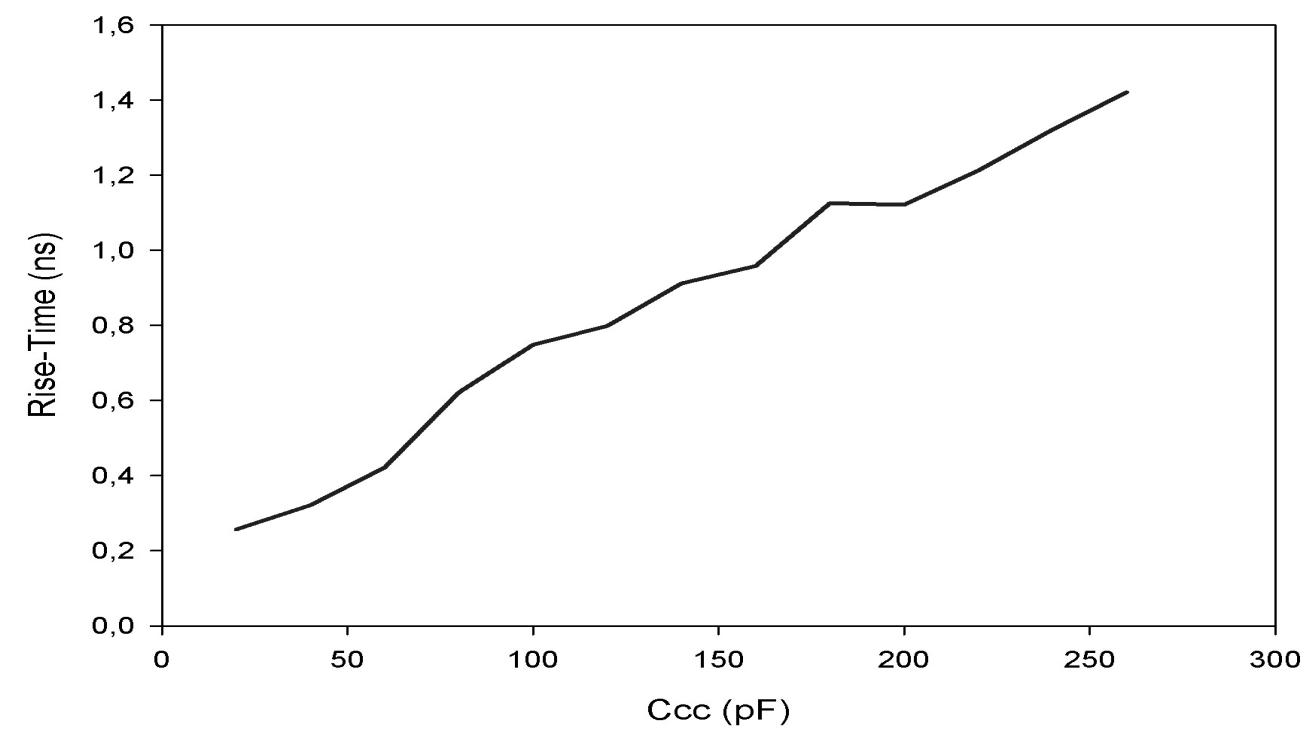

Figure 3.10: Rise-time and FWHM of output pulse of Avalanche transistor circuit versus $C_{c} c$

\subsubsection{The variation of the pulse characteristics versus the pulse repetition frequency.}

In order to complete the pulse analysis, it is important to measure the output pulse parameters e.g. its amplitude, as a function of pulse repetition frequency $P R F$. The $P R F$ of the avalanche transistor circuit is limited by two factors. The first one is the charging time of $c_{c} c$. It very important to ensure that $c_{c} c$ is fully 
recharged before the next trigger pulse comes. The second factor is the transistor temperature. More increasing $P R F$, more increasing the average dissipation power; it's are varied proportionally. This is also see in figure 3.11 for lower value of $P R F$. However, above $P R F=50 \mathrm{kHz}$, the influence of temperature seems to decrease. This can be understood as fellows.

The charge time constant two is calculated as: $t w o=c_{c} c \cdot R_{c} c=110 \mathrm{pf} \times 50$ $\mathrm{kOhm}=5.5$ us. The time to completely charge the capacitor is $5 t w o=27.5$ us, corresponding to a frequency of $36.4 \mathrm{kHz}$ (Shadowed region in figure 3.10). Above $P R F=36.4 \mathrm{kHz}$, the charge time period is too short to completely charge the capacitor. Which is reflected by the smoother decrease of $V_{o} u t$ with $P R F$ ib figure 3.10. [21], [124].

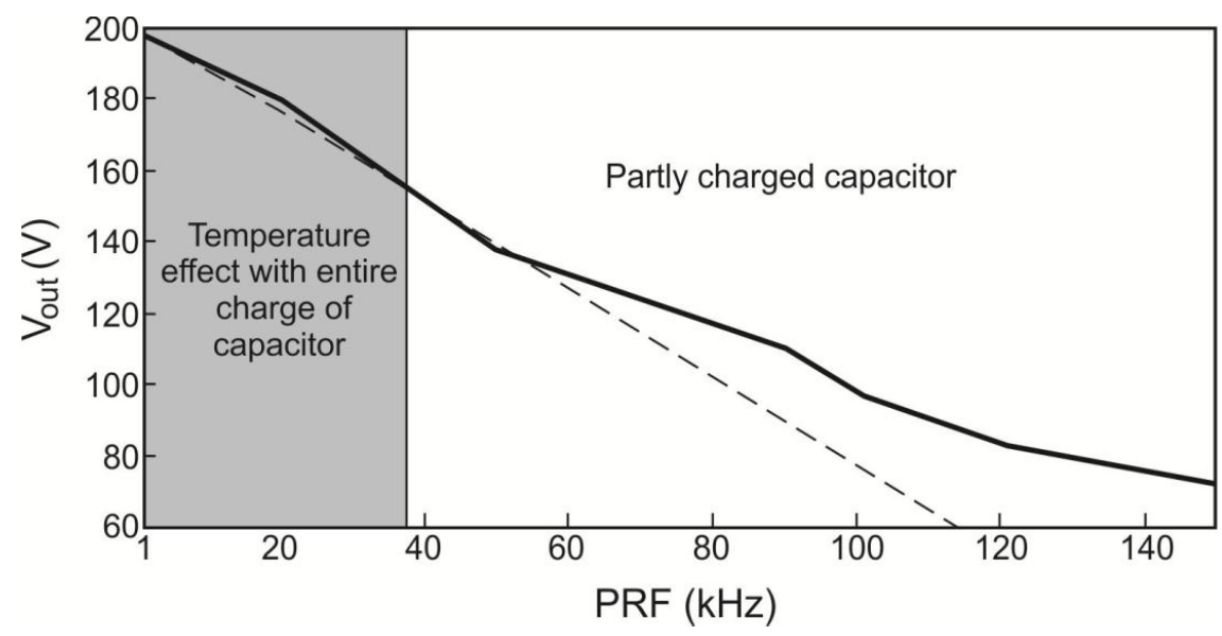

Figure 3.11: Amlitude of output pulse of Avalanche transistor circuit as a funcion PRF. [150]

The photo of the prototype circuit of the avalanche transistor is shown in figure.3.12. In a state steady e.g., when no input driving pulse is present, the avalanche bipolar transistor Q is closed, and the SRD pulse sharpener is forward biased by an adjustable current source. However, after triggering the transistor with a falling edge, the base voltage of $\mathrm{Q}$ is inverted, and it rises to a sufficient level able to saturate the transistor.

With the aim to reduce the parasitic inductive effects in the discharge current, the discharge path has been made as short as possible; this technic leads to minimize significantly the ringing in the output waveform. The figure. 3-12 shows the results before and after making the discharge path short, the ringing in our circuit has been established around $3.6 \%$ in overshoot, so that is better compared 
with [136], [137].

Using the MMBT2222A Transistor, $35 \mathrm{~V}$ supply voltage under $1 \mathrm{MHz}$ of PRF (Pulse Repetition Frequencies, the output pulse is - 6.4 V, 440 ps of fall-times at a $50 \Omega$ load. Finally, a coupling capacitor $C_{3}$ is added to prohibit the flux of the $D C$ bias current to attain the avalanche transistor circuit. Good responses with $C_{3}$ have been achieved with some $p f$.
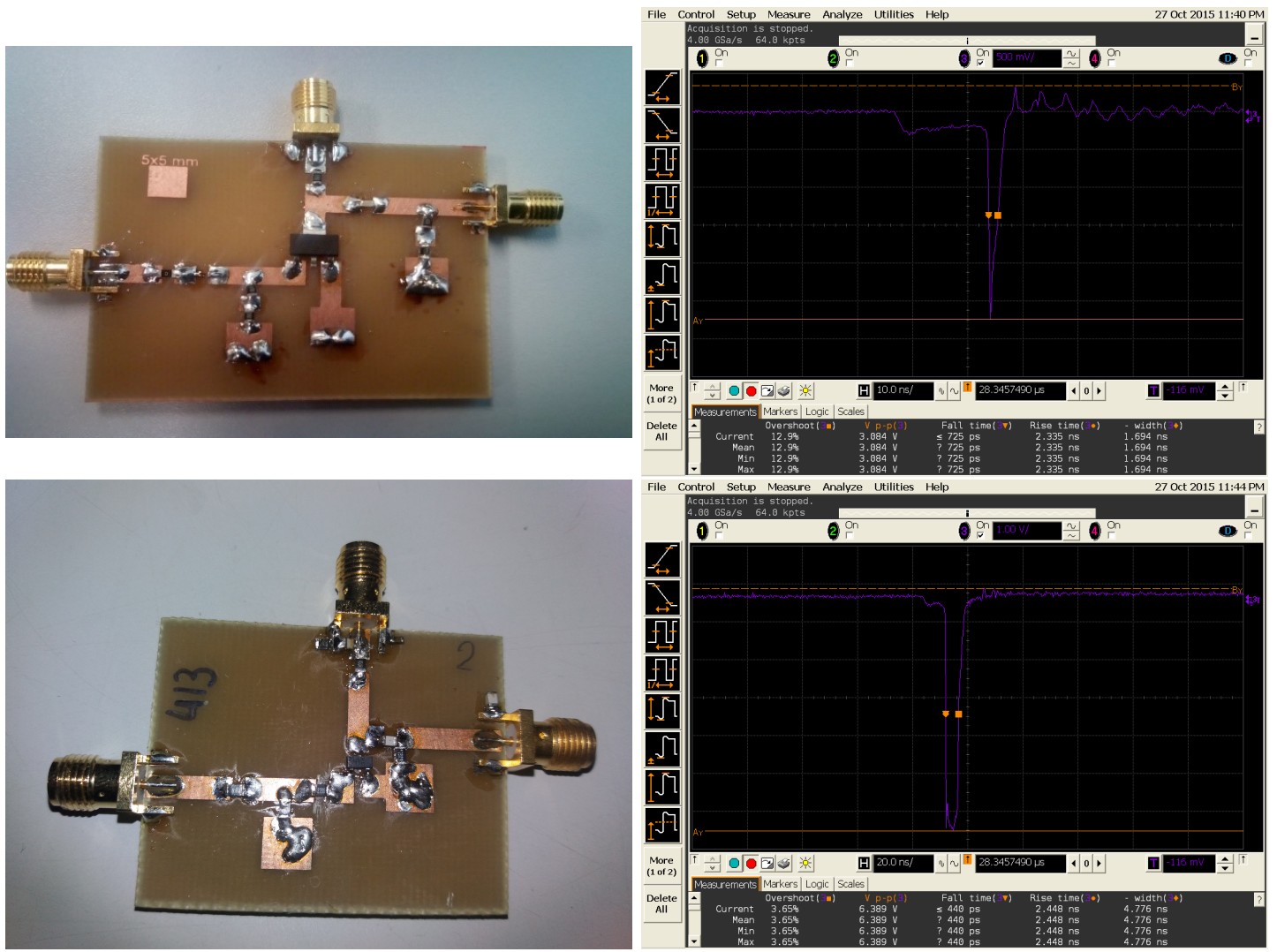

Figure 3.12: Photo and result before (a) and after (b) including the technic of the discharge path short.

\subsubsection{Pulser: SRD pulse Sharpener circuit.}

The second part of the generator is titled "SRD pulse sharping" which consists of a $S R D$ sharpener and a Gaussian pulse forming network. The principal role of the SRD pulse sharpener is to sharpen the edges of the driving waveform. The $S R D$, connected in parallel with a transition line, operates as falling edge sharpener. The sharpener pulses are processed in a pulse-forming-network circuit, which consists of Schottky diodes and delay lines to produce a Gaussian-like pulse.

During the steady-state e.g., forward bias condition, a large amount of charge is injected into the diode, the device appears as a low impedance. After applying 


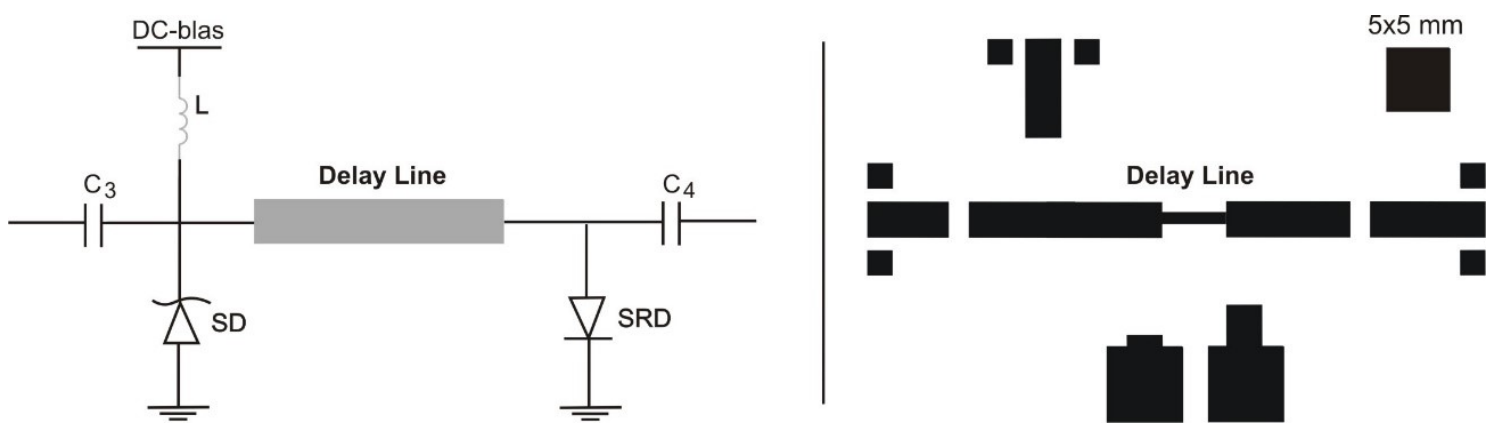

Figure 3.13: The circuit schematic and Layout of SRD pulse sharping circuit.

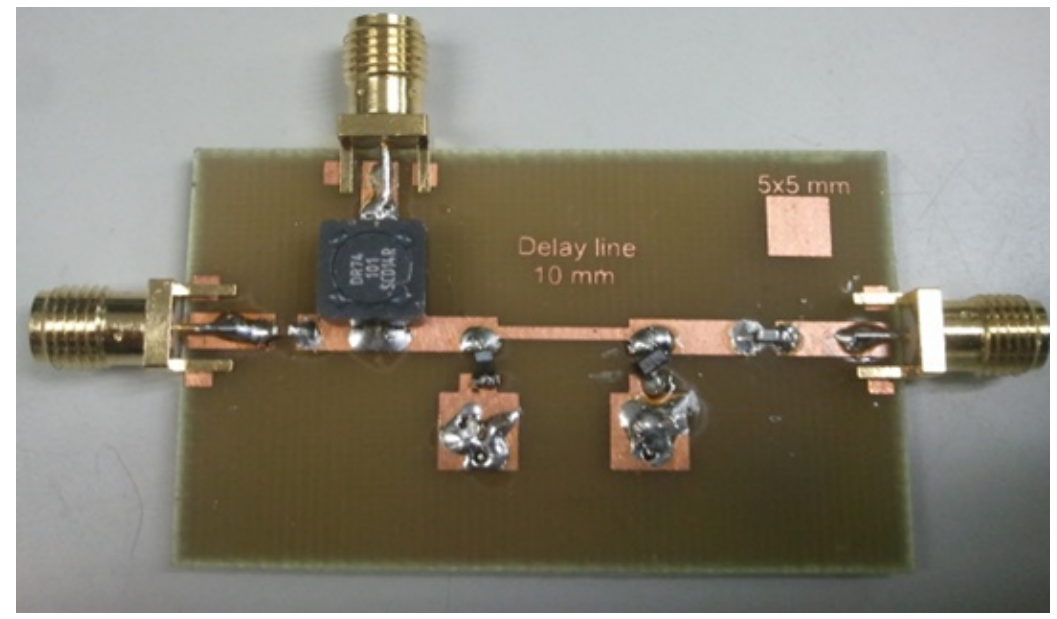

Figure 3.14: SRD pulse sharping circuit.

the negative driving pulse e.g., reverse biasing condition, the diode continuous as low impedance until all charge is totally removed, at the point where the diode rapidly switches from the low to high impedance. This ability of the $S R D$ to store charge and change its impedance level rapidly is used to sharpen the slow waveform edges. The figure 3.15 shows the commercials components of SRD used in this work.

In order to illustrates the great impact of choice the adequate SRD and bias currents Ic, we have choice the SRD proposed by AWR Microwave office, and we have changed the Ic. Fig 3.16 shows the variation of amplitudes with Ic for the SRD of AWR. While the Fig 3.17 shows the variation of amplitudes with the length of Delay line.

The pulse generator was implemented on an ARLON AD450 substrate of 0.7262 $\mathrm{mm}$ in thickness. The waveform was measured using an Agilent 86100C sampling Oscilloscope at $50 \Omega$ load [139]- [140]. figure.3.18 shows the operating mode of $S R D$ pulse sharpening circuit, which in a steady state, the Schottky diode has a low impedance. When a driving waveform applied to $S R D$ pulse sharpening. 


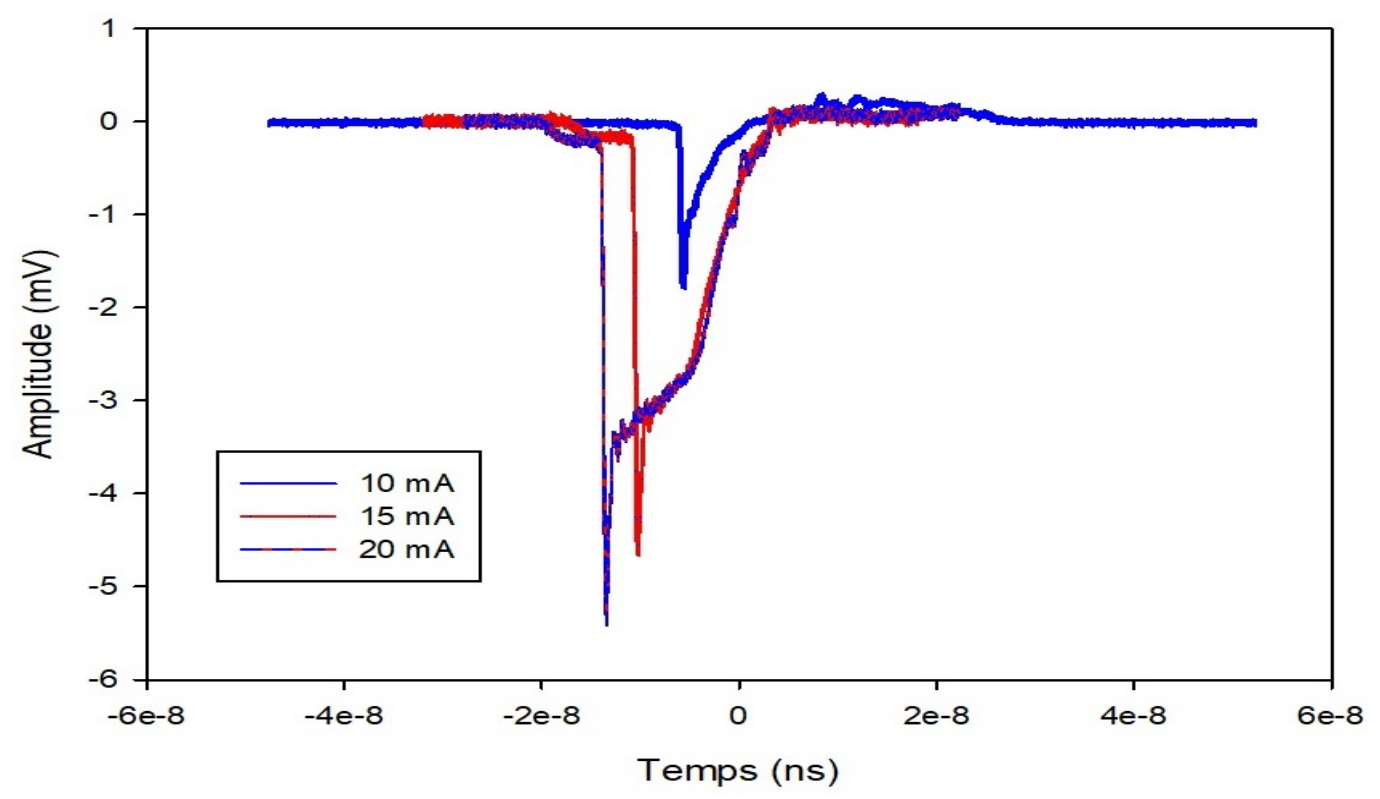

Figure 3.15: Amplitudes variation with the bias currents Ic for the SRD of AWR

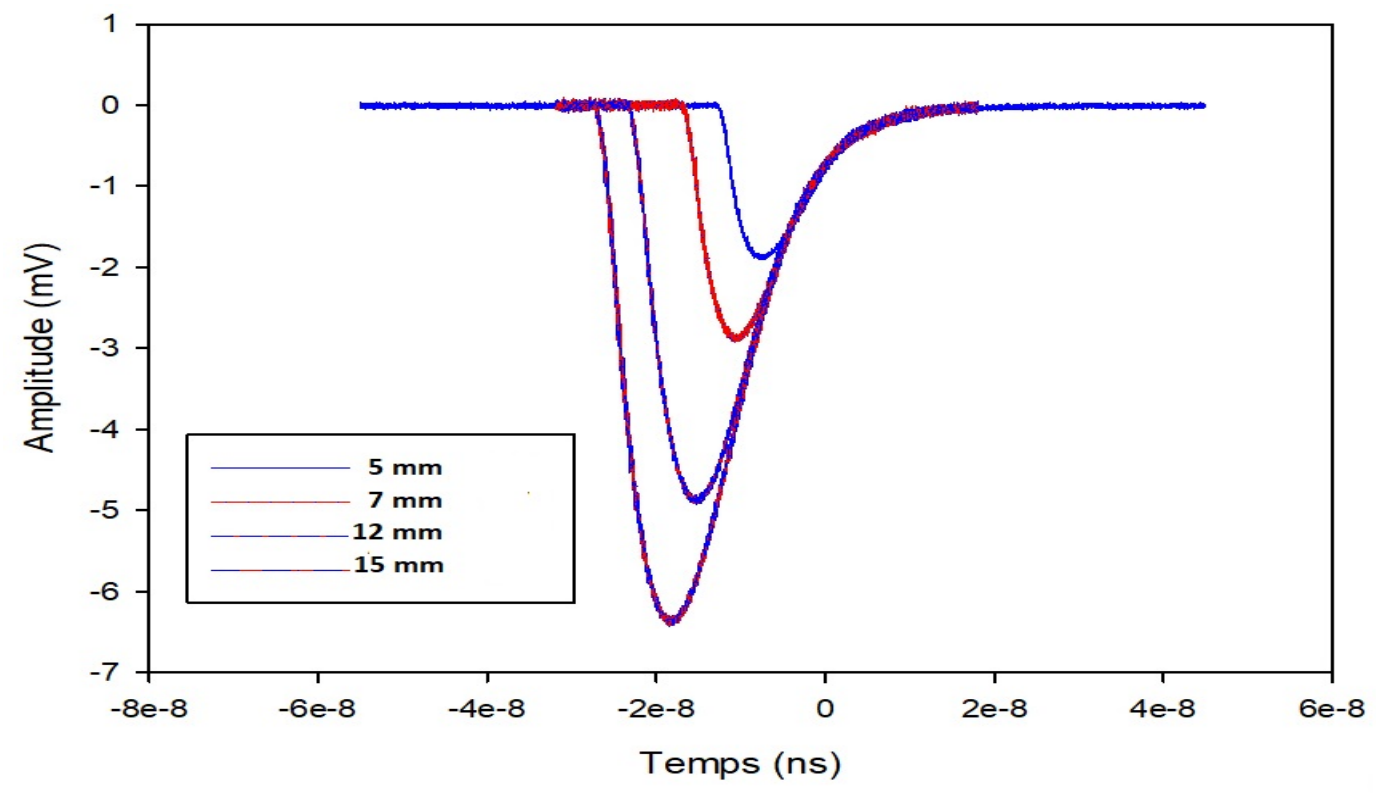

Figure 3.16: Amplitudes variation with the length of Delay line the SRD of AWR

The device switches rapidly from a low to high impedance. At this moment, a fast fall-time step waveform propagates in two different directions through the circuit. The first step propagates forward the output, whereas the second one propagates throughout the delay line back to the input.

Before the driving waveform was applied, the Schottky diode $(S D)$ was reversebiased and did not affect the circuit; nevertheless, this diode is now opened by the negative driving pulse and act enough as low impedance to really short-circuit the transmission line. The step waveform that has been propagating forward the input 


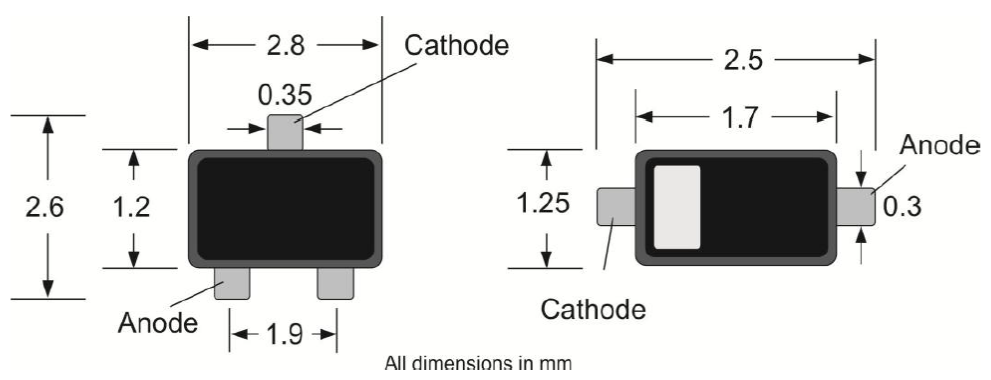

(a)

(b)

Figure 3.17: (a): SRD in SOT-23 package, (b): Shottky diode in SOD-323 package.

is reflected back by the low impedance state effect of the diode. Finally, the Gaussian pulse is composed of both step wave-forms produced on the circuit; e.g. the step waveform unaltered continue to propagate to the output with the retarded and inverted step waveform.

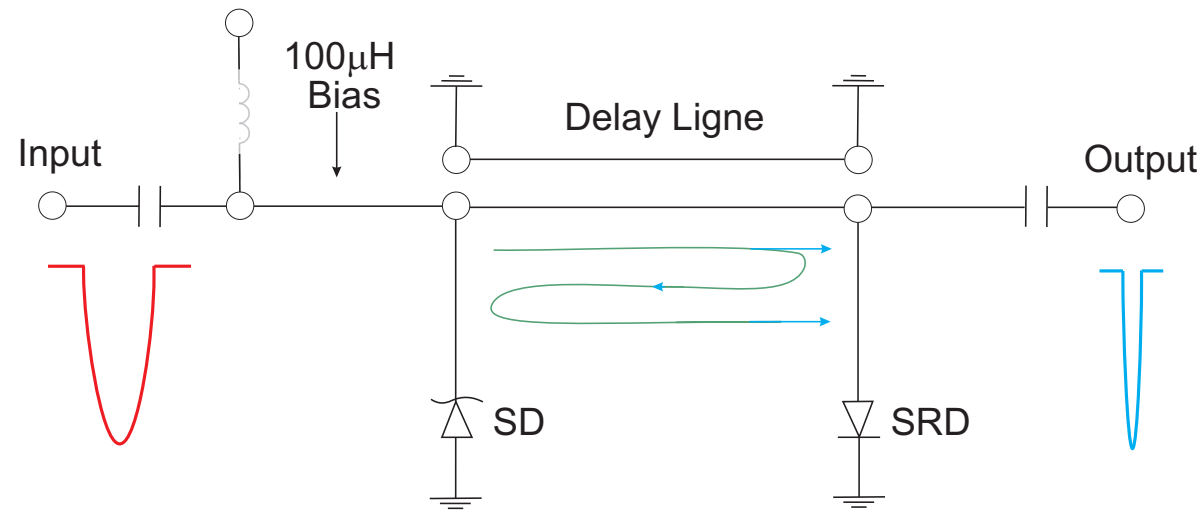

Figure 3.18: operating mode of SRD pulse sharping circuit.

The $S R D s$ has a crucial role in our generator circuits; ever since the computer simulation of an $S R D$ is a challenging question. This challenge consists significantly of the difference between the $S R D$ and the classical $P N$ junction.

In the conventional time-domain Simulators like AWR Microwave office, ADS and Multisim; an advanced $S R D$ models are not yet implemented. In addition, the simulation of this diode on the Spice simulator provides always incorrect results.

To face the challenge described above, a new model of $S R D$ has been proposed. The choice of this model was decided after studying many models existing in the literature. One of the advantages of this model is to increase the rise-time. figure.3.19 shows the elected voltage-switch model of $S R D$ and its corresponding equivalent circuit. Where $R_{s}$ and $C_{j}$ are the nonlinear impedance capacitance respectively, while $L_{s}$ and $C_{p}$ represent the parasitic parameters of the $S R D$ com- 
ponent.

After many measurements, we have concluded that the diode $M A 44769-287 T$ of $M / A-C O M$ Corporation was the nearest one to our requirements in term of output waveform performance.

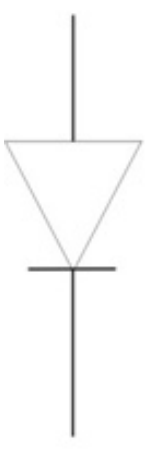

(a)

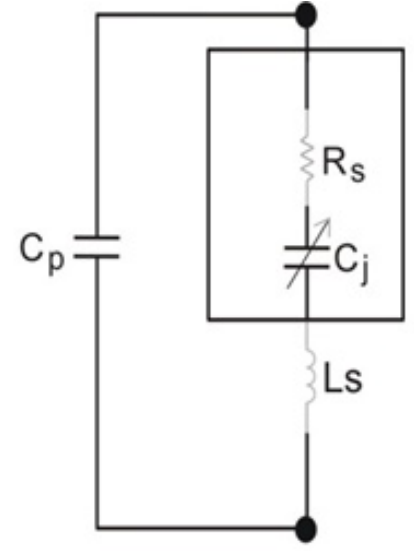

(b)

Figure 3.19: (a): SRD of AWR Microwave Office. (b): New model of a step recovery diode (SRD).

Then a basic $S R D$ model proportionate by $A W R$ simulator has been implemented with the parameters adopted from the datasheet of the diode $M A 44769-$ 287T. The simulations were realized with the HSPICE transient simulator included in the $A W R$ Microwave Office design suite. We have noted that the elected Diode has a reverse capacitance of $1 \mathrm{pF}$, a minority-carrier lifetime of $10 \mathrm{~ns}$, a minimum transition time of $150 \mathrm{ps}$, a reverse breakdown voltage of $30 \mathrm{~V}$, forward bias current $50 \mathrm{~mA}$ and a $S O D 323$ package. The behavior of the $M A 44769-287 T$ diode is shown in figure.3.21.

The simulation results are shown in figure.3.20. figure.3.17-a corresponding to the output waveform with the usual $S R D$ proposed by the AWR Microwave Office design suite. While the output waveform in figure.3.20-b has been generated when the $S R D$ model described below was applied. The $S R D$ in both results was connected at the input of the microstrip with a $10 \mathrm{~mm}$ in the delay line and $90 \Omega$ a characteristic impedance. The connection of the $S R D$ at the length of the delay line was chosen with the aim to get the highest possible output amplitude. The generated Gaussian pulses are $-6 \mathrm{~V}$ in amplitude and approx. 180psFW HM (FullWidth at Half Maximum) in width.

It is clearly seen in figure.3.20, the great difference between the output wave- 
(a)

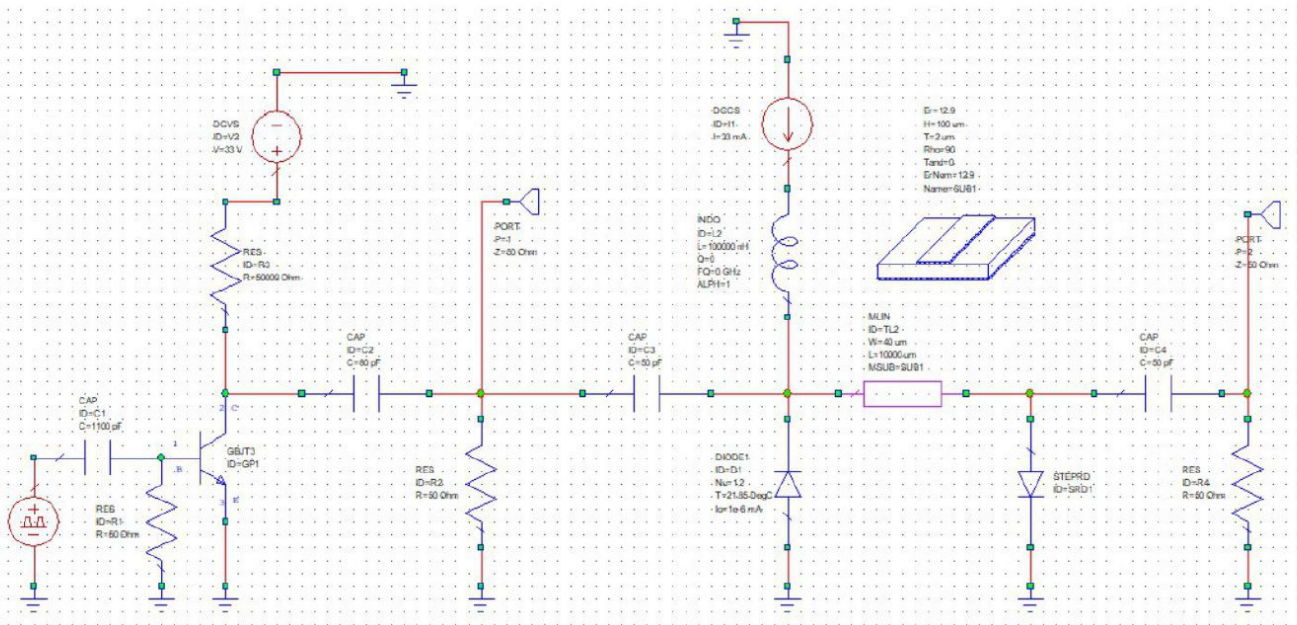

(b)
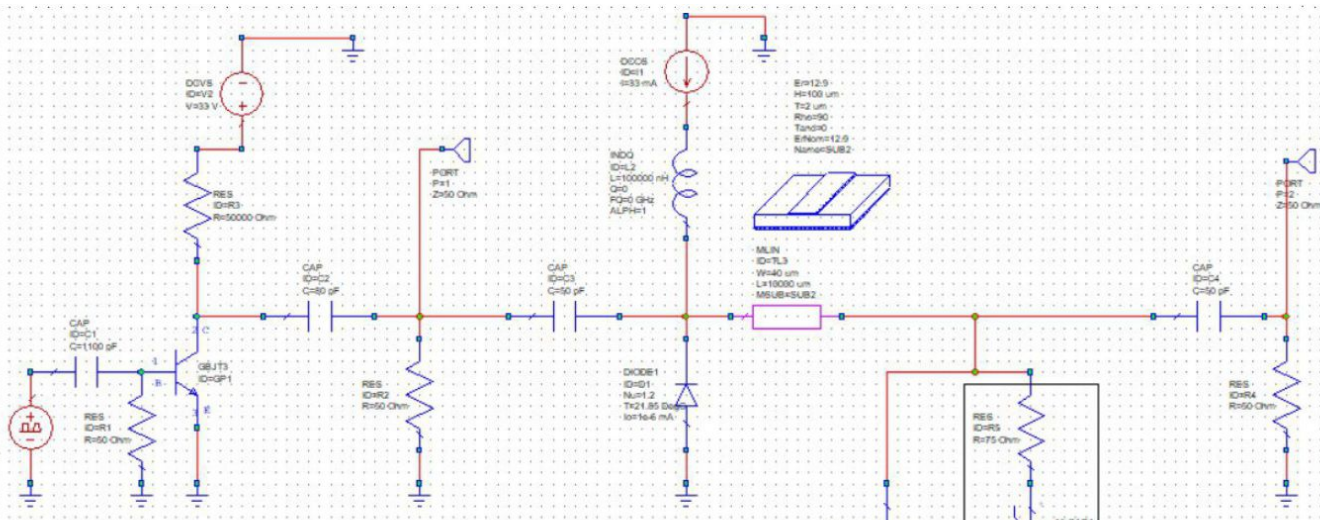

form of the circuit before and after inserting the new model of $S R D$. This differences consisting in remove the most ringing happen just after the descent of the pulse; that leads us to more understanding the great role played by the $S R D$ diode in the formation final of the Gaussian pulse. The generated Gaussian pulses are now $-6 \mathrm{~V}$ in amplitude with $3.5 \%$ in overshoot.

\subsubsection{MFN: Monocycle Forming Network}

The third parts is the monocycle-forming network MFN. The principal aim of MFN is to convert the Gaussian pulse into a monocycle pulse. Normally, there are two kinds of networks implemented as an MFN: The transmission line and the RC differentiators. The both are carried out with a cascade connection at the output 

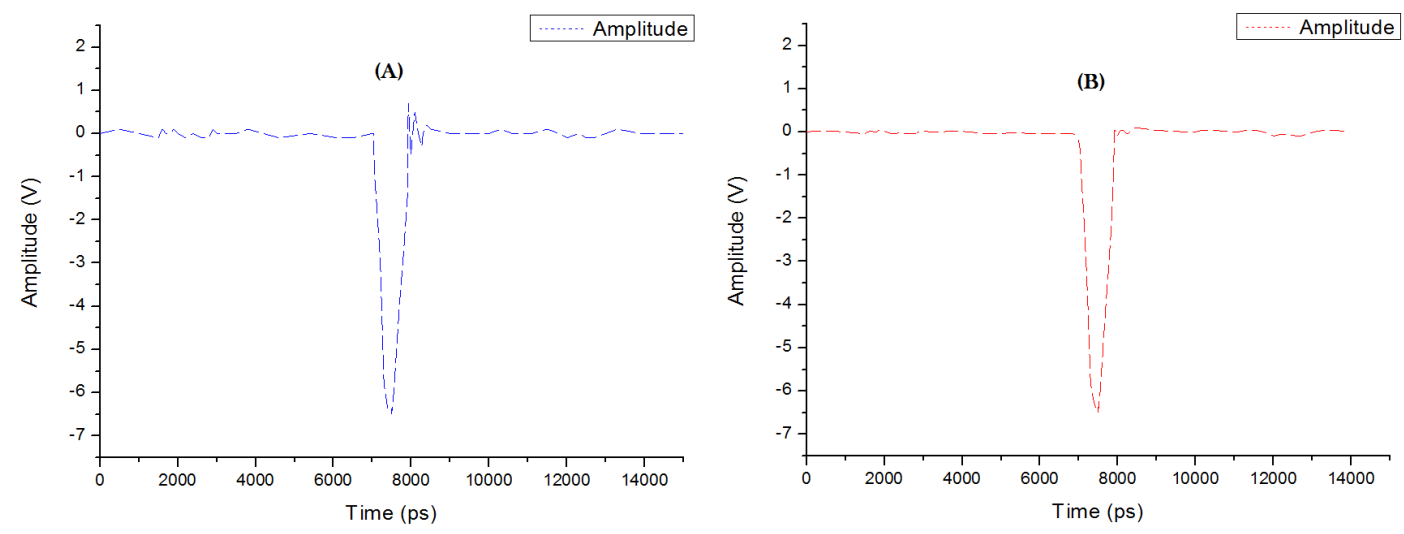

Figure 3.20: Output waveform before (a) and after (b) the application of new model of SRD respectively.

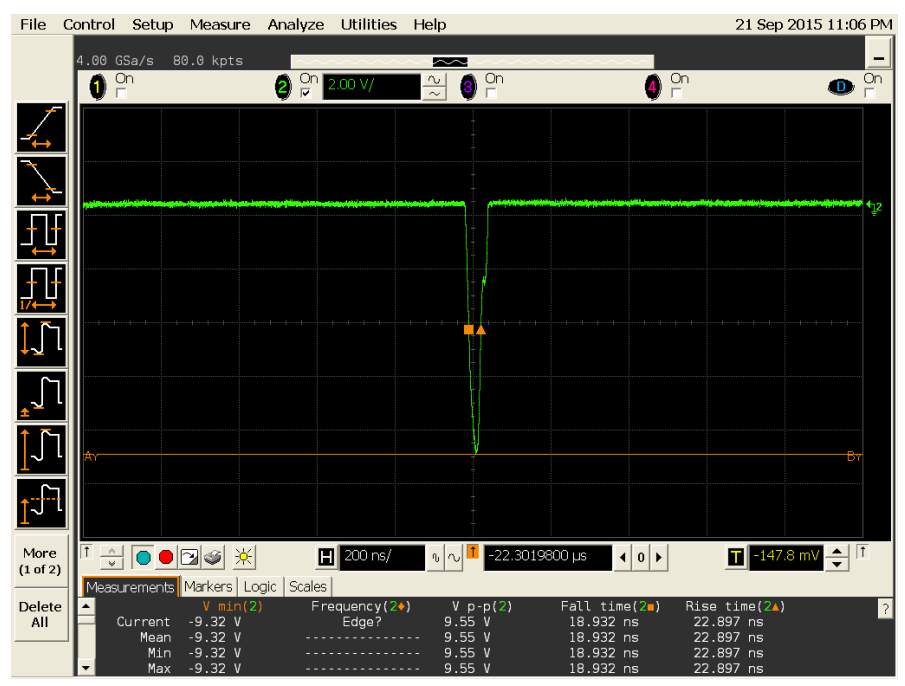

Figure 3.21: Output waveform Gaussian measured using SRD from MA44769$287 \mathrm{~T}$

of the SRD sharpener circuit [125], [126]. Unlike this tradition concept, this work adopts the transmission line network with a parallel connection; in this way, a good result has been obtained in term of falling edge sharpener.

In other hands, the MFN can be implemented as a lumped RC differentiator (figure. 3.22.b) or as a distributed transmission line pulse forming network (figure. 3.22.b). Both circuits include a Schottky diode to reduce output ringing, which is a consequence of multiple reflections between the pulser output and the monocycle forming network input. Fig.3.22 shows the variation Of the monocycle waveform with the length of the stub in the distributed form of the MFN.

In our design, we prefer the distributed structure, since the simulation presents 


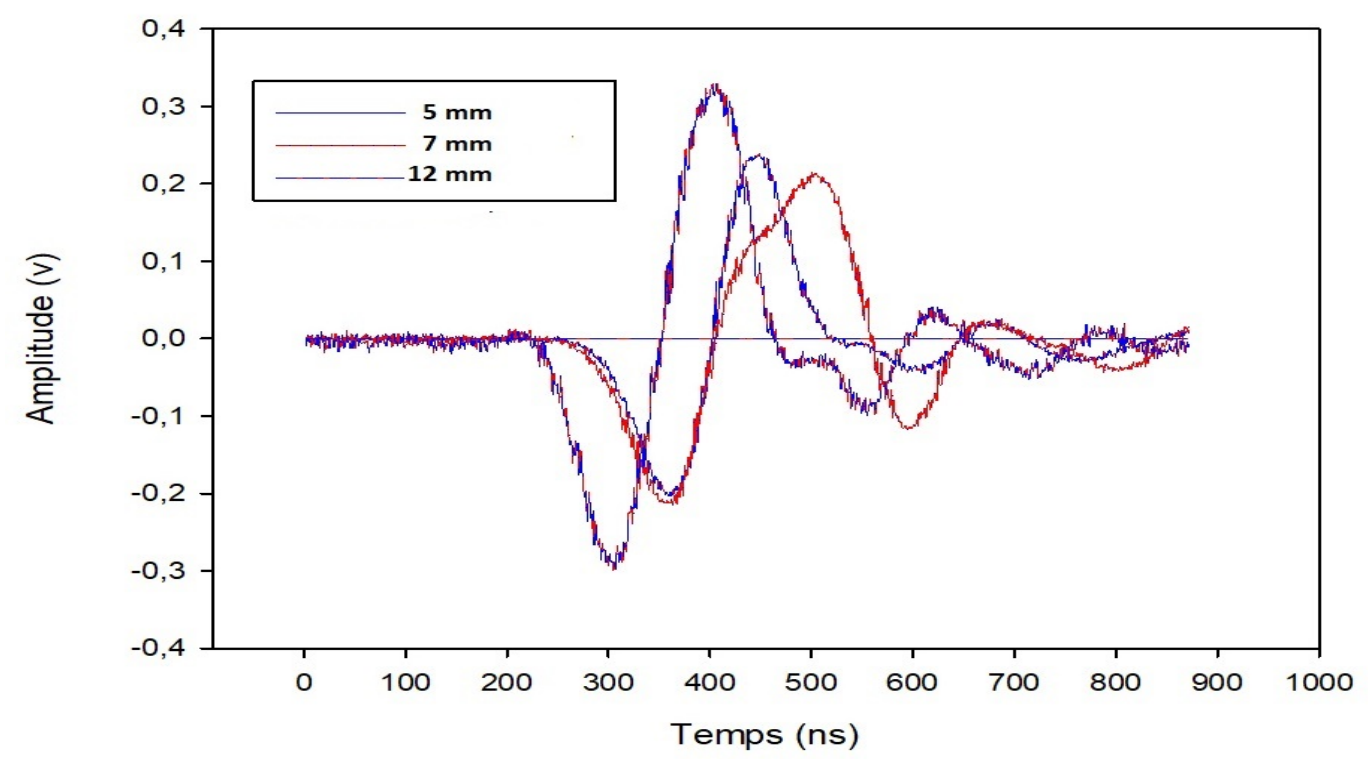

Figure 3.22: the variation Of the monocycle waveform with the length of the stub in the distributed form of the MFN

good results compared with the lumped differentiator : a higher output amplitude, a lower ringing level and lower dependence on the pulse repetition frequency. However, the distributed structure generates wider pulse width monocycles than the lumped differentiator [141]. figure. 3.24 shows the fabricated monocycle forming network.

The AWR Microwave Office was used to design a layout of the network. The length of the shortened shunt-stub was optimized to $15 \mathrm{~mm}$ in order to generates a symmetrical monocycle with the maximum possible output amplitude. The impedance of all the microstrip lines is $50 \Omega$.

\subsection{The complete pulse generator}

The resulting circuit of the ultra-short pulse generator is shown in figure.3.25 in mode separated; E.g, each part is connected to the next one, while the figure.3.26, shows the photo of the compacted design of the Ultra-short pulse generator. The pulse generator circuit was realized in microstrip technique using RO4003C Substrate with dielectric permitivity of 3.38, dielectric substrate thickness of $0.81 \mathrm{~mm}$, and conductivity thickness of some um.

A Hameg 8035 pulse generator delivered the trigger pulses with amplitude of $5 \mathrm{~V}$, pulse width of $50 \mathrm{~ns}$, and repetition frequency of $1 \mathrm{kHz}$ to trigger the avalanche transistor. The waveform of the output pulses have been measured with $12 \mathrm{Ghz}$ 


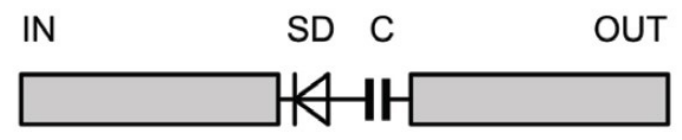

a)

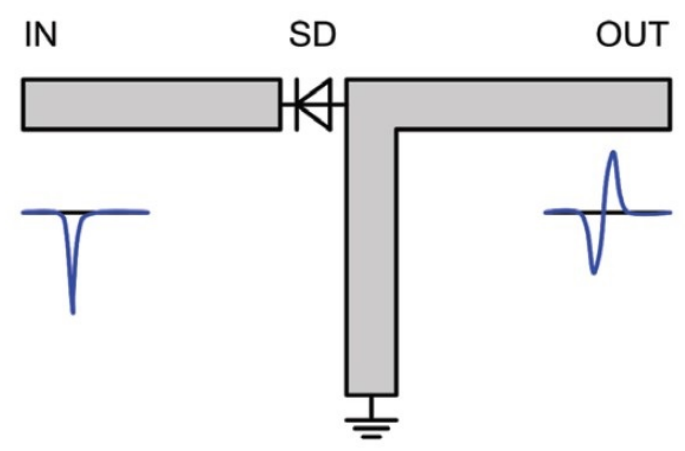

b)

Figure 3.23: (a) Lumped and (b) distributed monocycle forming network.

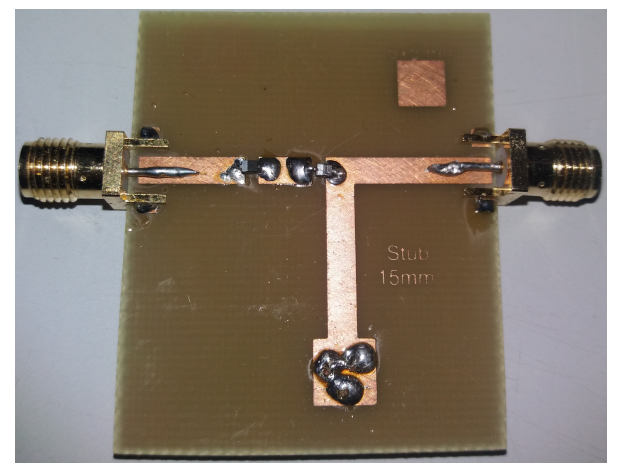

Figure 3.24: Fabricated monocycle forming network.

sampling oscilloscope Agilent 86100C type with 50 ohm input impedance manufactured by agilent.

Two DC Power supply sources were used to bias the step recovery diodes. The bias current of each source was set $90 \mathrm{~mA}$ during the measurement. A personal picture with all instrument used in the measurement during this work in Dimas laboratory of ITACA Institut is shown in figure 3.25.

The simulated output waveform of the proposed network is plotted in figure. 3.27. The full width at Half-maximum of these monocycles is 420 ps. While, the resulted waveform of the output monocycle pulse generator is shown in figure.3.27, as it can be observed, good results of the output waveform are obtained in term of amplitude and fall-time. The full width at Half-Maximum of these monocycles is 440 ps.

A good agreement between the simulated and measured results has been achieved, 

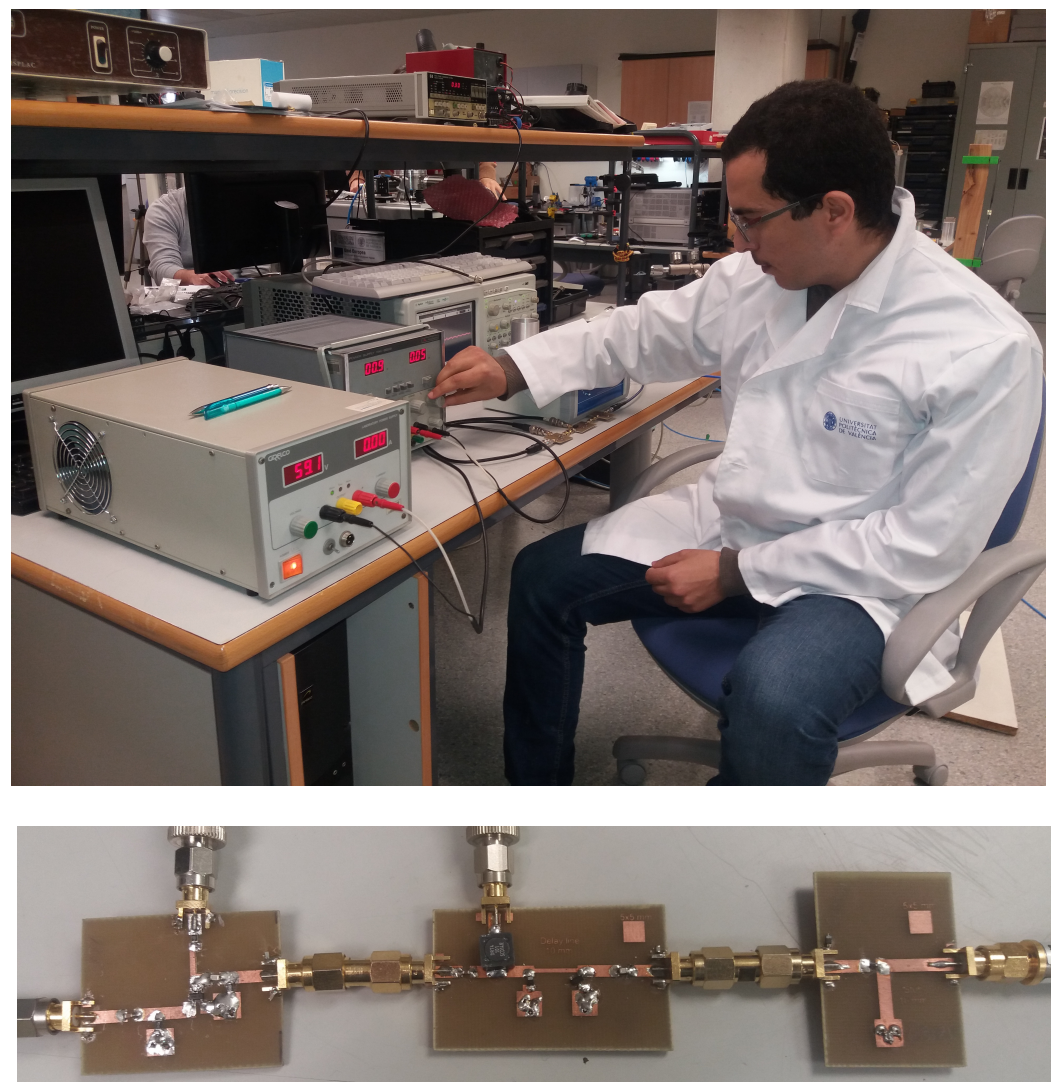

Figure 3.25: A personal picture at Dimas laboratory of ITACA Institut, and the Photo of the separated Ultra-short pulse generator.

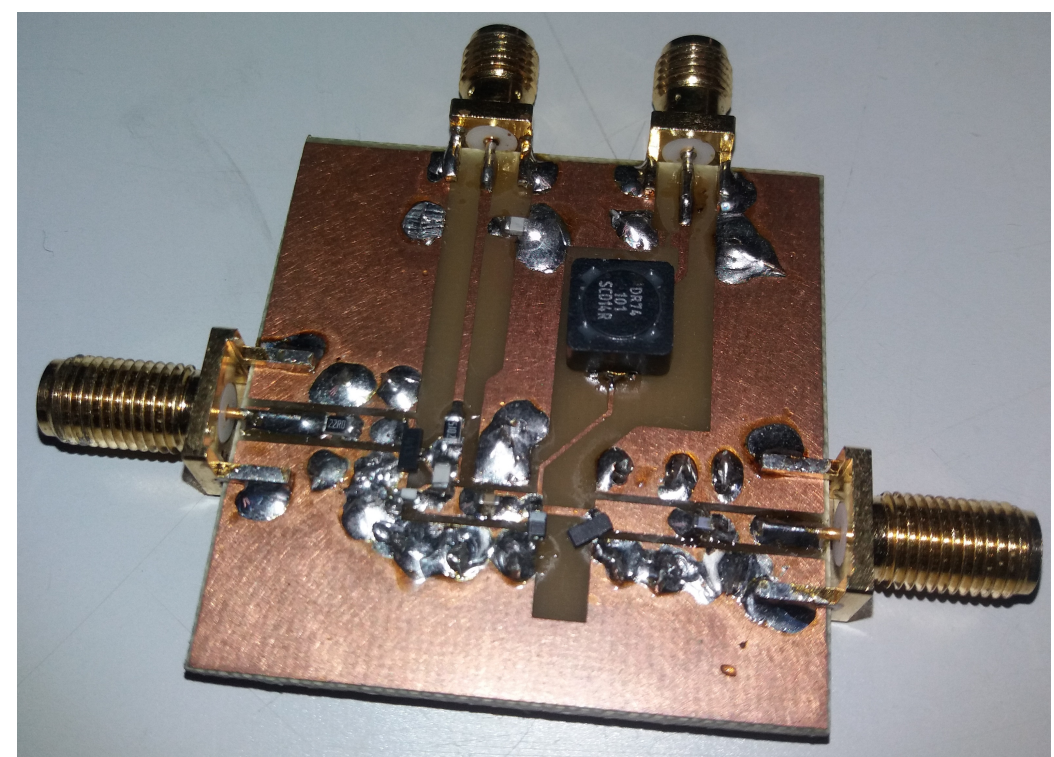

Figure 3.26: Photo of the compacted Ultra-short pulse generator.

which make this pulse generator a very attractive solution for many UWB radar sensor 

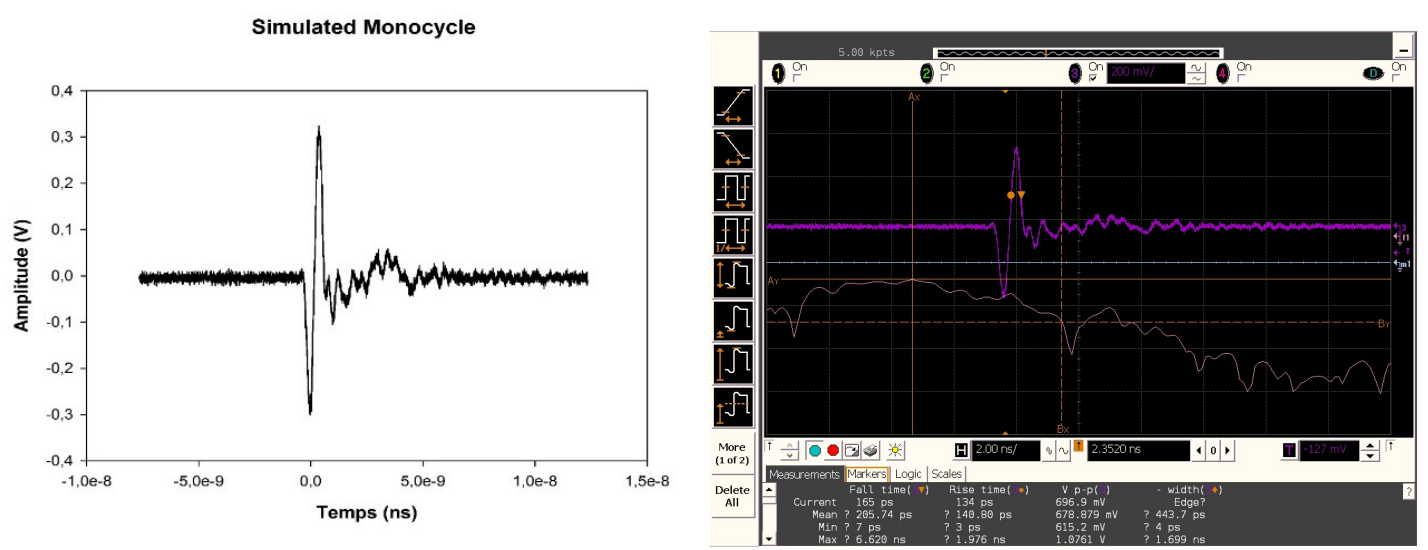

Figure 3.27: Simulated and measured results of the monocycle pulse generator..

Finally, and in order to verify the impact of the frequency, we have made two kinds of Filter (Low pass filter and High pass filer) after the monocycle pulse generated. Fig.3.23 shows the different impact of each one.
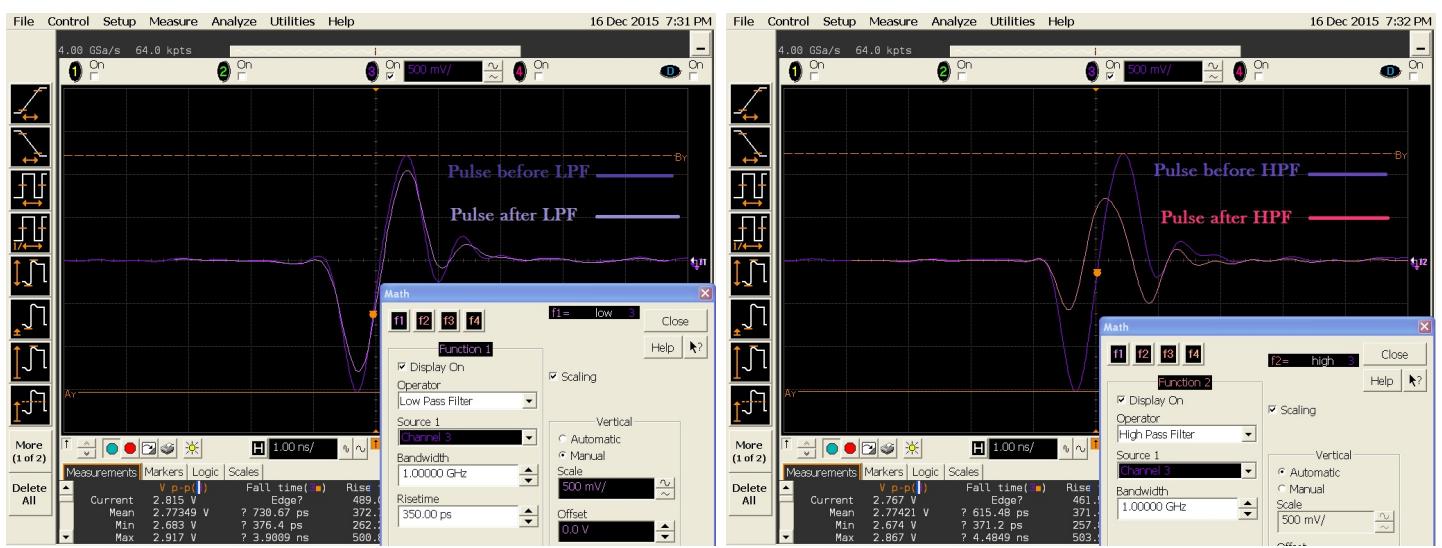

Figure 3.28: monocycle pulse with impact of LPF and HPF..

This measurement shows clearly the great impact of low frequency in the configuration of the output waveform pulse. Therefor, an antenna of a ultra wideband begging from low frequencies ( $a$ tens og $\mathrm{MHz}$ ) is required. 


\subsection{Conclusion}

In this chapter, a sub-nanosecond pulse generator for UWB radar sensor has been presented. The transistor driver and transmission line pulse have been investigated in detail. The principal aim was to transform a square waveform signal to a driving pulse with the timing and the amplitude parameters required by the $S R D$ to form an output Gaussian pulse and then to transform it into a monocycle pulse. Two useful techniques have been proposed to eliminate the ringing of the pulse, the first one consists of shorting the discharge pathway as much as possible, while the second one consists of proposing a new model of the $S R D$ step recovery diode. The pulse transmitter circuit is completely fabricated using micro-strip structure technology characteristics, which has the characteristic of low-cost, compact and small size. Waveforms of the generated monocycle pulses over $10 \mathrm{~V}$ in amplitude with $3.5 \%$ in overshoot have been obtained. With an additional output $M F N$, the monocycle pulses have a 9V in amplitude and 600 ps in total width. The high agreements between simulated and measurement results show a very high performance of the designed systems. The high power, low cost, and compactness of this monocycle generator make this system very attractive and useful tool for many NDT applications. However, increasing the pulse in amplitude e.,g getting a high power pulse is always desirable for some applications; in this way, the main objective of the next chapter, will be concentrated on the study and the possibilities to achieve this purpose. For this reason, the next chapter will presents and studies the different way to achieve this purpose. 


\section{High power pulse generator for UWB \\ Radar Sensor}

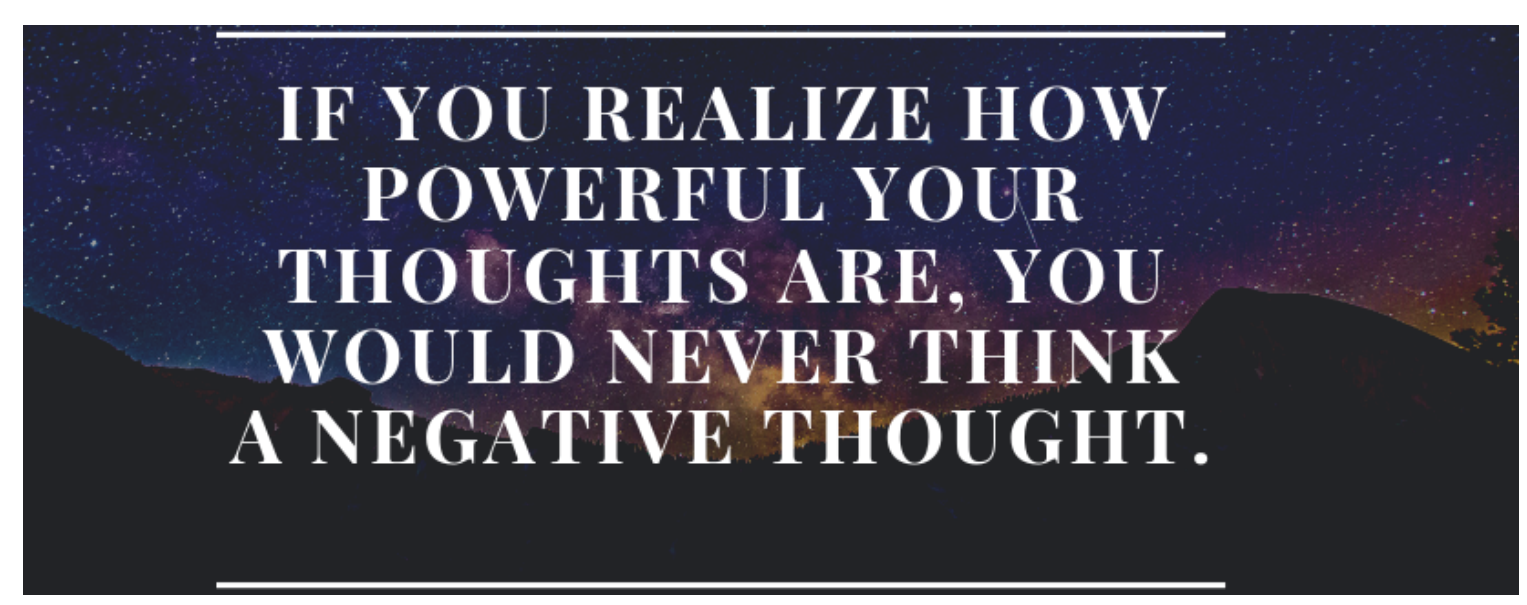

Spiritual teacher 1908-1981.

Peace Pilgrim

In this chapter, a high power sub-nanosecond pulse generator for Ultra-wideband radar sensor is presented. Two techniques are proposed and presented in details to fulfill the desired results. 


\subsection{Introduction}

Tor a good and long-range UWB radar sensor, a high amplitude pulse is much

1 desired and sometimes indispensable, especially when it comes to penetrating the thick lossy material. However, high power $U W B$ pulse generators are expensive and are in most cases not compatible with the modern planar technology. In order to overcome this challenge, two useful techniques with approval and solutions are proposed to increase the output amplitude of the transmitter. These techniques consist firstly to connect the outputs of two identical pulse generators in parallel respecting the restrictions required. The second proposition consists of new design proposition called TWO - STAGE of UWB radar sensor. The pulse transmitter circuit is completely fabricated using micro-strip structure technology characteristics. The waveform of the generated monocycle pulses has a high amplitude with a minimum of ringing. Good agreement has been achieved between measurement and simulation results.

\subsection{High power Monocycle pulse transmitter design}

\subsubsection{Combining two identical pulse generators}

There are many ways to increase the output power. One of them is to combine the output waveforms from two or more sources. Nevertheless, combining ultrawideband Gaussian pulses is a difficult task. The conventional power combining structures, e.g. Wilkinson power divider, are basically narrowband and distort $U W B$ waveforms; In addition, applying a short $U W B$ pulse results in unwished reflections and ringing at other ports. Some dividers/combiners using planar multilayer techniques have also been described in the literature [142], [143]. Regrettably those dividers/combiners show proper $U W B$ performance, but unfortunately are suitable primarily for the higher $U W B$ band ranging between (3.1-10.6) GHz. The goal of our proposition design is to obtain a powerful waveform with a minimum insertion loss. This requirement is well achieved using a Mini-circuit called power splitter ZN2PD2 which works in the band ranging from 0.5 to $5 \mathrm{GHz}$. Figure 4.1 shows the photo of the Mini-circuit power Splitter ZN2PD2. The equivalent circuit of this $Z N 2 P D 2$ power splitter was designed in Dimas laboratory at IT ACA institute in University Polytechnic of Valencia. 


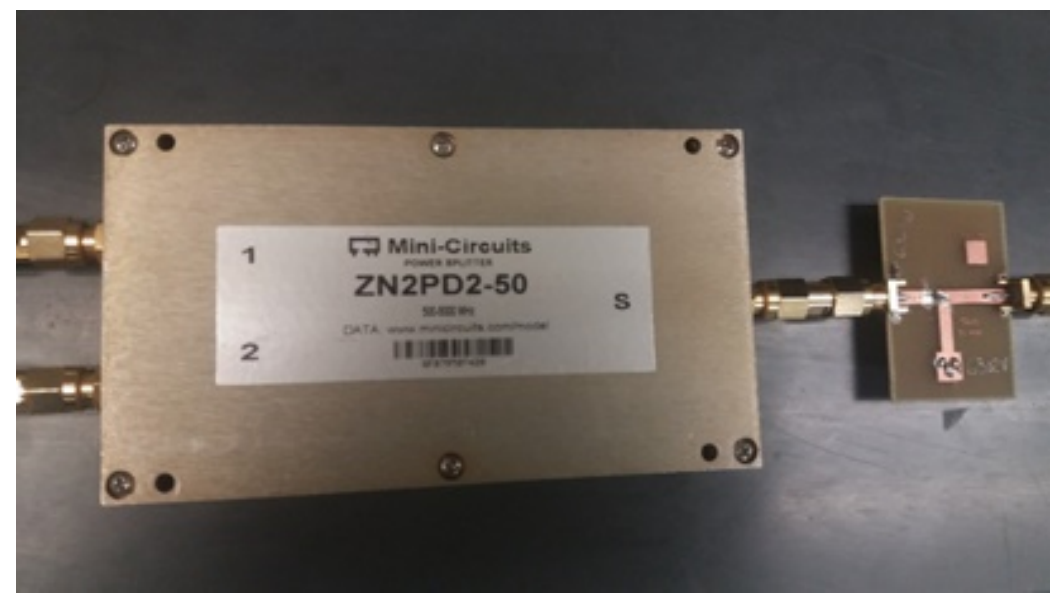

Figure 4.1: Photo of the Mini-circuit power splitter ZN2PD2.

A block diagram of the proposed high power monocycle pulse transmitter is shown in Fig.4.2. The transmitter consists of two $S R D$ pulse sharping circuit connected in parallel after the avalanche transistor circuits. Both sharpening circuit are synchronized and trigged by one timing source. The outputs of two identical pulse generators are combined in order to obtain higher output pulse in amplitude.

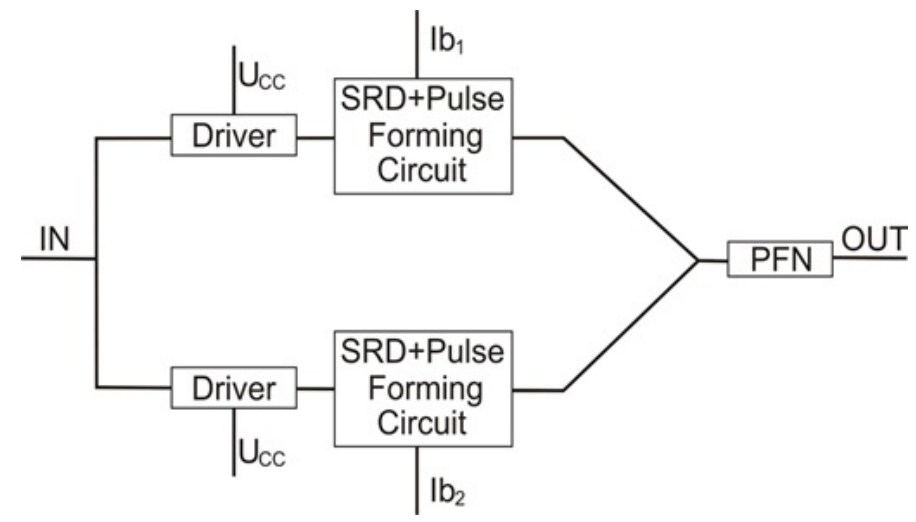

Figure 4.2: Block diagram of the proposed Radar pulses transmitter.

As it is mentioned in a previous chapter, the monocycle pulses are a special interest because their spectrum does not contain low-frequency components and the implementation of MFN is an easy task. For this reason, the Monocycle Forming Network $(M F N)$ was connected in the output of the transmitter in order to form the monocycle pulses.

The photo of the proposed powerful compound monocycle pulse transmitter is shown in Fig.4.3. It is made up of five parts, an avalanche transistor circuit, the splitter divider $E C @ D V P$ which divide the Gaussian waveform generated by the transistor avalanche into identical one, Two $S R D$ pulse sharpening circuit connected in parallel, The power splitter $Z N 2 P D 2$, and an $M F N$. 
To test all functionality of the whole system, we collected two identical pulse generators on a single board. In order to obtain the sum of the pulses without any disturbance, it's important that both generators provide an output pulse exactly at the same time. The pulse amplitude is now over $10 \mathrm{~V}$ compared with $4.8 \mathrm{~V}$ of a single Gaussian pulse generator. The pulse peak power has getting to $1.5 \mathrm{~W}$, which is quasi the double of a stand-alone pulse generator.

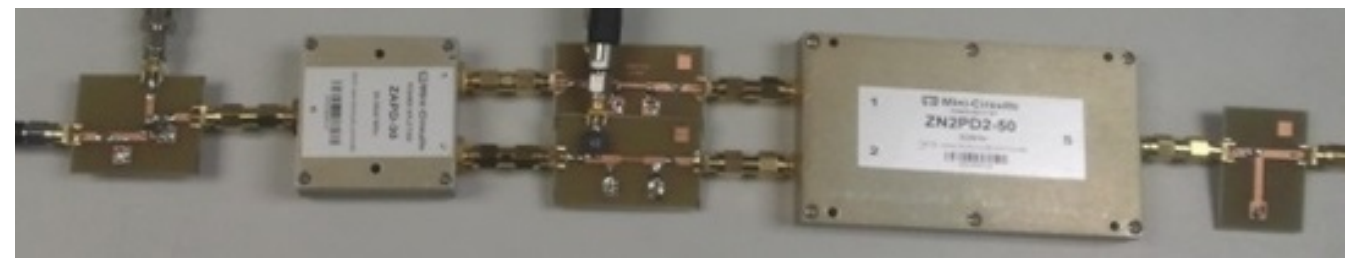

Figure 4.3: Photo of the proposed Radar Transmitter.

The result output waveform for this designed transmitter pulses proposed is plotted in Fig.4.4.

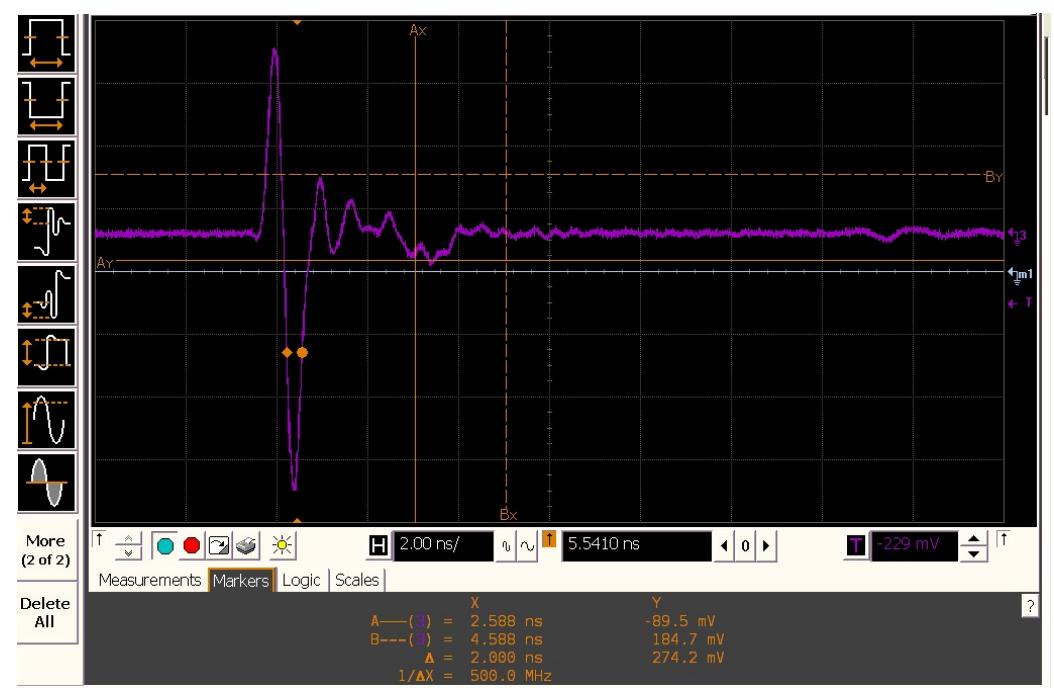

Figure 4.4: Output waveform of the proposed radar transmitter.

More improvement on the signal reception and better use of data at the reception can be taken out with a developed signal processing, but this not the principal aim of this chapter. Our purpose was to report the hardware development and to demonstrate the workability of this system.

\subsubsection{TWO STAGE of the pulse generators}

In some applications in industry application, such as detection in long-range distance or in fields with a lossy obstacle. A high amplitude pulses are much 
desired. However, high power UWB pulse generators are expensive and are in most cases not compatible with the modern planar technology. For this reason, a useful technique has been proposed to powerfully the output pulse. The proposed technique is described as follow:

Theoretically, the avalanche transistor circuit is triggered when a square wave having high voltage is added between the collector and emitter; this high voltage ensures and leads the transistor to operate in his critical state. Moreover, triggering the avalanche transistor could be implemented by an additional of over-voltage with short rising time between collector and emitter. In this thesis, we propose a circuit composed by two-stage, the voltage required to trigger the first stage, while the over-voltage will trigger the second one, see Figure. 4.5.
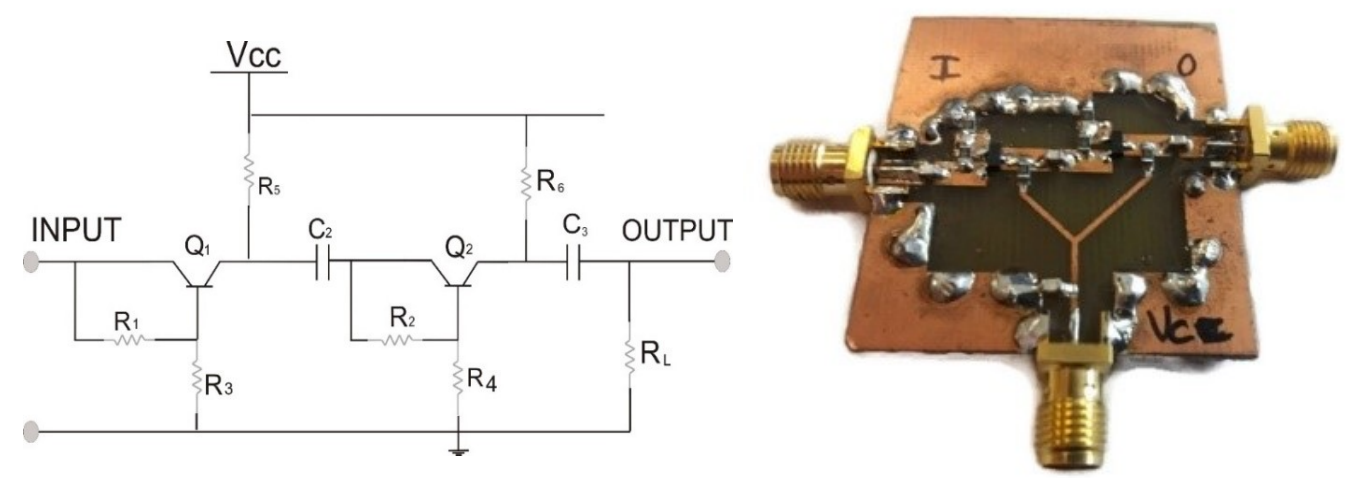

Figure 4.5: Circuit design and a photo of the two-stage generator based on avalanche transistor.

In the one-stage pulse generator described previously, a good performance of waveform pulse can be obtained by optimizing the charging capacitor C2, supply voltage VCC, and isolating resistor RL.

For the purpose to trigger a two-stage transistor circuit, some technical specification is required. To fulfill this task, first a powerful square wave was triggered forward the input of the circuit, and then the charging capacitor must be optimized to generate the suitable pulse: these specifications are indispensable to make the effect avalanche in the developed two-stage transistor circuit.

In a steady state, e.g., without triggering, the transistor operates in a critical state, and the capacitors (C2, C3) are charged by the DC power supply. However, when the powerful square has been triggered, the transistor Q1 will be excited under the voltage required, and Q2 will also be excited under the over-voltage. One important challenge in this circuit configuration is to reduce the breakdown voltage of the first transistor, for the sake of the second transistor works under full 
avalanche effect. To face this task, the Rbe Value must be increased. On another hand, the simulation results show that the output performance can be improved by optimizing the charging capacitors. The amplitude and pulse width for different charging value is showing in tables 4.1. it is clear to see that, the small charging capacitance generate a narrow pulse width and a reduced pulse amplitude. The first one is due to the short time discharge of the capacitance, while the second result is due to the fewer stored energy in the capacitor.

An alternative to this paradox is to choose the medium charging capacitor value. Nevertheless, some technical limitation is presented when the capacitance decrease under the threshold.

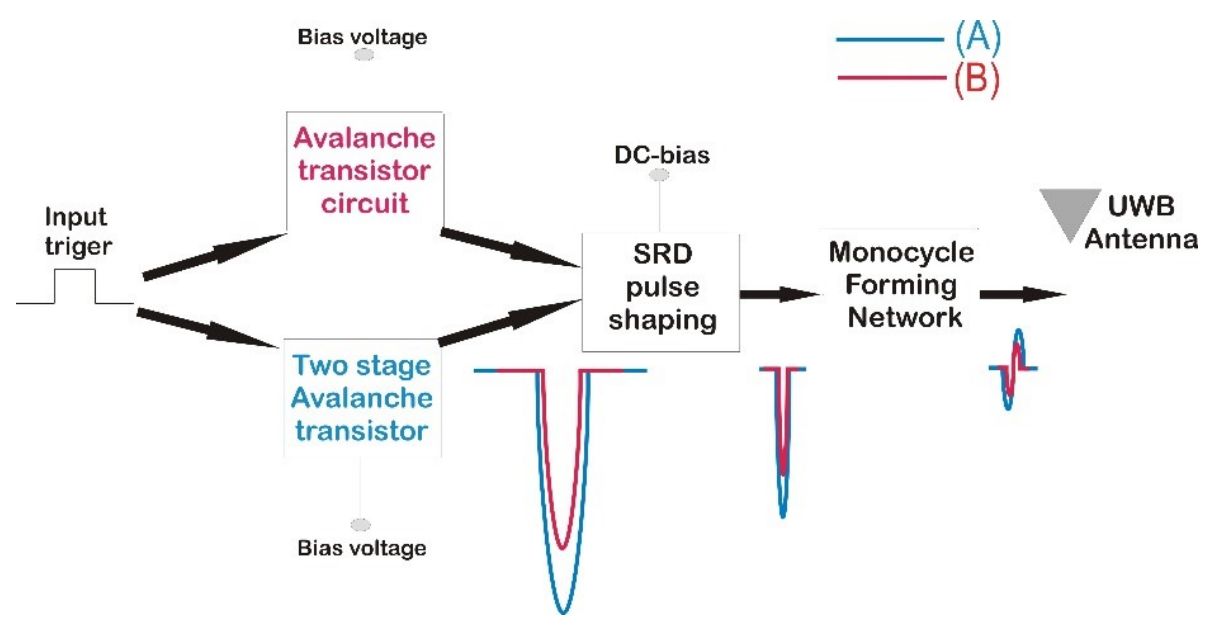

Figure 4.6: Output waveform of the proposed radar transmitter.

Table 4.1: Output pulse parameters for diferent charging capacitor values.

\begin{tabular}{|c|c|c|c|c|}
\hline Charging capacitor value (pF) & 100 & 33 & 15 & 8.2 \\
\hline Pulse amplitude (mV) & 9.8 & 6.1 & 4.3 & 2.3 \\
\hline Pulse width (ps) & 1453 & 932 & 541 & 440 \\
\hline
\end{tabular}

To resolve this issue, the RL must be optimized. Therefore, another measurement has been implemented to demonstrate the efficiency of RL optimizing technique. For this reason, the charging capacitance was fixed at $8.2 \mathrm{pf}$, and the resistance of RL was ranged from $10 \Omega$ to $100 \Omega$. The output pulses parameters for different RL value has been summarized in Table 4.2.

From the table 4.2, the pulse amplitude increase when $\mathrm{RL}$ is increased, however, the pulse width is practically still constant. The results of the proposed two- 
Table 4.2: Output pulse parameter for different RL values.

\begin{tabular}{|c|c|c|c|c|c|}
\hline $\mathrm{RL} \Omega$ & 10 & 20 & 30 & 50 & 100 \\
\hline Pulse Amplitude (V) & 0.97 & 1.38 & 1.59 & 2.4 & 3.7 \\
\hline Pulse Width (ps) & 481.62 & 480.12 & 48.82 & 440 & 479.48 \\
\hline
\end{tabular}

stage high power monocycle pulse generator are showing in Figure. 4.7. The output performance of this proposed circuit design is $2.3 \mathrm{~V}$ in amplitude and 170 ps in rising time.

In all the experiments, the Pulse repetition frequency was fixed at $1 \mathrm{MHz}$, and the entire waveform at the output load resistor of $50 \Omega$ was measured by an Agilent oscilloscope with $1 \mathrm{GHz}$ sampling bandwidth and $4 \mathrm{Gs} / \mathrm{s}$ sampling rate via a 22 $\mathrm{Db}$ attenuation as can be seen in Figure.4.7

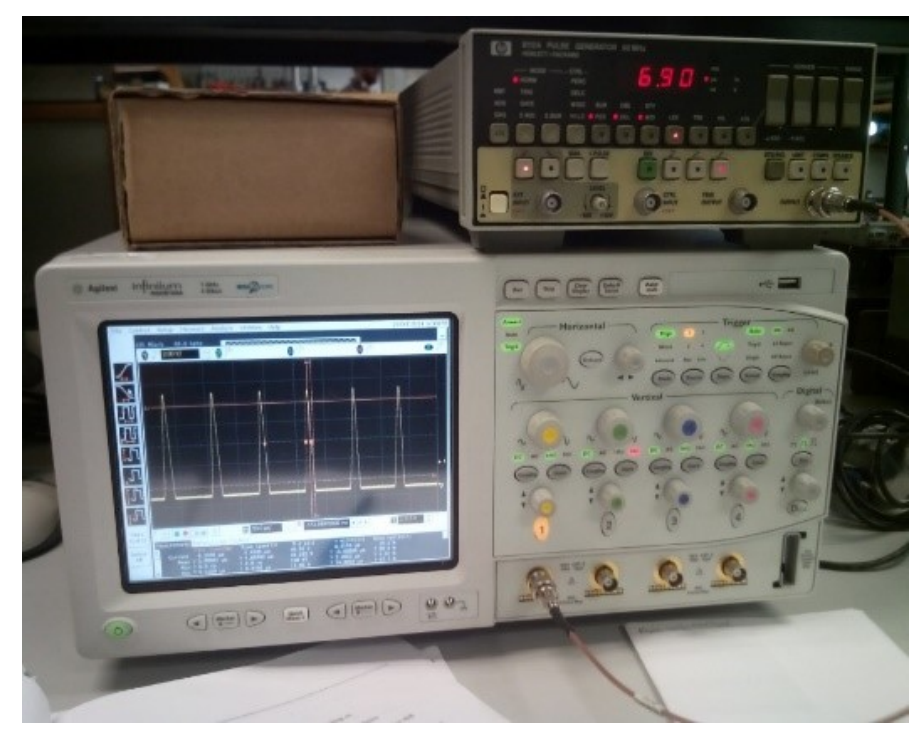

Figure 4.7: The photo of the function generator and the oscilloscope used in the all of the measurement.

With the aim to validate the performance of the designed high power monocycle pulse generator, some range distance measurement for lossy material at 2 and 3.2 meters have been implemented. In all measurements, the target chosen is a plate of Polyvinyl chloride (PVC). The results of the distance measurements are plotted in Fig 4.9. and Fig 4.10.

In both figures, two monocycle pulses can be distinguished clearly; the first one it is due to the coupling connection between the transmission antenna TX, 


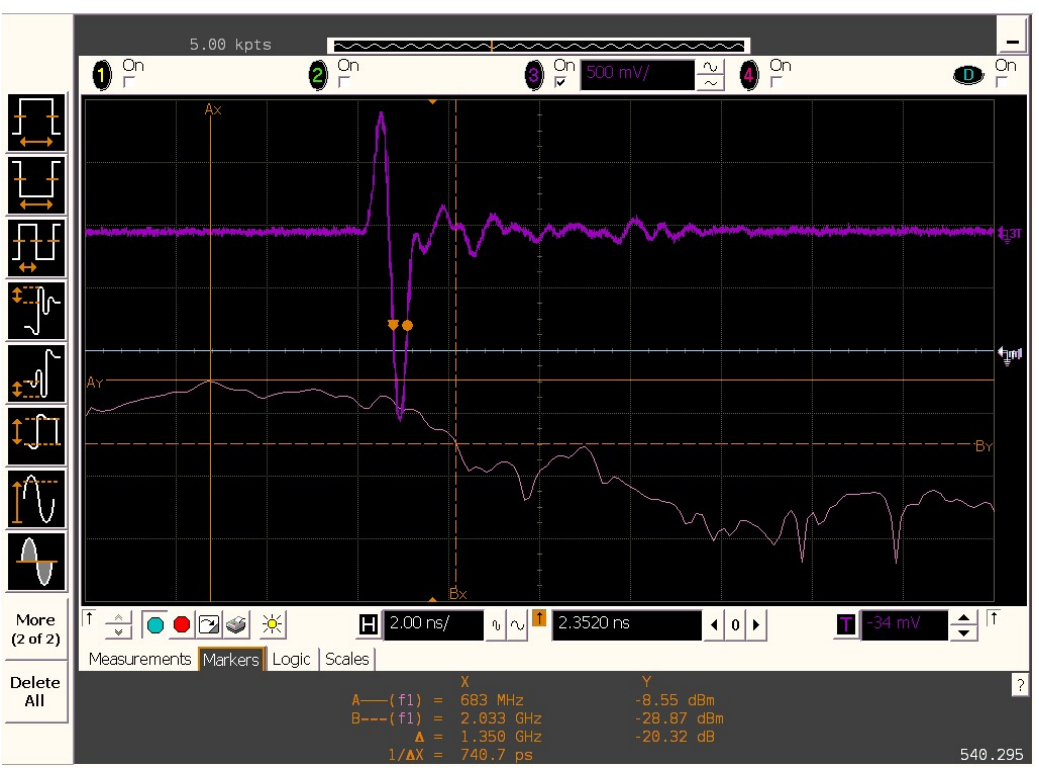

Figure 4.8: Results of the proposed high power monocycle pulse two stage generator.

and the reception antenna $\mathrm{Rx}$, while the second one it is a consequence of the reflection energy detected from the target. The position of the monocycle in the oscilloscope screen is proportional to the target position under test. The amplitude of the coupling connection detected is small than the monocycle generated, because the transmitting antenna Tx and receiving antenna was placed with an angular of 160 degree. The measurements described previously validate perfectly the performance of the high-power monocycle pulse generator circuit proposed in this work.
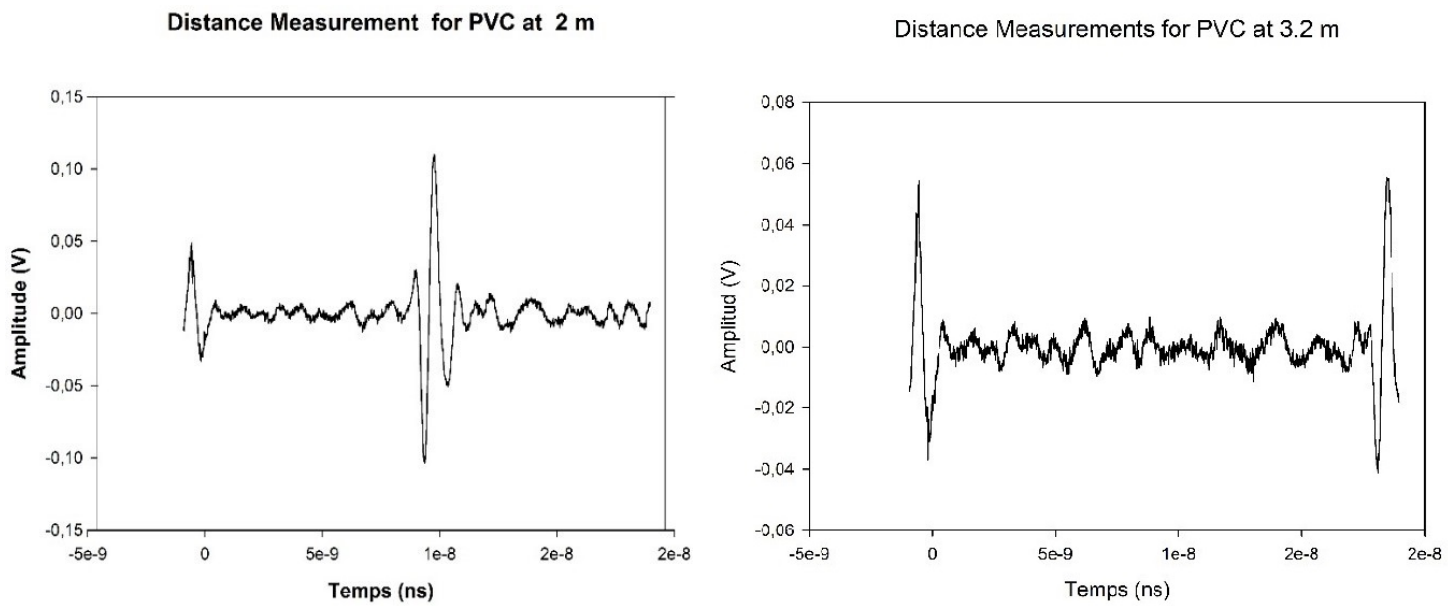

Figure 4.9: The distance measurements for the PVC placed at 3.25 meters. 


\subsection{Conclusions}

In this chapter, a high power sub-nanosecond pulse generator for Ultra-wideband radar sensor has been presented. Two useful techniques and solutions are introduced to increase the output amplitude of the pulse generator.

The pulse transmitter circuit is completely fabricated using micro-strip structure technology characteristics. the waveform of the generated monocycle pulses over give a high amplitude with a minimum of ringing have been obtained. Good agreement has been achieved between measurement and simulation results.

In the next chapter, two kind of measurements ; the range distance measurement and the electrical property of materials measurement, will be presented in order to validate the work-ability of the designed system. . 


\section{CHAPTER}

\section{System Integration and \\ Measurements}

\section{WELLNESS IS THE COMPETE INTEGRATION OF BODY, MIND, AND SPIRIT}

Canadian actor.

Greg Anderson

Wis chapter reports on the presents UWB radar sensor, and the measurements
of the range distance and electrical properties of some materials. The UWB Radar sensor used in this section consists of a high power ultrashort-monocyclepulse generator of $330 \mathrm{ps}$, an oscilloscope as an ultrawideband sampling receiver with a high wide band of $6 \mathrm{GHz}$, and two UWB antennas ranging from 0.4 to 6 GHz. 


\subsection{Introduction}

To validate the workability and the performance of the designed monocycle pulse described previously, some measurements have been made. In all experiment the designed monocycle pulse was triggered by a quadratic pulse generator, this trigger pulse has $5 \mathrm{~V}$ in amplitude and rise-time of $5 \mathrm{~ns}$. After that, the monocycle generated has been transmitted by a UWB TX antenna forward a target, and the reflected pulse was received by a UWB RX antenna. The result in the time domain has been shown on the screen of the oscilloscope. Finally, the control in real-time of the whole of experience has been made with a developed program in LabVIEW. The quadratic pulse generator used in this experience is the 8112A $50 \mathrm{MHz}$ Programmable Pulse Generator, while the oscilloscope is an Agilent Infiniium 8000 Series. The developed radar sensor was constructed in bi-static configuration. The measurement setup of the sensor is shown in Fig.5.1.

To respect the principles of electromagnetic compatibility and to avoid any parasitic signal between the transmitter $(\mathrm{Tx})$ and receiver $(\mathrm{Rx})$, the separation distance between them has been chosen at $25 \mathrm{~cm}$ for all measurements. All measurement has been carrying out in an anechoic chamber in which any disturbance of parasitic signals are avoided, and the distance of target was varied from 80 to $300 \mathrm{~cm}$. The full radar system provides good agreement between the experimental and the theoretical results, which demonstrate its application for many applications, especially for electrical Properties.

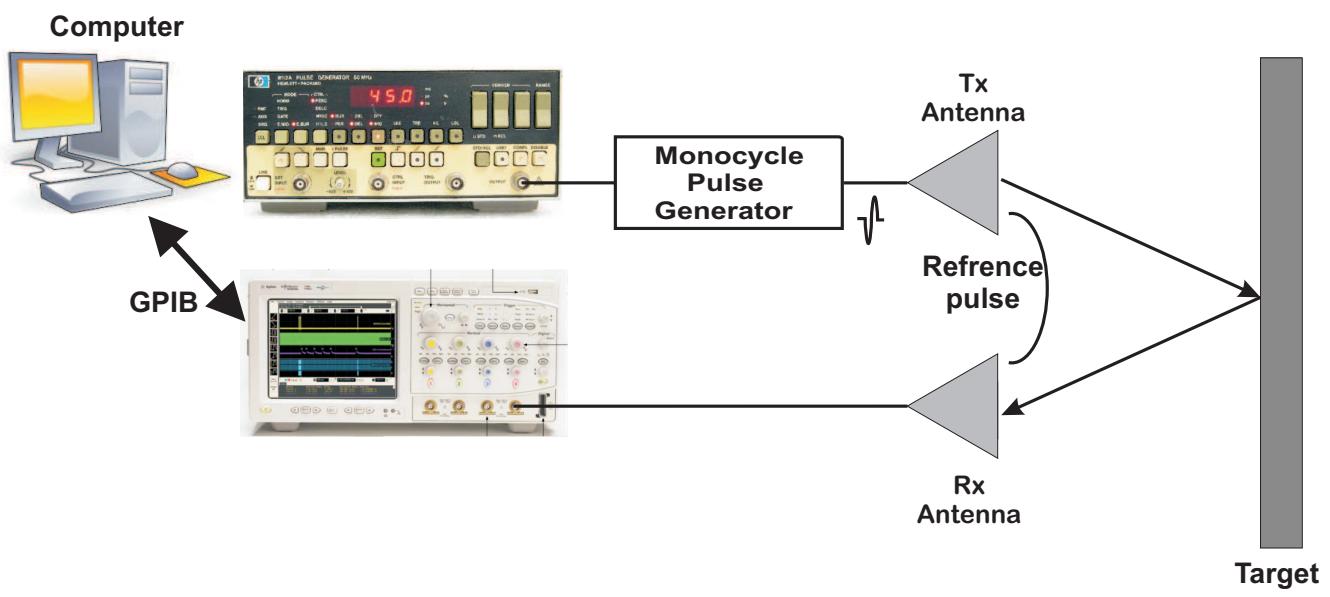

Figure 5.1: Diagram and setup of the whole system measurement. 


\subsection{Measurement of range distances.}

The designed system has been tested firstly for a distance measurement towards a horizontal perfect metal conductor; the choice of metal as a target has been used in order to get the maximum EM energy in the reception. The metal plate used in this experience has a width with a size of $30 \mathrm{~cm} \mathrm{x} 70 \mathrm{~cm} \mathrm{x} 3 \mathrm{~mm}$. The distance separating the target metal plate and the antennas have been ranged from $80 \mathrm{~cm}$ to $300 \mathrm{~cm}$. The measurements of the distance range have been made using the famous Time-of-Flight principle (ToF).

A high voltage pulses with an amplitude of $6.4 \mathrm{~V}$ at $50 \Omega$. Fig. 5.2 shows the antennas used in these measurements, are two UWB commercial antennas from RFSPACE Inc. The first one called TSA600-6000 is a PCB with a wide band from $0.6 \mathrm{GHz}$ to $6 \mathrm{GHz}$. While the second one it is called Tapered Slot Antenna is an aluminum with a wide band from $0.43 \mathrm{GHz}$ to $6 \mathrm{GHz}$. The two antennas have a linear polarization with excellent gain (10 dBi @ 2.4 Ghz, 11 dBi @ 4 Ghz and 12 dBi @ 6 Ghz) over the entire range, Low VSWR (600 - 6000 MHz < 2.0:1 Typ) over full range with no resonances, a clean impulse response, which make them very appropriate for our radar sensor applications.

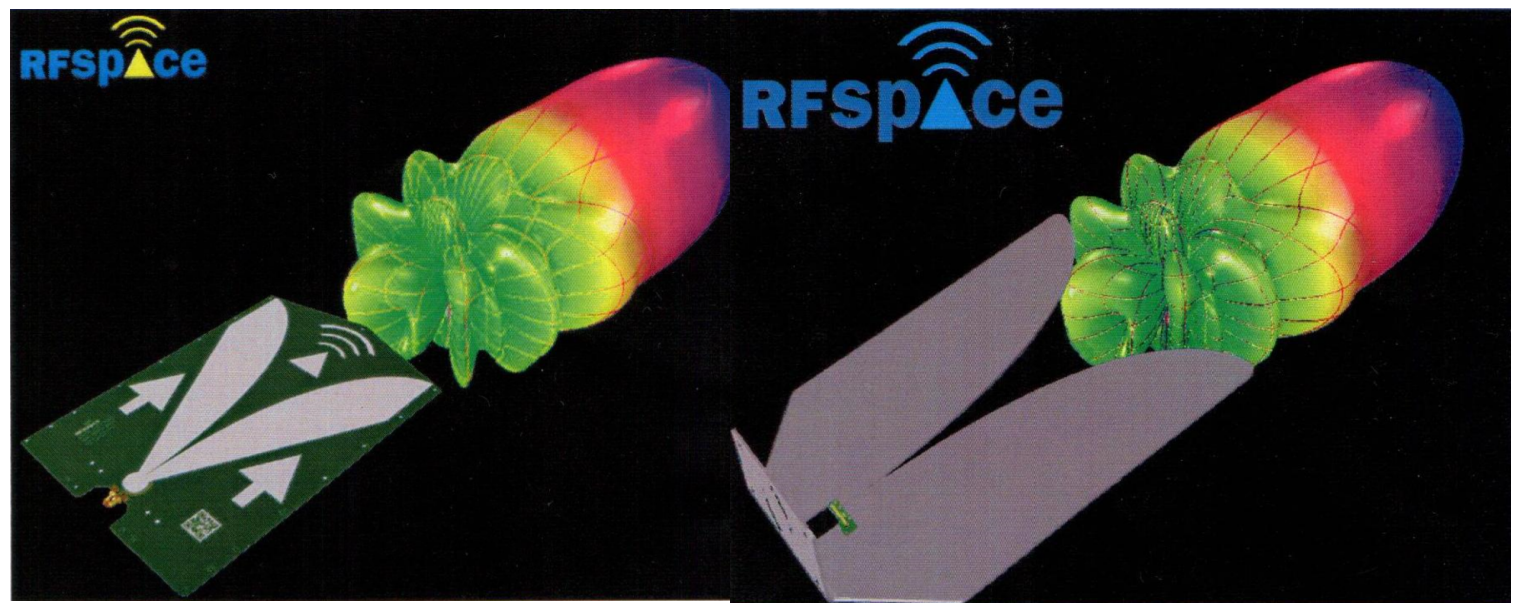

Figure 5.2: Photograph of the UWB antennas with the radiation pattern.

The distance of the target at 80, 180 and $300 \mathrm{~cm}$ has been fixed to compare the response of these two antennas used in the experience to confirm the performance operability of the designed system prototype. The measurements setup of the pulse radar sensor for the selected target distance is shown in Fig. 5.3, while the Time-domain response of the radar sensor measurement towards the metal plate is shown in Fig. 5.4. 


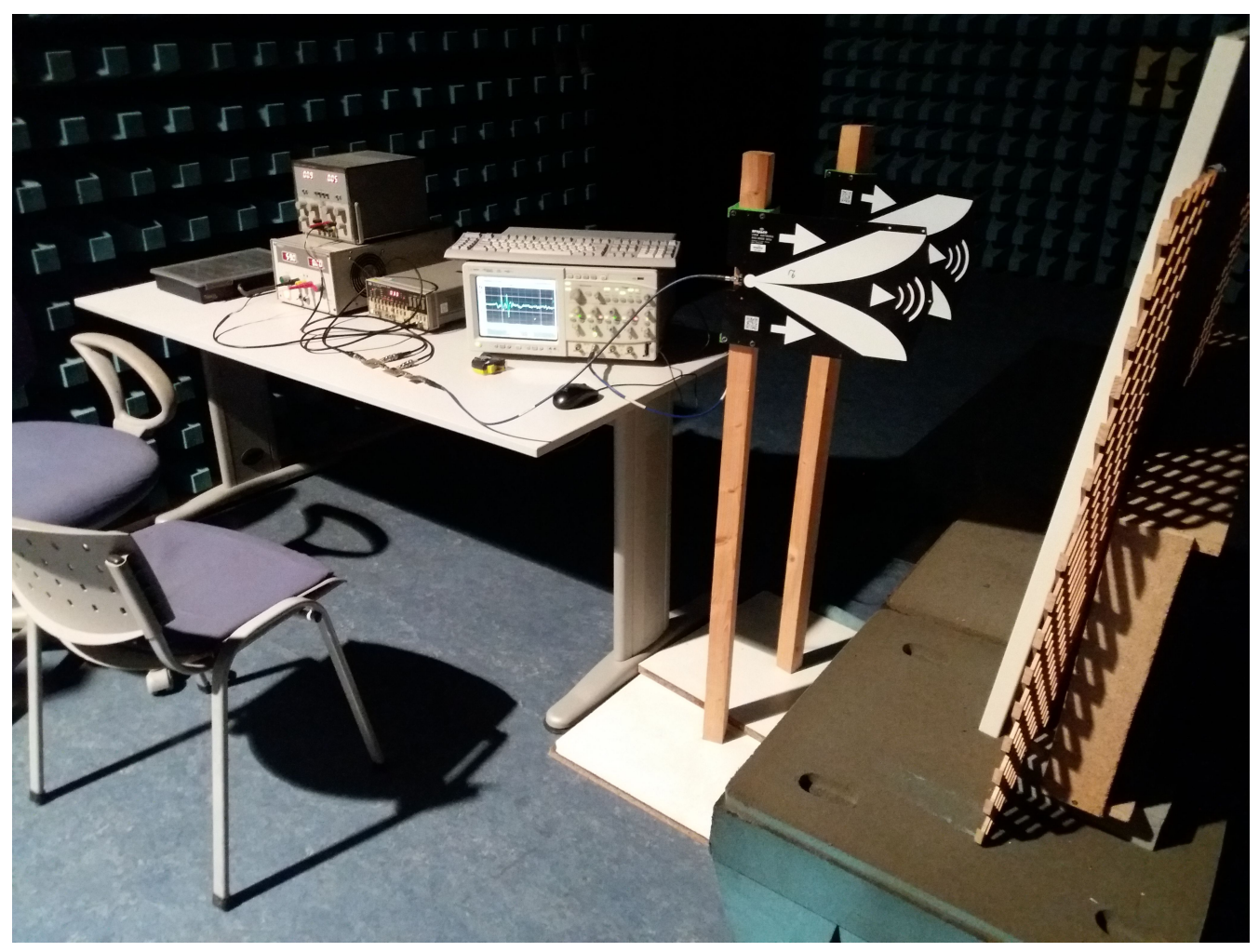

Figure 5.3: Photograph of measurement setup and a photograph of UWB impulse generator.
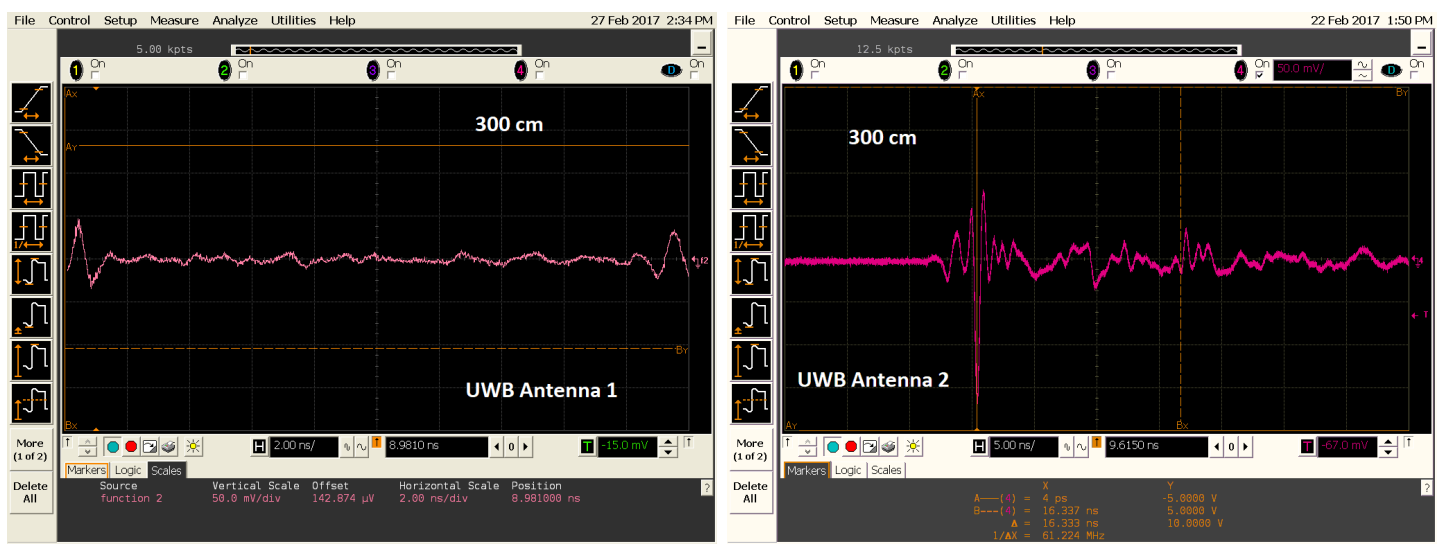

Figure 5.4: The time-domain response of the radar sensor measurement towards a metal plate located at $300 \mathrm{~cm}$.

We observe clearly from the behavior of the curve, the presence of the reference pulse and the reflected pulse from the object; the reflected pulse was accompanied with some unwanted peaks and some ringing, this unwanted ringing it occurred after the target return is received. 

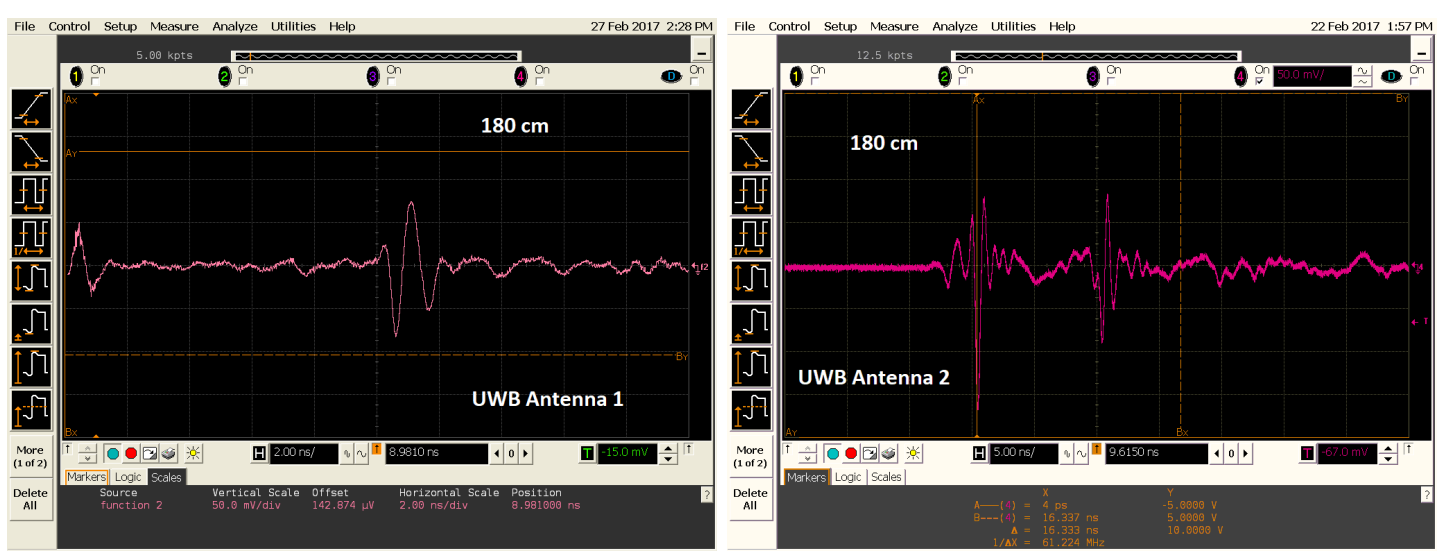

Figure 5.5: The time-domain response of the radar sensor measurement towards a metal plate located at $180 \mathrm{~cm}$.
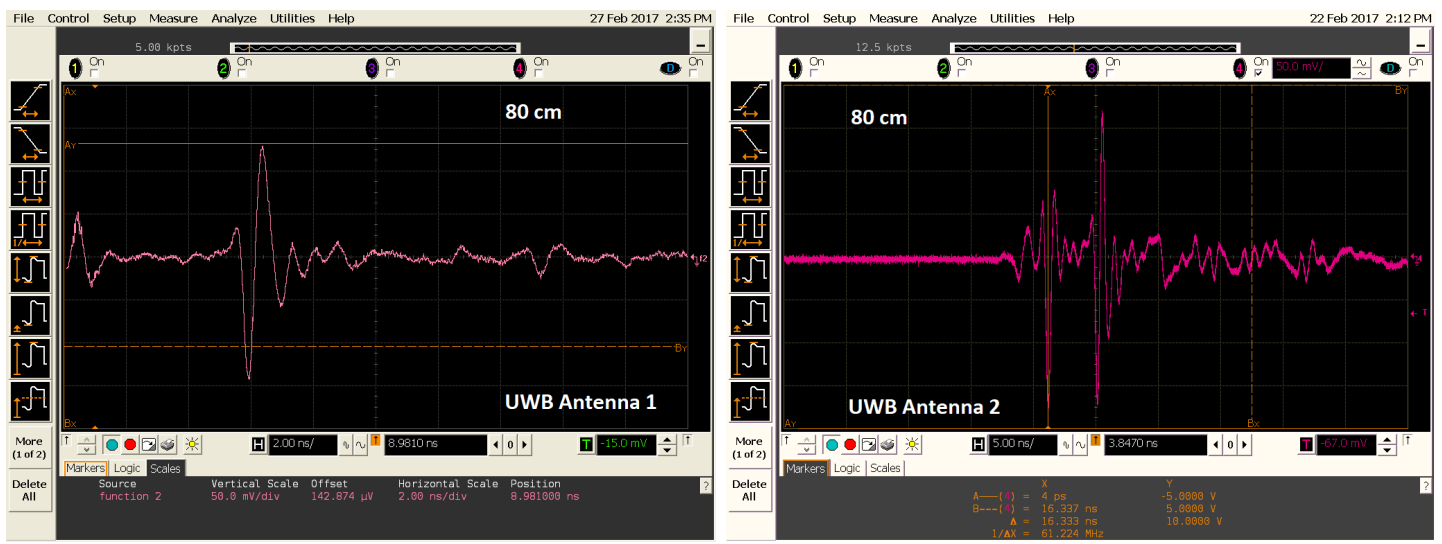

Figure 5.6: The time-domain response of the radar sensor measurement towards a metal plate located at $80 \mathrm{~cm}$.

The first pulse it is due to coupling antennas transmission, while the second one it is the reflected pulse from the material of the target, this reflected pulse approaches or moves away from the principal pulse proportionally with the movement of the targets. From the results obtained above, it seems that the first antenna Tapered Slot Antenna get a great result in terms of transmission and reception, and presents little loss in measurements, therefore the pulses at reception showed are with a minimum of ringing.

In the time-domain measurement point of view, an antenna with a bandwidth begining from lower frequencies give more accuracy compared with an antenna with a bandwith begining form high frequencies. Therefore, the design of an UWB antenna with these requirement and criteria is required and presented as a very challenge recentlly [144]- [147]. Nevertheless, this work it is focused only on the 
design of an impulse generator for a radar sensor, and demonstrate her workability for measuring the distance and the electrical properties for some materials.

\subsection{Measurements of electrical properties.}

Now a day, an accurate measurement of the electrical properties of materials is very important. Because each material has a unique electrical characteristic, this electrical property establishes the behavior of material with the presence of EM fields. In addition, an accurate measurement of this properties provides a valuable information to incorporate this material in such application [148, 149], to be able to perform a specific design $[150,151]$, or to monitoring some industrial process $[52,153]$. Moreover, the importance of these properties is due also to a direct correlation with other principal parameters such as; viscosity, curing degree, the percentage of humidity, etc.

Actually, there are many methods in the characterization dielectric of materials. All kind of these methods can summarize it in four principal groups such as techniques based on concentrated circuits, techniques based on transmission lines, techniques based on resonant cavities and techniques based on free space propagation. The techniques based on free space propagation consist normally of a designed Radar Sensor.

Compared with the other techniques presented previously, a designed UWB Radar Sensor presents many advantages:

- It is a non-destructive method,

- It is a non-invasive method,

- Able to penetrate materials without any alteration or contamination.

This advantage makes them a very attractive solution for some specific measurement; e.g.,Measurement of the intern property in in-homogeneous or of granular materials.

In addition, the UWB radar sensor gives a lot of accuracy in measurements and has less dependency on the exterior conditions, like temperature or humidity.

On another hand, the interest in UWB radar sensors systems as a non-destructive application has increased significantly [154]- [157]. Numerous of these systems work in the time domain and has an effective UWB frequency spectrum of around $0.1 \mathrm{GHz}$ to $10 \mathrm{GHz},[157,158]$. The principal part of any UWB radar sensors is 
the UWB nanosecond pulse generator. The UWB radar sensors system described in this work is composed by a designed UWB pulse generator part, two UWB antennas, and an oscilloscope as a receiver. The UWB pulses were generated by an avalanche transistor and sharpened by a step recovery diode.

The pulse generator circuit is completely fabricated on the microstrip structure, which has the characteristic of compactness and small size. A good agreement between the measured and the calculated result was achieved.

Normally, there are two principal configurations in the systems of radar, the bistatic and the mono-static configuration $[159,160]$. Compared with the bi-static, the mono-static presents many disadvantages and needs more technical requirements for accuracy measurements, for this reason in this thesis work, we have chosen the bi-static configuration for the purpose to get the accurate and efficient results. In Fig. 5.5, The whole system in bi-static configuration is presented. To avoid any perturbations and interference during the measurements, the separating distance between the transmitting Tx and the receiving antenna $\mathrm{Rx}$ has been fixed at $25 \mathrm{~cm}$. In addition, we consider that $(0,0)$ is the origin position located at half distance separating the antennas used in the experience, while D is the distance from the origin position to the target.

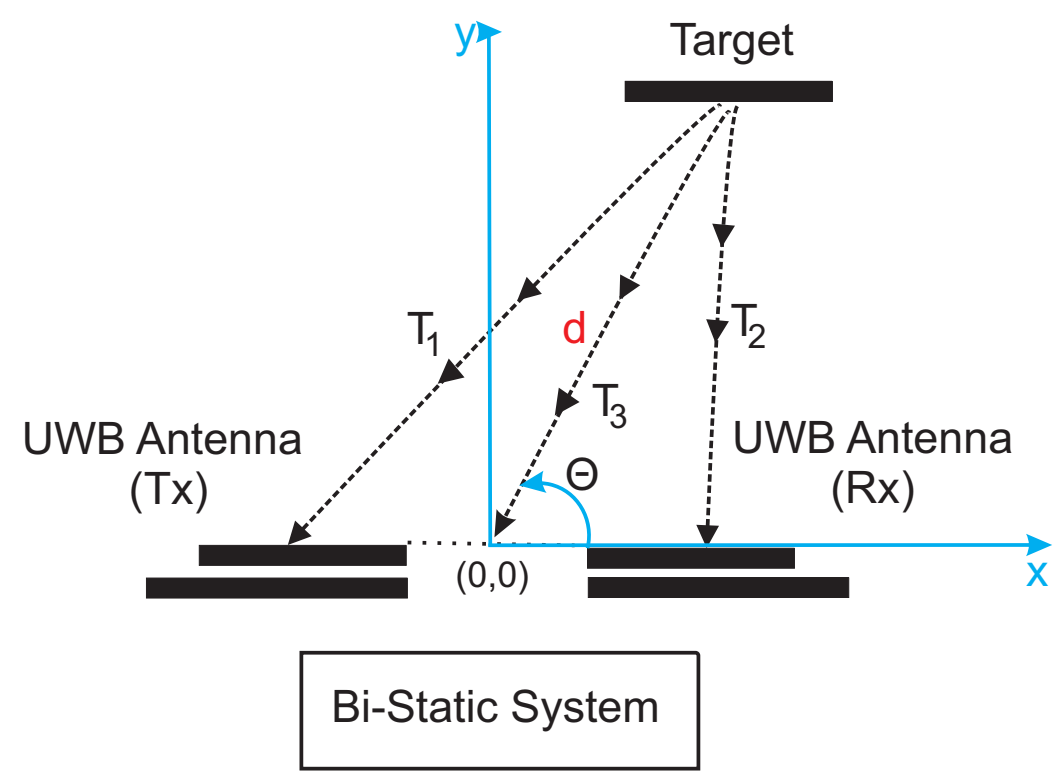

Figure 5.7: Bi-static System Configuration and measurement setup.

The overall radar system consists of two antennas with a wide bandwidth, an oscilloscope as a receptor and the proposed designed UWB monocycle impulse generator. A pivotal challenge in the design of UWB radar sensor system for this kind of applications is the availability of a pulse source with high peak power and 
short rise-time, knowing that the characteristic of the UWB pulse generator establishes the entire performance of the radar system. However, a monocycle pulse was selected over a Gaussian pulse because it has a narrower bandwidth, and does not contain the DC current; hence, provides little loss in the antennas, because the UWB antennas used in these measurements ranging from 0.4-6 GHz and 0.6-6 $\mathrm{GHz}$ respectively. Therefore the monocycle its very appropriate in our Radar sensor applications. The circuit schematic of the proposed pulse generator is shown in Fig. 5.6, It is constructed by three principal parts: The avalanche transistor circuit, SRD pulse sharpener circuit, and the Monocycle forming network.

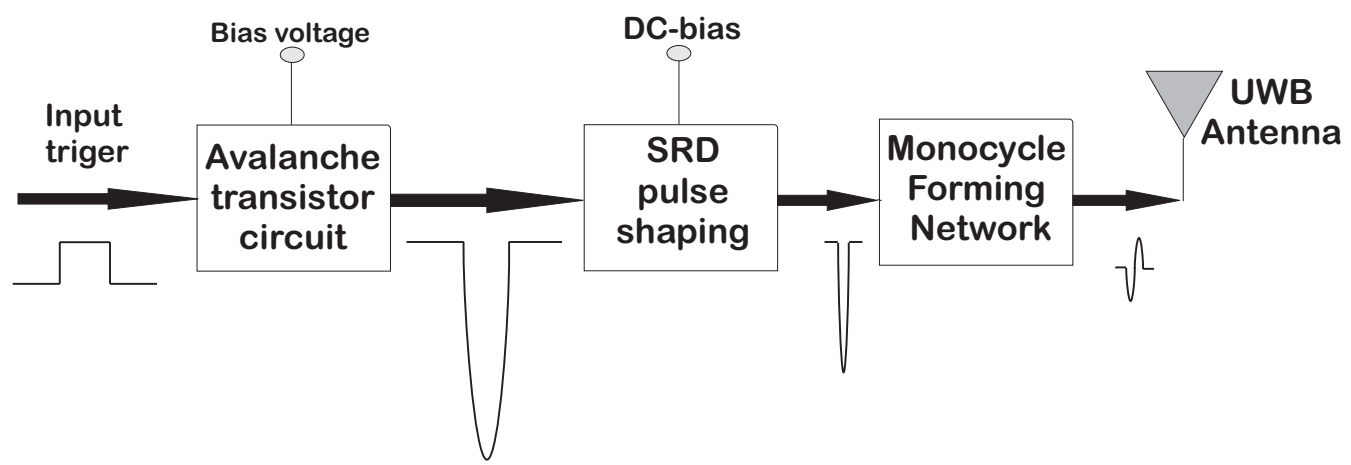

Figure 5.8: Circuit diagram of the proposed Gaussian pulse generator.

In this section, the designed system proposed in this thesis work has been tested for the electrical properties measurement towards a lossy dielectric. The Tapered Slot Antenna has been chosen, because have a wide bandwidth ranging from 0.46 to $6 \mathrm{GHz}$, and give better results in terms of transmission and reception of pulses.

The radar sensor is located in front of a dielectric material, and the antenna was placed orthogonal with a distance of $150 \mathrm{~cm}$ from the targets.

The relative permittivity of the materials can be measured using a useful procedure; this procedure is described as follows: First, we measure the amplitudes of the signals reflected from a metal plate and from the boundary of the dielectric of the target. After that, we conclude the intrinsic impedance $\eta_{1}$ of the dielectric using this equation(5.1):

$$
\eta_{1}=\eta_{0} \times \frac{E_{m}+E_{1}}{E_{m}-E_{1}}
$$

Where, Em is the amplitudes of the signals reflected from the metal plate, which is equal to the amplitude of the signal incident, E1 the amplitudes of the signals reflected from the first boundary between air and the top side of the dielectric materials and $\eta_{0}=377 \Omega$ is the intrinsic impedance of air. Therefore the 
relative permittivity $\varepsilon_{r_{1}}$ of the dielectric can be found with (5.2):

$$
\varepsilon_{r_{1}}=\frac{377^{2}}{\eta_{1}}
$$

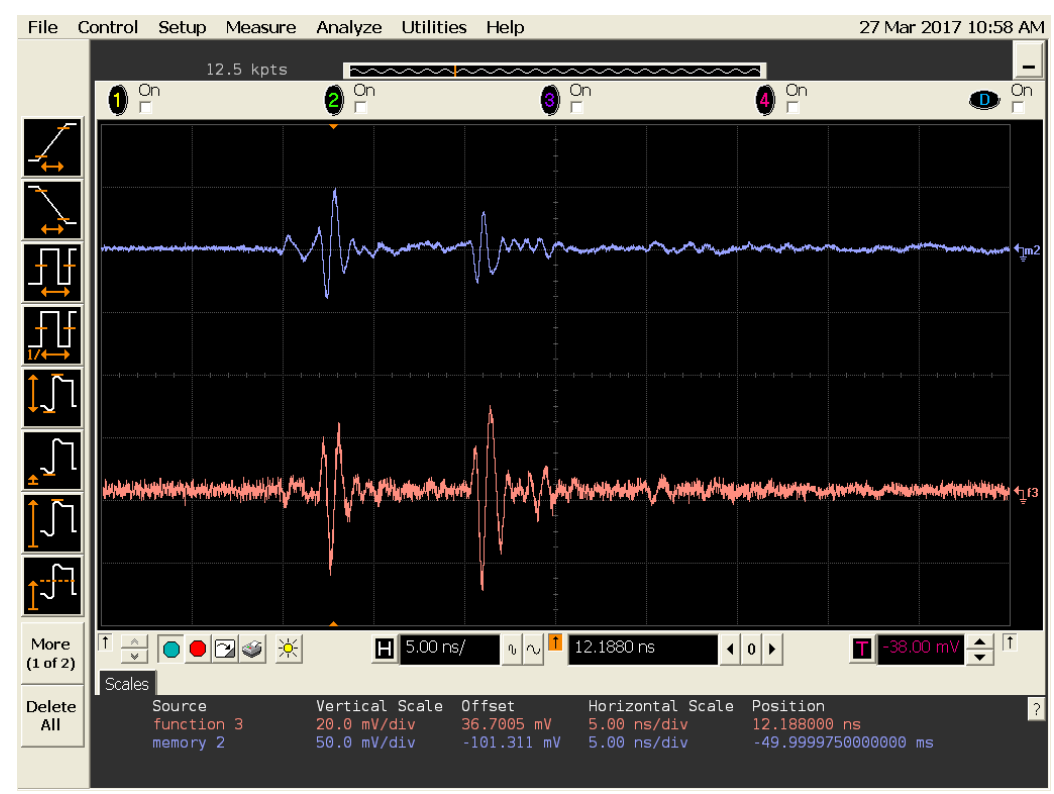

Figure 5.9: Results of measurement of distance at $50 \mathrm{~cm}$.

At first, the measurement of metal distanced at $150 \mathrm{~cm}$ was captured in channel 4; then, a Low Pass Filter (LPF) with a $\mathrm{fc}=20 \mathrm{GHz}$ has been applied and saved as Function 2 in the Oscilloscope. After that, a measurement from a PVC with LPF has been saved in memory 2; finally, the difference between the function 2 and memory 2 was showed in function 3 . Its clearly noticed the great difference between the response from a metal and the PVC, this difference its due physically from the difference of the electrical properties of this materials. The electrical properties of this materials can be calculated easily using the simple methods described above.

This method provides only the real parts of the complex intrinsic impedance. Nevertheless, although this simple and approximate measurement procedure that had been implemented, a good agreement between experimental and theoretical results has been achieved. For this purpose, this simple technique is actually preferred in the most practicals issue. Table 5.3 shows the experimental and theoretical results of the electrical properties 

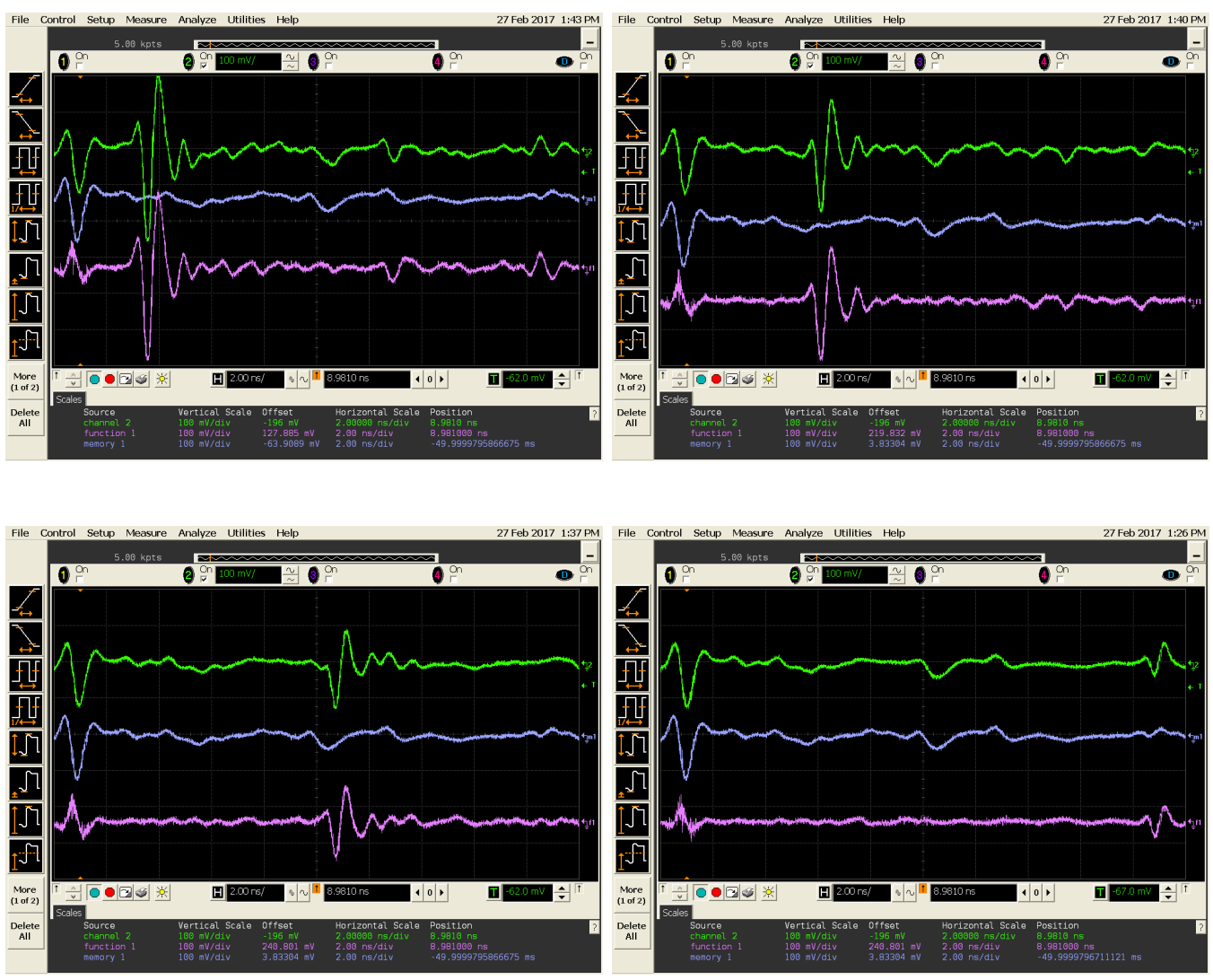

Figure 5.10: Results of measurement of PVC from a different distance.

\begin{tabular}{|c|c|c|}
\hline Materials & Theoretical results & Experimental Results \\
\hline Polyvinylchloride (PVC) & 4 at $3 \mathrm{GHz}$ & $3.7-4.3$ \\
\hline Wood & $1.5-2$ at $3 \mathrm{GHz}$ & $1.2-2.2$ \\
\hline Teflon (PTFE) & $2.0-2.1$ at $3 \mathrm{GHz}$ & $1.8-2.3$ \\
\hline
\end{tabular}

\subsection{Range accuracy.}

More improvement on the signal reception and better use of data at the reception can be taken out with a developed signal processing in Matlab, but it is not the principal aim of this paper. Our purpose was to report the hardware development and to demonstrate the workability of the radar sensor prototype in non-destructive measurements and his accurate application in distance and electrical properties measurements.

Fig. 5.9 shows the accuracy variation of the measurement according to the variation of the target's location; its quasi-linear proportionally, which make the 
our designed pulse generator very attractive especially in the Near range measurement. Therefor, this technique it is very useful as a non-contact and nondestructive measurement of distance and the electrical properties of material in many industrial applications.

The accuracy variation vs Range Distance

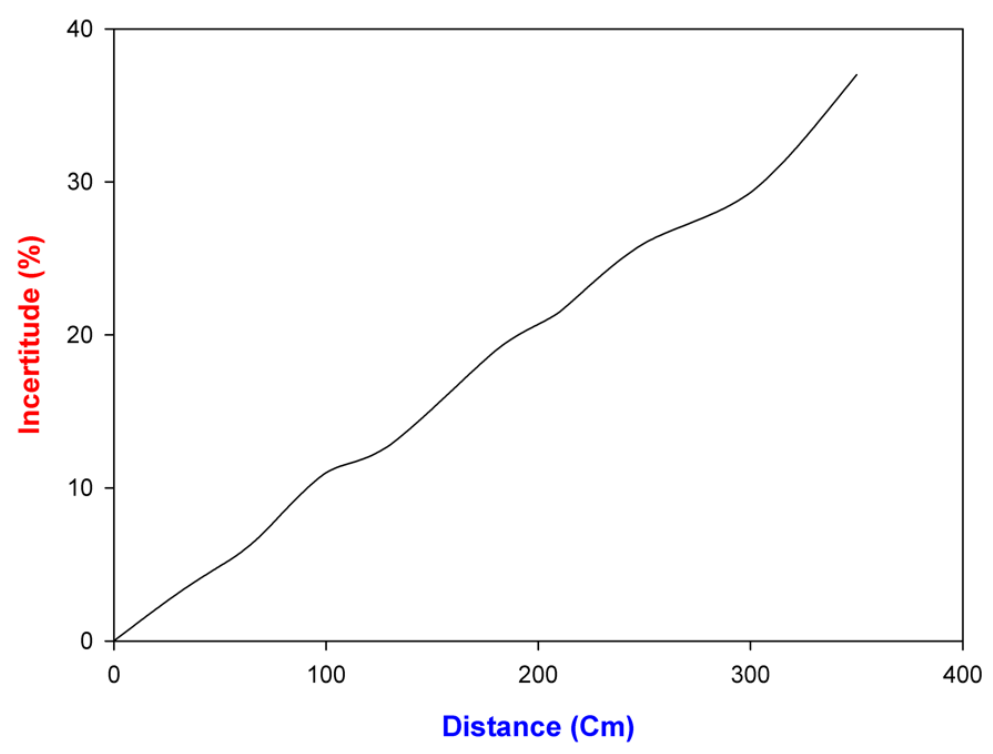

Figure 5.11: The accuracy Variation vs atahe range distance.

\subsection{Conclusion}

A useful UWB radar sensor prototype has been developed for NDE applications using all microwave integrated circuits. The UWB radar sensor employs a $333 \mathrm{ps}$ monocycle-pulse transmitter, 0-6 GHz Sampling Receiver (Oscilloscope) and two antennas operating from $460 \mathrm{Mhz}$ to at least $6 \mathrm{GHz}$. A simple mathematical formula has been used to calculate the range distance and the electrical permittivity of materials. Many measurements have been made to confirm the performance and operability of this system prototype. All measurement has been made in an anechoic chamber to avoid the interference with other signals. Experimental data, obtained with the fabricated prototype in measurement procedure demonstrates the good agreements with the theoretical results. Good performances together with the compactness and low cost, make this system a very attractive and useful tool for NDE Applications. 


\section{CHAPTER}

\section{Conclusions and Further works}

\section{HAVE GOME TO THE GONGLUSION THAT POLITIGS ARE TOO SERIOUS A MATTER TO BE LEFT TO THE POLITICIANS.}

French general and politician 1890- 1970

Charles de Gaulle

THis chapter reports a conclusion of this thesis, and some further works. 


\subsection{Conclusions}

In This Thesis, a design, implementation and analysis of UWB radar subsystems and system integration for non destructive sensing purposes has been presented and discussed. New low cost UWB source has been presented, as well as the high power version. Validation tests in lab are also described.

In detail, the main focus of this thesis was to cover a measuring range from $50 \mathrm{~cm}$ to $300 \mathrm{~cm}$ with a great accuracy in mm range, toward different targets having different dielectric constant; such as metal, wood, and PVC. Moreover, another goal of this thesis was to measure the electrical property of some dielectric materials.

For this reason, a pulse generator of ultra-short pulses has been presented, studied and developed. The developed generator circuit has been made up form tree principal parts: an avalanche transistor circuit, an SRD sharpening circuit and a Monocycle forming network circuit. The three parts was studied and detailed each separate, in the first part; we made the charge pathway shorting as much as possible, while in the second one, a new model of SRD has been proposed and developed. The given output waveform present a good result, and provide good result compared with some work presents in bibliography (Protiva and Zhong Li).

In order to powerfully the generated pulse, two techniques has been proposed; the first one consist of assembling two identical generators in parallel, while the second one consist of a new design of Two-Stage of transistor. The resulted output waveform is around the fourfold compared of the single one.

In order to validate the workability of the proposed system, two kind of measurement has been made. The first one consist of the range distance measurement ranging from 50 meters to 300 meters, the target range was performed using the time of flight concept, In this method, the target distance was computed from the time difference between the detected pulse and the reference pulse. The timedependent measurement accuracy of the radar sensor was investigated also.

Once the achievement of the good agreement between the measured and the real measure of the target. Another kind of measurement has been made. This measure consist of calculating the real part of electrical property of some dielectric materials. The electrical properties measurements has been made using a simple technique described in the bibliography; however good results has been achieved. A measurement uncertainty of mm was obtained. And good agreement between 
the simulated and the measured results have been achieved.

All measurements, has been carried out in an anechoic chamber, to avoid any electromagnetic perturbation. And the Radar sensor was built in bi-static configuration.

Regarding the block of contents related to the radar sensor design, the techniques presented in this thesis provide the following main advantages with respect to the state of the art:

1. simple design procedure, low profile and easy to manufacture.

2. Enhanced pulse generated with a minimum of ringing.

3. powerful the pulse generated around the fourfold of the traditional pulse generator.

4. Miniaturization capability with the shorting the discharge pathway in the transistor circuit..

5. Simplicity Integration feature with other circuit parts.

\subsection{Further works}

Further research may be started to enhance radar sensor performance. The following subjects could be treated in the future:

1. searching for more techniques to increase the power of the pulse.

2. investigating additional details to decrease the rise-time of the pulse.

3. Integration feature.

4. implementing and designing a compact circuit for the receptor.

5. Designing a new UWB antenna for its use in the radar sensor

6. regarding compactness of radar sensor, a mono static radar concept would be desirable, therefor, it's could be investigated in details.

7. studying the influence of the frequency bandwidth, The effect of the frequency dispersion, Angle of incidence for the estimation of the dielectric properties. 
8. studying the influence of the frequency bandwidth, The effect of the frequency dispersion, Angle of incidence for the estimation of the range distance. 


\section{Bibliography}

[1] Atzori, L., Iera, A., and Morabito, G. (2010). "The internet of things" A survey. Computer networks, 54(15), 2787-2805

[2] Marcelo Tsuguio Okano "IOT and Industry 4.0: The Industrial New Revolution", Conference: ICMIS-17 - International Conference on Management and Information System At: Bangkok Volume: 17, September 2017.

[3] B. Colosimo, and N. Senin, Geometric Tolerances, Springer-Verlag London 2011.

[4] D. Patrick, Industrial Process Control System, 2 nd Edition, Fairmont press, Inc., Indian, 2009.

[5] G. Kompa, " Optical short-Range Radar for Level Control Measurement," IEEE Proceeding, Vol, 131, June 1984, pp. 159-164.

[6] A. Biernat, Erzeugung und Anwendung von ultrakurzen Laserradarimpulsen mit hoher leistung, Doctoral Thesis, university of Kassel, 1998.

[7] V. Magori, “Ultrasonic Sensor in Air, “IEEE Ultrasonic Symposium, October 1994, pp. 471-181.

[8] G. Kompa, Private Communications.

[9] Various Technics of Liquids and Solids Level Measurements, Indumart Inc http://www.indumart.com

[10] G. Kompa, High Frequency Sensors, Lecture Notes, University of Kassel, April 2002.

[11] Christopher R. Anderson, Jeffrey H. Reed, R. Michael Buehrer, Dennis Sweeney, and Stephen Griggs. An Introduction to Ultra Wideband Communication Systems April 2005 
[12] FCC 02-48 First Report and Order: Revision of PART 15 of the Commission Rules Regarding Ultra-Wideband transmission system Federal communication commission. Adopted February 14, 202, released 22 April, 2002.

[13] Ahajjam Younes, Jose M Catala-Civera, Felipe Peñaranda Foix. Abdellah Driouach “ Bibliography, Background and overview of UWB radar sensor?, Journal of enginieering Research and appliactions. Vol,4, Issue 11 (version5), november 2014, pp. 37-40

[14] Meng Miao. “ Radio frequency RF complementary metal-oxide semiconductor CMOS ultra wideband UWB transmitter and receiver frond-end design ”, Doctoral Diss, Texas A and M University, May 2008

[15] K. Siwiak. Ultra-Wide Band Radio: Introducing a New Technology. In IEEE Vehicular Tech. Conference (VTC)- Plenary session, May 2001.

[16] A. Gupta and P. Mohapatra, "Ultra Wide Band Medium Access Control Schemes," Computer Networks, vol. 51, pp. 2976-2993, August 2007.

[17] Menag Miao (2008) Radio Fequency (RF) Complementary Metal-Oxide Semiconductor (CMOS) Ultra Wideband (UWB) Transmitter and receiver frond-end design, Unpublished $\mathrm{PhD}$ thesis, Texas A and M University, United State.

[18] Paul Richardson, Weidong Xiang, Dan Shan (2014) ?UWB outdoor channel environments: analysis of experimental data collection and comparison to IEEE 802.15.4a UWB channel model? International Journal of Ultra Wideband Communications and Systems Vol. 3, No.1 pp. 1 - 7.

[19] Dieter Genschow; Johannes Kloas “Evaluation of a UWB radar interface for low power radar sensors" Radar Conference (EuRAD), 2015 European, page (s) 321-324, 2015

[20] Yu Guo; Guofu Zhu; Zhimin Zhou “ A novel design and implementation of sub-nanosecond smpling pulse generator for ultra-wideband equivalent sampling receiver?, Computing, Communication and Networking Technologies (ICCCNT), 2014 International Conference on page (s): 1-5

[21] Ahmed abbas Husseien Ameri. “ Long-Range Ultra-wideband Radar Sensor for Industrial Applications” Doctoral Diss, Kassel University, November 2012 
[22] K. Siwiak and D. McKeown, Ultra-Wideband Radio Technology. Wiley, 2004.

[23] M. Gerding, T. Musch, and B. Schiek, Generation of short electrical pulses based on bipolar transistors, Adv Radio Sci 2 (2004), 712.

[24] E.K. Miller, Time-domain measurements in electromagnetics, Springer, New York, NY 1986

[25] J.D. Taylor, Ultra-wideband radar technology, CRC Press, Boca Raton, FL, 2001.

[26] A. Ouslimani, G. Vernet, H. Hardallah, and R. Adde, Large amplitude picosecond step generation with FETs,Electron Lett 26 (1990), 15631564

[27] Hewlett-Packard application note AN918: pulse and waveform generation with step recovery diodes. Hewlett-Packard, 1984.

[28] J.S. Lee, C. Nguyen, and T. Scullion, New uniplanar subnanosecond monocycle pulse generator and transformer for time-domain microwave application, IEEE Trans Microwave Theory Tech., vol 49, pp. 1126-1129, 2001.

[29] T.-G. Ma, C.-J. Wu, P.K. Cheng, C,-F. Chou, Ultra wideband monocycle pulse generator with dual resistive loaded shunt stubs, IEEE Microw.Opt. Technol., vol, pp 459-462 2007.

[30] Z. Li , X. X. Lv , Y. F. Long and T. Qin ?An ultra-wideband monocycle pulse generator with good performance?, Proc. Int. Conf. Computat. ProblemSolving (ICCP), pp.253 -254 2011.

[31] Ruengwaree, A.; Ghose, A.; Weide, J.; Kompa, G., ?Ultra-fast Pulse Transmitter for UWB Microwave Radar 9? Microwave Conference, 2006. 36th European, 10-15 Sept. 2006 Page(s):1833-1836

[32] P. Protiva , J. Mrkvica and J. Machac ?High power monocycle pulsegenerator for through-the-wall radar transmitter?, Proc.IEEE Asia-Pacific Conf. Circuits Syst., pp.2324 -2327 2009

[33] P. Pongsoon, K. Bunnjaweht and D. Kaemarungsi, ?Edge-Triggered Driver Circuit for Ultra-Wideband Pulse Generator with Cascode Impulse Shaping,?9th International Conference on Electrical Engineering/Electronics, Computer, Telecommunications and Information Technology (ECTICON), pp.1-4,2012. 
[34] Yu Guo; Guofu Zhu; Zhimin Zhou ?A novel design and implementation of sub-nanosecond sampling pulse generator for ultra-wideband equivalent sampling receiver?, Computing, Communication and Networking Technologies (ICCCNT), 2014 International Conference on, On page(s): 1 ? 5

[35] C. Paulson, J. Chang, C, Romero, J. Watson, F. Pearce, N. Levin, “ UltraWideband Radar Methods and Techniques of Medical Sensing and Imaging," International Symposium on Optics, October 2005, pp. 1-12.

[36] Ahajjam Younes, Jose M Catala-Civera, Felipe Peñaranda Foix. Abdellah Driouach “ Bibliography, Background and overview of UWB radar sensor?, Journal of enginieering Research and appliactions. Vol,4, Issue 11 (version5), november 2014, pp. 37-40

[37] Z. Li, X. X. Lv, Y. F. Long, and T. Qin, An ultra-wideband monocycle pulse generator with good performance, in Proc. Int. Conf. Computat. ProblemSolving (ICCP), 2011, pp. 2532549

[38] P. Protiva, J. Mrkvica, and J. Machc, High power monocycle pulse generator for through-the-wall radar transmitter, in Proc. IEEE AsiaPacific Conf. Circuits Syst., 2009, pp. 23242327

[39] D.J Daniels, Surface Penetrating Radar. London, U.k. IEE Press, 1996

[40] D.J Daniels, D.J, Gunton, and H.F.Scoot, Introduction to subsurface radar, IEE Proc, Vol.135 .no.4,pp.278-320, Aug 1988.

[41] S.Azevedo and T.E.McEwan, Micropower impulse radar, Science and Tech Review, pp.17- 29, Ja./Feb.1996.

[42] A.Duzhar and G.Kompa, Applications using a low-cost baseband pulsed microwave radar sensor, in Proc, 18 the IEEE Instrumentation and Measurement Technology Conf., 2001,pp.239-243.

[43] A.Yarovoy and L.Ligthart, Full-Polarimitic video impulse radar for landmine detection: Experimental verification of main design ideas, in Proc. 2 nd Int Workshop on Advanced Ground Penetrating Rdar 2003, p-p.148-155.

[44] L.Ligthart and A.Yarovoy, STW Project: Advanced relocatable multi-sensor system for buried landmine detection, in Proc, 2 nd Int. workshop on advanced ground penetrating radar 2003 pp 5-8. 
[45] J.S.Lee, C. Nguyen, and T.Scullion, Impulse ground penetrating radar for nondestructive evaluation of pavement, in 2002 IEEE MTT-S International Microwave Symposium Digest,2002,pp.1361-1363.

[46] J. Sachs, P. Peyerl, S. Wöckel, M. Kmec, R. Herrmann, R. Zetik, Liquid and moisture sensing by ultra-wideband pseudo-noise sequence signals, Meas. Sci. Technol., vol. 18, pp. 1074-1088, 2007.

[47] F. Thiel, M. Helbig, U. Schwarz, C. Geyer, G. Rimkus, W. A. Kaiser, I. Hilger, M. Hein, J. Sachs, F. Seifert Implementation of ultra-wideband sensors for biomedical applications Frequenz, Journal of RF-Engineering and Telecommunications, vol. 63, no. 9-10, pp.221-224, (2009).

[48] J. W. Han and C. Nguyen, On the development of a compact subnanosecond tunable monocycle pulse transmitter for UWB applications, IEEE Trans. on Microwave Theory and Techniques, vol. 54, no. 1, pp. 285293, January 2006.

[49] J. S. Lee and C. Nguyen, Novel low-cost ultra-wideband, ultra-short-pulse transmitter with MESFET impulse-shaping circuitry for reduced distortion and improved pulse repetition rate, IEEE Microwave and Wireless Components Letters., vol. 11, no. 5, pp. 208-210, May 2001.

[50] G.Kompa, “sensoren im MHI-Bereich-Eantwicklungsstand und trens," VDIZ. vol 130, 1988, pp 42-54.

[51] Y. Tao, J. Nin, and G. Deliste, “ Ka-Band Solid-state Pulsed Gunn Oscillator and Power Combiner," International Journal of infrared and millimetre waves, vol, 16, 1995, pp,1769-1772.

[52] R.J.Baker, " High Voltage Pulse Generation Using Current Mode Second Breakdown in a Bipolar Junction Transistor." Review of scientific instruments. Vol. 62, April 1991, pp. 1031-1036.

[53] A. Kipela, Pulsed Time-of-Flight Laser Range Finder Techniques for Fast, High Precision Measurement Applications, Doctoral Thesis, University of Oulu, Finland, January 2004.

[54] Rao, T.; Dutta, A.; Singh, S.G.; De, A.; Sahoo, B.D. A Tuneable CMOS Pulse Generator for Detecting the Cracks in Concrete Walls, VLSI (ISVLSI), 2012 IEEE Computer Society Annual Symposium on 
[55] Muhr, E.; Vauche, R.; Bourdel, S.; Gaubert, J.; Sparrow, O.R.; Dehaese, N.; Benamor, I.; Barthelemy, H. High output dynamic UWB pulse generator for BPSK modulations, Ultra-Wideband (ICUWB), 2013 IEEE International Conference on.

[56] E. K. Miller, Time-domain measurements in electromagnetics, New York, NY, Van Nostrand Reinhold Company, 1986.

[57] A. Ruengwaree, R, yowuno, and Gkompa Ultra-fast Pulse Transmitter for UWB Microwave Radar European microwave conference proceedings Septembers 2006, pp 1833-1836.

[58] A, Ameri, G, Kompa, and A Bangert, Balanced pulse generator for UWB radar application European microwave conference proceeding, October 2011 pp 198-2011.

[59] Issa, H.H., Eisa, S.M.; Shehata, K.A.; Ragai, H.F. Srd-based pulse generator for UWB wireless network applications Computer Applications Technology (ICCAT), 2013 International Conference on January. 2013 p-p 1 ? 4.

[60] Yu Xinfeng; Gao Min; Li Wenzhao Computer Simulation Design of a UWB Proximity Fuze Impulser Based on SRD, Computer Science and Information Engineering, 2009 WRI World Congress on, On page(s): 141 - 143 Volume: 2, March 31 2009-April 22009.

[61] P. Protiva, J. Mrkvica, and J. Machac, “A Compact step Recovery Diode Subnanosecond-Pulse Generator," Microwave and Optical Technology Letters, February 2010, pp. 438-440.

[62] Equivalent Time Sampling for High-Speed Repetitive Signals Using E Series Boards and NI-DAQ Software, Application Note 066, Nat. Instrum., Inc., Austin, TX, Jun. 1995. [Online]. Available: http://www. national.com

[63] D. J. Daniels, Ground Penetrating Radar, 2nd ed. London, U.K.: IEE, 2004, ch. 3.

[64] A. Reisenzahn, T. Buchegger, G. Kaineder, and C. Diskus, Phase synchronization in UWB receivers with sampling phase detectors, in Proc. IEEE MTT-S, Long Beach, CA, Jun. 2005, pp. 1887?1890. 
[65] A. Reisenzahn and T. Buchegger, Ultra-wideband sampling down converter with sampling phase detector, the Asia Pacific Microwave Conf., Suzhou, China, Dec. 2005.

[66] L. Liu and G. Fang, A novel UWB sampling receiver and its applications for impulse GPR systems, IEEE Trans. GeoscI Remote Sens., vol. 7, no. 4, pp. 690?693, Oct. 2010.

[67] J. Y. Tsui and J. P. Stephens, Sr., Digital microwave receiver technology, IEEE Trans. Microw. Theory Tech., vol. 50, no. 3, pp. 699?705, Mar. 2002.

[68] M.I. Skolink, AN introduction to impulse radar, Naval Research Laboratory, Washington, DC, NRL Memorandum Report 6755.Nov .1999.

[69] J.D.Taylor, Introduction to ultra-wideband Radar Systems, Boca Raton, EL; CRC Press, 1995.

[70] J.D.Taylor, Ultra-Wideband Radar Technology, Boca Raton, FL: CRC Press, 2001.

[71] Yang. and G.B. Giannakis, "Analog Space-time coding for multiantenna Ultra-Wideband transmissions ",IEEE Transactions on Communications, vol. 52, no. 3, pp. 507-517, March 2004.

[72] M. Z. Win. and R. A, " Scholtz, Impulse Radio: How it works ",IEEE Communications Letters, vol. 2, no. 2, pp. 36-38, February 1998.

[73] W. Siriwongpairat. and Ray, L.K.J, " On the performance evaluation of TH and DS UWB MIMO systems. Proceedings of International Conference Wireless Communications and Networking ", IEEE Communications Letters , pp. 1800-1805, March 2004.

[74] T. H. and Kaiser. and Arlan. and Chen. and Di Benedetto , "Analog Space-time coding for Ultra-Wideband Wireless Communication ",2006.

[75] Z. and Zou . and Baghaei Nejad. and Tenhunen," An efficient passive RFID system for ubiquitous identification and sensing using impulse UWB radio. Elektrotechnik and Informationstechnick Journal, Special Issue by Springer Wien ",vol. 124, no. 7, pp. 397-403, December 2007. 
[76] Hu. S. Chen. H. Law. C.L. and Dou. w, "Backscattering Cross Section of Ultrawideband Antennas ",IEEE Antennas and Wireless Propagation Letters, vol. 6, pp. 70-73, 2007.

[77] D. Dardari. and D?Errico . R, " Passive Ultrawide Bandwidth RFID ",Proceedings of Conference Global Telecommunications , pp. 3947-3952, November-December 2008.

[78] D. Manteuffel. and Chen . Z.N, " Concepts for Future Multistandards and Ultra Wideband Mobile Terminal Antennas using Multilayer LTCC Technology, Proceedings ", IEEE International Workshop on Antenna Technology , no. 978-1-4244-4395-6, pp. 3947-3952, March 2009.

[79] A.M. Sayeed. and Raghavan . V, " the Impact of Reconfigurable Antenna Arrays in Cognitive Radio, Proceedings ", IEEE International Conference on Acoustics , pp. 1353-1356, April 2007.

[80] J. D. Taylor, "Introduction to Ultra-Wideband Radar Systems". Boca Raton, FL: CRC Press, 1995.

[81] J. Foerster, E. Green, S. Somayazulu and D. Leeper, "Ultra-wideband technology for short-or medium-range wireless communications," Intel Technology Journal, vol. Q2, pp. 1-11, 2001

[82] J. S. Lee and C. Nguyen, "Novel low-cost ultra-wideband, ultra-short-pulse transmitter with MESFET impulse-shaping circuitry for reduced distortion and improved pulse repetition rate, " IEEE Microwave and Wireless Components Letters., vol. 11, no. 5, pp. 208-210, May 2001.

[83] J. W. Han and C. Nguyen, "On the development of a compact subnanosecond tunable monocycle pulse transmitter for UWB applications, " IEEE Trans. On Microwave Theory and Techniques, vol. 54, no. 1, pp. 285293, January 2006.

[84] C. Nguyen, J. S. Lee, and J. S. Park, "Ultra-wideband microstrip quasi-horn antenna, " Electronics Letters, vol. 37, no. 12, pp. 731-732, June 2001.

[85] V. G. Shpak, M. R. Oulmascoulov, S. A. Shunailov, M. I. Yalandin, "Active former of monocycle high-voltage subnanosecond pulses, "12th IEEE International Pulse Power Conference, vol. 2, pp. 1456-1459, June 1999. 
[86] G. S. Gill, H. F. Chiang, and J. Hall, "Waveform synthesis for ultra wideband radar, " Record of the 1994 IEEE National Radar Conference, pp. 29-31, March 1994.

[87] G. S. Gill, "Ultra-wideband radar using Fourier synthesized waveforms, " IEEE Transactions on Electromagnetic Compatibility, vol. 39, no. 2, pp. 124131, May 1997.

[88] I. Oppermann, M. Hamalainen, and J. Iinatti, "UWB Theory and Applications". Hoboken, NJ: John Wiley and Sons, Inc., 2004.

[89] Balanis C. A. Antenna Theory Analysis. and Design, 3rd ed. New Jersey, USA: JohnWiley and Sons ,2005.

[90] H.G. Schantz, "A Brief History of UWB antennas, Proceedings ”, IEEE Ultra Wideband Systems and Technologies Conference, pp. 209-213, November 2003.

[91] H.G. Schantz, "The Art and Science of Ultra-Wideband Antennas ", Artech House Publisher ,2005.

[92] Wiesbeck. W . and Adamiuk . G, “Antennas for UWB Systems ”, Proceedings of International ITG Conference on Antennas, pp. 66-71, March 2007.

[93] Chang. W . and D.C, “UWB Antennas and Their Applications ", Proceedings of International Workshop on Antenna Technology: Small Antennas and Novel Metamaterials , , pp. 14-19, May 2008.

[94] Akdagli. A . Ozdemir. C. Yamacli. S, "A Review of Recent Patents on Ultra Wide Band (UWB) ", Proceedings of International Workshop on Antenna Technology: Small Antennas and Novel Metamaterials , pp. 14-19, May 2008.

[95] Meng Miao. “ Radio frequency RF complementary metal oxide semiconductor CMOS ultra wideband UWB transmitter and receiver frond end design", Doctoral Diss, Texas A and M University, May 2008.

[96] D. J. Daniels, D. J. Gunton and H. F. Scott, "Introduction to subsurface radar," IEE Proc. vol. 135, pp. 278-320, Aug. 1988. 
[97] A. Langman and M. R. Inggs, "A 1-2GHz SFCW radar for landmine detection," in Proc. of the 1998 South African Symposium., pp. 453-454, Sep. 1998.

[98] C. J. Vaughan, "Ground-penetrating radar surveys used in archaeological investigations", Geophysics, vol. 51, no. 3, pp. 595-604, Mar. 1986.

[99] J. Otto, "Radar applications in level measurement, distance measurement and nondestructive material testing", in Proc. of the 27th European Microwave Conference and Exhibition, vol. 2, pp 1113-1121, Sep. 1997.

[100] J. Lee, "Design of high-frequency pulse subsurface penetrating radar for pavement assessment", Doctoral. Diss, Texas A and M Univ., College Station, TX, 2000.

[101] A. P. Annan and J. L. Davis, "Radar range analysis for geological materials, Geological Survey of Canada, no. 77-1B, pp. 117-124, 1977.

[102] A. Ruengwaree, R, yowuno, and Gkompa "Ultra-fast Pulse Transmitter for UWB Microwave Radar" European microwave conference proceedings Septembers 2006, pp 1833-1836.

[103] A, Ameri,G, Kompa, and A Bangert, “ Balanced pulse generator for UWB radar application "European microwave conference proccding, octobre 2011 pp 198-2011.

[104] Issa, H.H. , Eisa, S.M. , Shehata, K.A. , Ragai, H.F. "Srd-based pulse generator for UWB wireless network applications Computer Applications Technology $(I C C A T), 2013$ International Conference on January 2013 pp 1-4.

[105] E. K. Miller, "Time-domain measurements in electromagnetics", New York, NY, Van Nostrand Reinhold Company, 1986.

[106] C. H. Lee, Picosecond optics and microwave technology, IEEE Trans. Microwave Theory Tech., vol. 38, pp. 569-607, May 1990.

[107] L. L. Molina, A. Mar, F. J. Zutavern, G. M. Loubriel and M. W. O’Malley, "Subnanosecond avalanche transistor drivers for low impedance pulsed power applications, in Pulsed Power Plasma" Science-2001, vol. 1, pp. 178181, June 2001. 
[108] J. S. Lee and C. Nguyen, "Uniplanar picosecond pulse generator using step recovery diode", Electronics Letters, vol. 37, pp. 504-506, Apr. 2001.

[109] P. Dennis and S.E Gibbs, "Solid-state linear FM/CW radar systems-their promise and their problems", in IEEE MTT-S International Microwave Symposium Digest, vol. 74, no. 1, pp. 340-342, June 1974.

[110] S. O. Piper, "Frequency-modulated continuous wave systems", Norwood, MA, Artech House, 1993.

[111] A. E. Carr, L. G. Cuthbert and A. D. Oliver, "Digital signal processing for target detection in FMCW radar", IEE Proc. Communications, Radar, and Signal Processing, vol. 128, no. 5, pp. 331-336, Oct. 1981.

[112] D. R. Wehner, High resolution radar, Norwood, MA, Artech House, 1995.

[113] K. Iizuka and A. P. Freundorfer, Detection of nonmetallic "buried objects by a step frequency radar, IEEE Proc., vol. 71, no. 2, pp. 276-279, Feb. 1983.

[114] D. A. Noon, "Stepped-frequency radar design and signal processing enhances ground penetrating radar performance", doctoral diss, University of Queensland, Queensland, Australia, 1996.

[115] L. A. Robinson, W. B. Weir and L. Young, "An RF time-domain reflectometer not in real time, in GMTT International Microwave Symposium Digest", vol. 72, no. 1, pp. 30-32, May 1972.

[116] R. C. Pippert, K. Soroushian and R. G. Plumb, "Development of a ground penetrating radar to detect excess moisture in pavement subgrade", in Proc. of the Second Government Workshop on GPR-Advanced Ground Penetrating Radar" Technologies and Applications, pp. 283-297, Oct. 1993.

[117] A. Langman, P. D. Simon, M. Cherniakov and I. D. Langstaff, "Development of a low cost SFCW ground penetrating radar", in IEEE Geoscience and Remote Sensing Symposium, vol. 4, pp. 2020-2022, May 1996.

[118] G. F. Stickley, D. A. Noon, M. Cherniakov and I. D. Longstaff, "Preliminary field results of an ultra-wideband (10-620 MHz) stepped-frequency ground penetrating radar", in Proc. of the 1997 IEEE Int. Geoscience and Remote Sensing Symp., vol. 3, pp. 1282-1284, Aug. 1997. 
[119] D. Huston, J. O. Hu, K. Muser, W. Weedon and C. Adam, "GIMA ground penetrating radar system for monitoring concrete bridge decks", Journal of Applied Geophysics, vol. 43, pp. 139-146, May 2000.

[120] Joongsuk Park, "Development of microwave and millimeter-wave integrated circuit stepped-frequency sensors for surface and subsurface profiling", doctoral diss, Texas A and M University, DEC 2003.

[121] Ioan Nicolaescu "Performances of a Stepped-Frequency Continuous-Wave Ground Penetrating Radar" Journal of Applied Geophysics, vol. 82, pp. 5967, JUL 2012.

[122] Dieter Genschow, Johannes Kloas "Evaluation of a UWB radar interface for low power radar sensors," Radar Conference (EuRAD), 2015 European 321$324,2015$.

[123] Yu Guo; Guofu Zhu; Zhimin Zhou, "A novel design and implementation of sub-nanosecond smpling pulse generator for ultra-wideband equivalent sampling receiver"Computing, Communication and Networking Technologies (ICCCNT), 2014 International Conference on page (s): 1-5.

[124] Ahmed abbas Husseien Ameri, "Long-Range Ultra-wideband Radar Sensor for Industrial Applications ” Doctoral Diss, Kassel University, November 2012

[125] Ahajjam Younes, Josè M Catala-Civera, Felipe Peñaranda Foix. Abdellah Driouach , "Bibliography, Background and overview of UWB radar sensor," Journal of enginieering Research and appliactions, Vol,4, Issue 11 (version5), november 2014, pp. 37-40.

[126] Amin M. Abbosh, "Design of ultra-wideband three-way arbitrary power dividers,"IEEE Trans. Microwave Therory Tech vol. 56, no. 1 pp.194- 201, 2008.

[127] E.K. Miller, "Time-domain measurements in electromagnetics" Springer, New York, 1986.

[128] J.D. Taylor, "Ultra-wideband radar technology" CRC Press, Boca Raton, FL, 2001. 
[129] A. Ouslimani, G. Vernet, H. Hardallah, and R. Adde, "Large amplitude picosecond step generation with FETs" Electron Lett, 2615631564.

[130] T.-G. Ma, C.-J. Wu, P.K. Cheng, C,-F. Chou, "Ultra wideband monocycle pulse generator with dual resistive loaded shunt stubs, "IEEE Microw.Opt. Technol vol, pp 459-462.2007.

[131] Z. Li , X. X. Lv , Y. F. Long and T. Qin, "An ultra-wideband monocycle pulse generator with good performance"Proceedings of Int. Conf. Computat. Problem-Solving (ICCP), pp.253 -254. 2011.

[132] Hewlett-Packard application note AN918, "Pulse and waveform generation wih step recovery diodes"Hewlett-Packard, Tech. Rep., 1986.

[133] Ruengwaree, A.; Ghose, A.; Weide, J.; Kompa, G., ?Ultra-fast Pulse Transmitter for UWB Microwave Radar 9? Microwave Conference, 36th European, 10-15 Sept. 2006 Page(s):1833-1836

[134] P. Pongsoon, K. Bunnjaweht and D. Kaemarungsi, ?Edge-Triggered Driver Circuit for Ultra-Wideband Pulse Generator with Cascode Impulse Shaping? 9th International Conference on Electrical Engineering/Electronics, Computer, Telecommunications and Information Technology (ECTICON), pp.1-4,2012.

[135] Yu Guo; Guofu Zhu; Zhimin Zhou ?A novel design and implementation of sub-nanosecond sampling pulse generator for ultra-wideband equivalent sampling receiver?, Computing, Communication and Networking Technologies (ICCCNT), 2014 International Conference on, On page(s): 1 ? 5

[136] Z. Li, X. X. Lv, Y. F. Long, and T. Qin, ?An ultra-wideband monocycle pulse generator with good performance?, in Proc. Int. Conf. Computat. ProblemSolving (ICCP), 2011, pp. 253254

[137] P. Protiva, J. Mrkvica, and J. Machc, High power monocycle pulse generator for through-the-wall radar transmitter, in Proc. IEEE AsiaPacific Conf. Circuits Syst., 2009, pp. 23242327

[138] Z. jianming, G, Xiaowei, and F, Yuanchun, "A New CAD Model of step Recovery Diode and Generation of UWB signals,"IEICE Electronics Expess, Vol, 3, p-p 534-539, Decembre 2006. 
[139] Ahajjam Younes, Josè M Catala-Civera, Felipe Peñaranda Foix. Abdellah Driouach , "Simple, Compact and low cost Pulse Transmitter for UWB Microwave Radar," Mediterranean Conference on Information \& Technologies Saidia, Morocco, 2015.

[140] Ahajjam Younes, Otman Aghzout, Josè M Catala-Civera, Felipe Peñaranda Foix. Abdellah Driouach, "A compact UWB sub-nanosecond pulse generator for microwave radar sensor with ringing miniaturization"Multimedia Computing and Systems (ICMCS), 5th International Conference on, Marrakech, Morocco, 2016.

[141] HAN, J., NGUYEN, C. "A new ultra-wideband, ultra-short monocycle pulse generator with reduced ringing". IEEE Microwave and Wireless Components Letters, 2002, vol. 12, no. 6, p. 206 - 208.

[142] A. Ouslimani, G. Vernet, H. Hardallah, and R. Adde, "Large amplitude picosecond step generation with FETs" Electron Lett, 2615631564.

[143] Amin M. Abbosh, "Design of ultra-wideband three-way arbitrary power dividers"IEEE Trans. Microwave Therory Tech, vol. 56, no. 1 pp.194-201, 2008.

[144] Ibtisam Amdaouch, Otman Aghzout, Azzeddin Naghar, Ana V. Alejos, and Francisco Falcone "Breast Tumor Detection System Based on a Compact UWB Antenna Design," ? Progress In Electromagnetics Research M, Vol. 64, 123 ? 133,2018

[145] B. Borja, J. A. Tirado-Mendez, and H. Jardon-Aguilar "An Overview of UWB Antennas for Microwave Imaging Systems for Cancer Detection Purposes," ?Progress In Electromagnetics Research B, Vol. 80, 173-198, 2018.

[146] M. Baharuddin, V. Wissan, J. T. Sri Sumantyo, and H. Kuze "Equilateral Triangular Microstrip Antenna for Circularly-Polarized Synthetic Aperture Radar," ? Progress In Electromagnetics Research B, , Vol. 8, 107-120, 2009.

[147] N. Takemura and S. Ichikawa "Broadbanding of Printed Bell-Shaped Monopole Antenna by Using Short Stub for UWB Applications," ? Progress In Electromagnetics Research B, , Vol. 78, 57-67, 2017.

[148] Dieter Genschow, Johannes Kloas "Evaluation of a UWB radar interface for low power radar sensors," Radar Conference (EuRAD), 2015 European 
321-324, 2015.

[149] Yu Guo; Guofu Zhu; Zhimin Zhou, "A novel design and implementation of sub-nanosecond smpling pulse generator for ultra-wideband equivalent sampling receiver"Computing, Communication and Networking Technologies (ICCCNT), 2014 International Conference on page (s): 1-5.

[150] Ahmed abbas Husseien Ameri, "Long-Range Ultra-wideband Radar Sensor for Industrial Applications "Doctoral Diss, Kassel University, November 2012

[151] Ahajjam Younes, Josè M Catala-Civera, Felipe Peñaranda Foix. Abdellah Driouach , "Bibliography, Background and overview of UWB radar sensor," Journal of enginieering Research and appliactions, Vol,4, Issue 11 (version5), november 2014, pp. 37-40.

[152] Amin M. Abbosh, "Design of ultra-wideband three-way arbitrary power dividers,"IEEE Trans. Microwave Therory Tech vol. 56, no. 1 pp.194- 201, 2008.

[153] E.K. Miller, "Time-domain measurements in electromagnetics"Springer, New York, 1986.

[154] J.D. Taylor, "Ultra-wideband radar technology" CRC Press, Boca Raton, FL, 2001.

[155] A. Ouslimani, G. Vernet, H. Hardallah, and R. Adde, "Large amplitude picosecond step generation with FETs" Electron Lett, 2615631564.

[156] T.-G. Ma, C.-J. Wu, P.K. Cheng, C,-F. Chou, "Ultra wideband monocycle pulse generator with dual resistive loaded shunt stubs, "IEEE Microw.Opt. Technol vol, pp 459-462.2007. 
[157] Z. Li , X. X. Lv , Y. F. Long and T. Qin, "An ultra-wideband monocycle pulse generator with good performance"Proceedings of Int. Conf. Computat. Problem-Solving (ICCP), pp.253 -254. 2011.

[158] Hewlett-Packard application note AN918,"Pulse and waveform generation wih step recovery diodes"Hewlett-Packard, Tech. Rep., 1986.

[159] Han, J., Nguyen, C, "A new ultra-wideband, ultra-short monocycle pulse generator with reduced ringing,"IEEE Microwave and Wireless Components Letters,

[160] T.-G. Ma, C.-J. Wu, P.K. Cheng, C,-F. Chou, "Ultra wideband monocycle pulse generator with dual resistive loaded shunt stubs, "IEEE Microw.Opt. Technol vol, pp 459-462.2007. 


\section{Acronyms}

UWB, Ultra-Wideband

FCC, Federal Communications Commission

LPI, Low Probability of Intercept.

CPW-fed, Coplanar Waveguide fed

BJT, Bipolar Junction Transistor

BW, frequency bandwith

CW, countinous wave

DC, direct current

FMCW, Frequency modukated continous wave

FWHM, full widht half maximum

IEEE, Institute of electronic and electrical enginiering

LADAR, Laser detection and ranging

PRF, Pulse repetition frequency

SD, Schottky diode

SMA, sub-miniature version A

SODAR, sound detection and ranging

SRD, Step recovery diode

VCO, Voltage controlled oscillator

VNA, Vector network analyzer

VSWR

LPF, Low Pass Filter

FBW, Fractional Bandwidth

TEM, Transverse Electromagnetic

VSWR, Voltage Standing Wave Ratio

EM, Electromagnetic Simulation

WiMAX, Worldwide Interoperability for Microwave Access

ISM, Industrial, Scientific and Medical

WLAN, Wireless Local Area Network

WBAN, Wireless Body Area Network

MB-OFDM, Multi-Band Orthogonal Frequency Division Multiplexing 
MC-CDMA, Multi-Carrier Code Division Multiple Access

RFID, Radio Frequency Identification

MIMO, Multiple Input Multiple Output

SNR, Signal-to-Noise Ratio

WPAN, Wireless Personal Area Network

RF, Radio Frequency

EM, Electromagnetic

PCB, Printed Circuit Board

HPBW, Half-Power Beam Width

FNBW, First-Null Beam Width

IR-UWB, Impulse Radio-UWB

TEM, Transverse Electromagnetic

CPW, Coplanar Waveguide

MIC, Microwave Integrated Circuit

I/O, Input/Output 


\section{Others}

\subsection{R \& D Project}

1. 01/09/2013 - 15/04/2016: Emmag Erasmus Mundus Scholarship (Grant nÂ $\hat{A}^{\circ}$ Strand 1. 2012-2621/001-001-. EMA2.), supported by the European Union

\subsection{Reviewer}

1. 30/09/2018: Reviewer at International Journal of Microwave and Wireless Technologies (Manuscript ID MRF-RP-18-282), entitled "Mitigation techniques for phase noise degradation under vibration of microwave sources for airborne radar applications".

2. 20/04/2019: Reviewer at International Journal of Microwave and Wireless Technologies (Manuscript ID MRF-RP-19-105), entitled "Trgets Interaction in Trough-The-Wall Radars under Path-noss Compensated Multipath Exploitation-Based Model for Spars Image Reconstruction". 


\section{Research internships}

1. $01 / 06 / 2017-31 / 07 / 2017$ and 01/09/2017 - 31/10/2017 : Fabrication of an impulse generator UWB circuit in the purpose to design and implementation of a radar sensor, The Mohammed VI international Academy of Civil Aviation, Casablanca, Morroco.

Advisor: Prof. Jamal El Aoufi 


\section{Attended Courses}

1. Distributed Doctoral School on Metamaterials, "ANTENAS Y RADIOCOMUNICACIONES", Universitat Politecnica de Valencia, 23/10/2014 to 23/05/2015, Valencia, spain, 2015

2. Transversal courses, "'HERRAMIENTAS INNOVADORAS Y GRATUITAS PARA LA SIMULACION DE PROCESOS", Universitat Politecnica de Valencia, Spain, 2014-2015.

3. Transversal courses ,"Comunicacion cientifica: High standards for scientific production and communication", Universitat Politecnica de Valencia, Spain, 2014-2015.

4. Transversal courses "“"Comunicacion cientifica: High standards for scientific production and communication", Universitat Politecnica de Valencia, Spain, 2014-2015.

5. Transversal courses, "Herramientas informaticas para la investigacion: composicion de documentos y presentaciones de alta calidad con LATEX", Universitat Politecnica de Valencia, Spain, 2014-2015.

6. Transversal courses ,"DOCUMENTACION CIENTIFICA", Universitat Politecnica de Valencia, Spain, 2014-2015.

7. Valencia Worksop 20th November 2015 UPVC Tweether,"On 5G realistic outcomes 2020, EFFORTS, CHALLENGES and TRENDS", Universitat Politecnica de Valencia, Spain, 11/11/2015.

8. FECYT | Fundacion Espanola para la Ciencia y la Tecnologia "CURSO FORMACION ONLINE SCOPUS - NIVEL AVANZADO", Universitat Politecnica de Valencia, Spain, 01/02/2016. 


\section{COOPERATION AGREEMENT BETWEEN THE UNIVERSITAT POLITÈCNICA DE VALÈNCIA AND THE UNIVERSITE ABDELMALEK ESSAADI FOR THE COTUTELLE OF A DOCTORAL THESIS}

In Valencia, on the $31 / 04 / 2015$

The Universitat Politècnica de València, hereafter referred to as UPV, whose VAT no. is Q-4618002-B, established by the Spanish Government Act no. 495 of the 11th of March 1971, published on the Spanish Official State Gazette the 26th of March 1971, with head office at Camino de Vera, s/n, in Valencia, P.C. 46022, Spain, and on its behalf the RectorProf. Francisco José Mora Mas, appointed by the Valencian Regional Government Act no. 65/2013, of 30th May, and pursuant to the authority conferred by article 53-d of the UPV Statues, approved by Valencian Regional Government Act no. $182 / 2011$, of 25 th November,

And

The UNIVERSITE ABDELMALEK ESSAADI, hereafter referred to as UAE, with principal offices located at Quartier M'haneche II, avenue Palestine B.P. 2117 Tétouan, and on its behalf and representation the President Mr Houdaifa Ameziane.

\section{AGREE}

\section{FIRST - OBJECT.}

This agreement aims to establish the foundations for the realization of joint supervision scheme (cotutelle) of the thesis detailed below, this is, the direction, development, defence and evaluation of the doctoral thesis, under the joint responsibility of both universities, within the corresponding doctoral programmes, leading to a doctoral degree for each of the two universities:

Doctoral candidate: Ahajjam Younes

Thesis proposal: Diseño e implementación de un radar sensor de impulsos UWB para aplicaciones de detección no destructiva NDT.

Director at UPV: Catalá Civera, José Manuel / Peñaranda Foix, Felipe Laureano.

Director at UAE: Abdellah Driouach

Programme at UPV: Programa de Doctorado en Telecomunicación.

Programme at UAE: Programme doctoral en physique.

\section{SECOND - DEFENCE AND EVALUATION}

5.1) The Thesis will be defended only once, and the defence will take place at UAE.

5.2) The tribunal acting in the evaluation and defence of the thesis will be chosen by the two partner institutions, according to their regulations in force.

THIRD - ACADEMIC REQUIREMENTS.

3.1) The registration and defence of the doctoral thesis, within this framework of cotutelle, will take place according to the rules applicable to doctoral studies on each of the two universities. In particular: 
3.2) Doctoral students must meet the access requirements at each university.

3.3) Doctoral students will be enrolled at both universities. During the academic years corresponding to periods of stay at UPV, the student will pay the enrolment fees at this university. For the rest of the academic years, the students must formalize the enrolment at UPV, although they will be exempt from paying fees.

They shall be eligible for fellowship programmes promoted by each institution and shall have the rights recognized at each institution for doctoral students, including the right to an academic supervision, and the use of resources and facilities necessary for the development of their work.

3.4) Each University will assign the student a thesis supervisor who will commit to jointly exercise this function.

\section{FOURTH - THE THESIS DEVELOPMENT}

4.1) the thesis will take place in alternating periods in the two universities. The period of stay in any of the two institutions shall not be less than twelve months.

4.2) the thesis shall be written in English. The thesis will be complemented with a summary of it in Spanish, and a summary in French.

4.3) the publication, exploitation and protection of the thesis shall comply with Spanish regulations and Moroccan regulations.

\section{FIFTH - CONDITIONS OF THE STAY}

5.1) During the stay in both universities, the doctoral candidates should be covered by an insurance including health, accident and liability insurance.

5.2) The doctoral candidate will be the person responsible for carrying out all the proceedings required to obtain visas and immigration documents.

SIXTH - DEGREE ISSUE

6.1) Each of the two Universities, once the thesis has been evaluated and defended, will issue the corresponding degree, prior payment of the established academic fees.

6.2) The Doctor degree expedited by UPV may include the reference of "international doctor" if it conforms to the rules and requirements determined for obtaining this mention.

6.3) The Doctor degree expedited by UAE may include the reference of "national doctor" if it conforms to the rules and requirements determined for obtaining this mention.

\section{SEVENTH-MODIFICATION, APPLICABILITY AND CANCELATION}

7.1) The parties may amend this agreement at any time, provided the two signing parties expressly agree to do so.

7.2) This agreement will remain effective while the student fulfils the established requirements 
by both institutions and until the defence of the thesis.

7.3) This agreement may be terminated for the following reasons:

1. By mutual agreement between the parties.

2. By expiry of the initial period of validity or of its extensions.

3. By failure to fulfil the obligations that were established or due to having breached the duty of trust.

4. By unilateral decision taken by one of the parties, provided written notice to this effect is given six months before the date on which the agreement is to be terminated.

\section{EIGHTH - PROTECTION OF PERSONAL DATA}

In accordance with the Spanish Law 15 /1999 of December 13th regulating the Protection of Personal Data, UPV states that by signing the present agreement UPV will be allowed to process the personal data referred to therein. The data will be filed with the only purposes that emerge directly from the relationship established with UPV, and with the limitations arising from this agreement.

Moreover, UPV states the possibility to data access, rectification, cancellation and opposition by sending a request in writing to the UPV in the address: Camino de Vera, s / n , CP 46022, Valencia, with the reference "Protection Personal Data".

UPV undertakes to treat confidentially the personal data of the UPV personnel included in the agreement, to treat them in accordance with the laws on protection of personal data, and to use them exclusively with the above purposes.

\section{NINTH: MONITORING COMMITTEE}

With the purpose of control, follow up and interpret the duties and rights deriving from the signing of this Agreement, a committee settled by the following persons will be set up:

- On behalf of the UPV, the head of the Doctoral School Amparo Chiralt Boix, and the Coordinator of the student's PhD programme, Alejandro Valero Nogueira.

- On behalf of the UAE, the head of Doctoral School Hassane RIADI

\section{TENTH -. RESOLUTION OF CONTROVERSIES}

All disputes arising out of or in connection with the present agreement shall be first discussed by the Monitoring Committee. Previously, an amicable solution must have been attempted, based on good faith and good will criteria, in order to avoid disputes. In case of conflict the parties shall be subject to the Rules of Arbitration of the International Chamber of Commerce by one arbitrator appointed in accordance with the said Rules.

AND IN WITNESS WHEREOF, this Agreement is signed in two copies, in the place and on the date indicated above. 

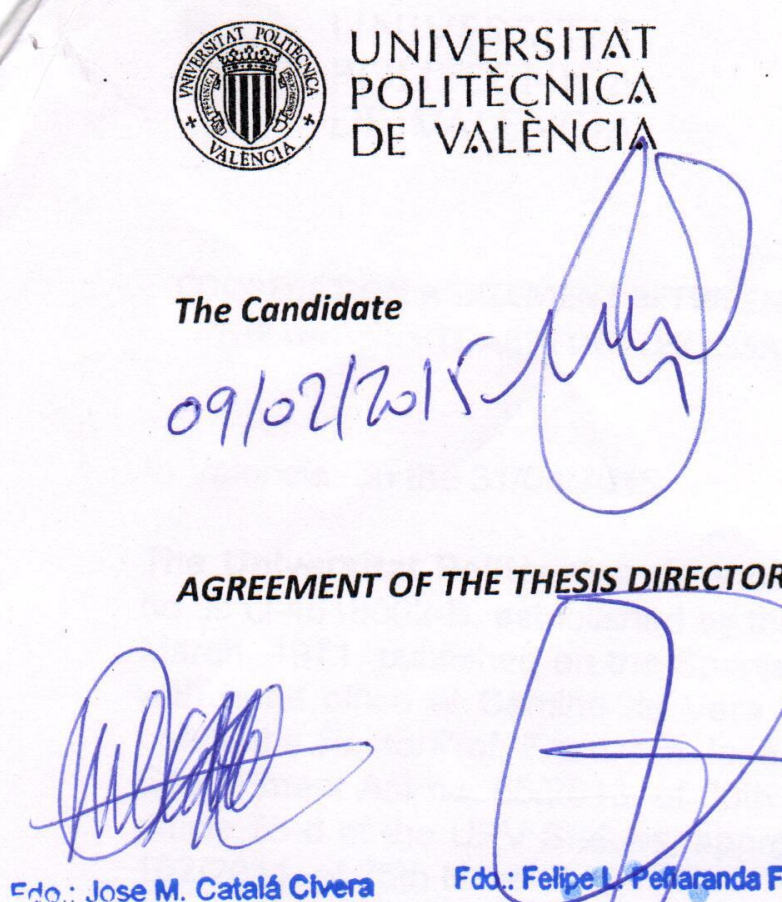

Eto: Jose M. Catalá Civera

BY UPV

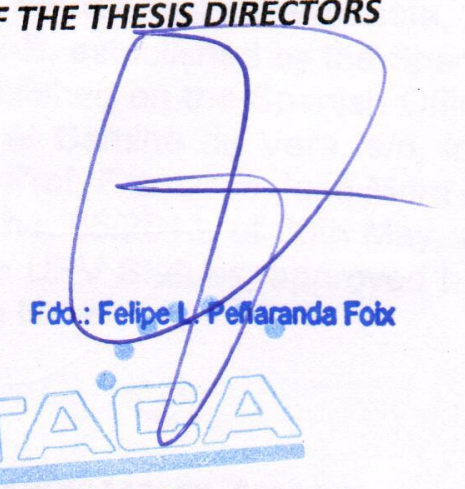

APROVEMENT OF THE UNIVERSITIES

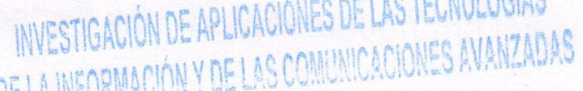

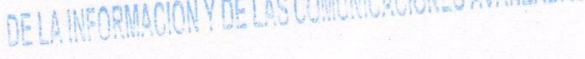

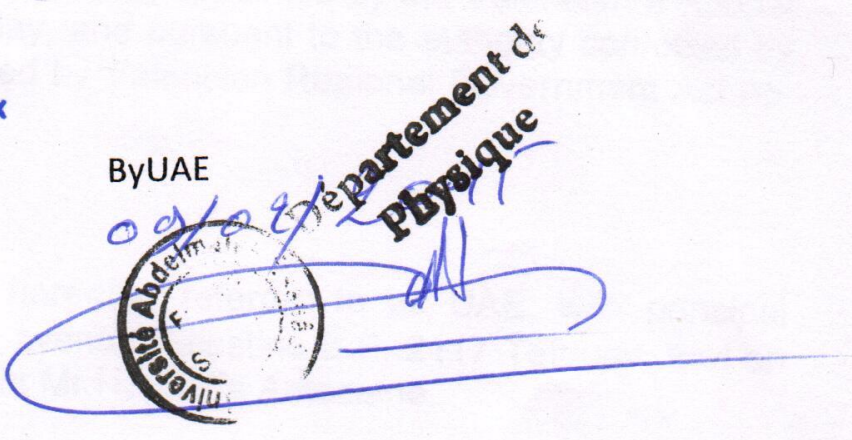

By UPV, the President of the Permanent Commission of the By UAE, the president of the Doctoral Studies Centre

Doctoral School

BY YPV, the RECTOR

francisco José Mora Mas

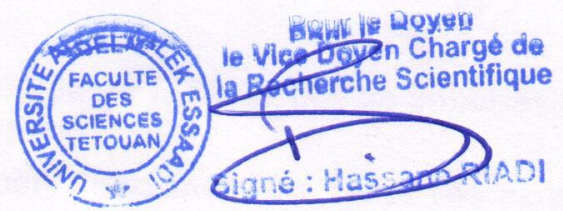

By UAE, the RECTOR Houdaifa Ameziane

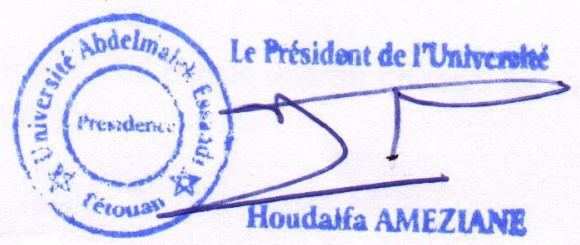




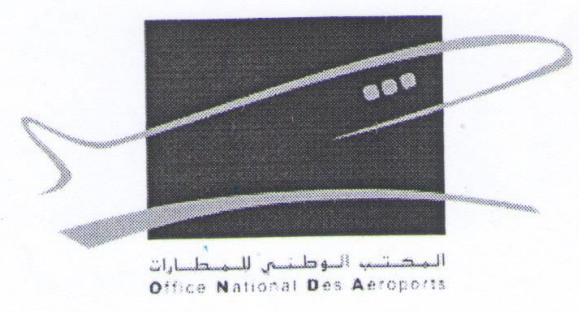

Jamal El Aoufi

Professor-Researcher \& Deputy Director

The Mohammed VI international Academy of Civil Aviation

Casablanca, Morocco

E-mail: j.elaoufi@onda.ma / Jml.elaoufi@gmail.com

GSM: +2126601000237

\section{CERTIFICATE}

Casablanca, 04 December 2017

As a Jamal El Aoufi, Professor-Researcher, Assistant Direction for Research Continuing Education and Cooperation \& Vice Director of The Mohammed 6th international Academy of Civil Aviation, Casablanca, morocco.

I herby certify that The Ph.D Student Younes Ahajjam, has attended for a stay-research period of 4 months at our research group in Royal Air School of Casablanca.

During this stay, Younes Ahajjam has focus her work in conducting some researchers in fabrication of an impulse generator UWB circuit in the purpose to design and implementation of a radar sensor.

The stay-research has been divided in two principal periods:

First period: starting from 01/06/2017 until 31/07/2017.

Second period: starting from 01/09/2017 until 31/10/2017.

This stay-research is the first step to shape a future collaboration between, The Mohammed 6th international Academy of Civil Aviation of Casablanca, and Dimas Group, ITACA institute, UPV, Spain.

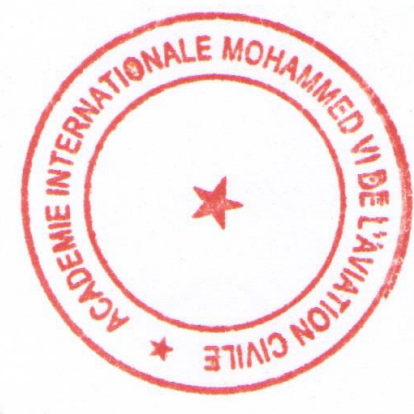

Yours Sincerely

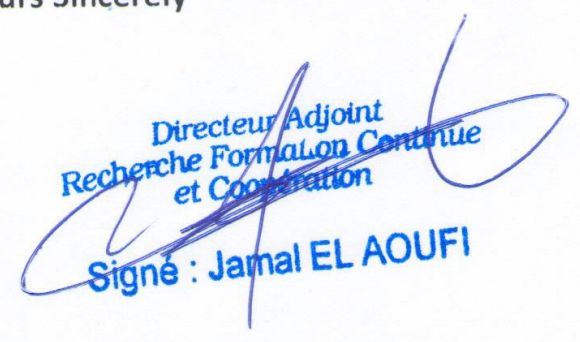

